\title{
Anion Transport with Chalcogen Bonds
}

Sebastian Benz, Mariano Macchione, Quentin Verolet, Jiri Mareda, Naomi Sakai, and Stefan Matile*

Department of Organic Chemistry, University of Geneva, Geneva, Switzerland

stefan.matile@unige.ch

\section{Supporting Information}

\section{Table of Content}

1. Materials and Methods $\quad$ S2

2. Synthesis S4

3. Anion Binding S16

$\begin{array}{ll}\text { 3.1. TBACl } & \mathrm{S} 17\end{array}$

$\begin{array}{ll}\text { 3.2. } \mathrm{TBANO}_{3} & \mathrm{~S} 21\end{array}$

$\begin{array}{ll}\text { 3.3. } \mathrm{TBAPF}_{6} & \mathrm{~S} 22\end{array}$

4. Anion Transport $\quad$ S23

$\begin{array}{ll}\text { 4.1. Vesicle Preparation } & \text { S23 }\end{array}$

$\begin{array}{ll}\text { 4.2. Transport Activity } & \text { S24 }\end{array}$

$\begin{array}{lr}\text { 4.3. Ion Selectivity } & \text { S29 }\end{array}$

$\begin{array}{lr}\text { 4.4. Non-Specific Leakage } & \text { S30 }\end{array}$

5. Electrochemistry $\quad$ S31

6. Supporting References $\quad$ S33

$\begin{array}{ll}\text { 7. Computational Data } & \text { S34 }\end{array}$

8. NMR Spectra $\quad$ S43 


\section{Materials and Methods}

As in refs. S1 to S5, Supporting Information. Reagents for synthesis were purchased from Fluka, Sigma-Aldrich, Apollo Scientific and Acros, buffers and salts of the best grade available from Fluka or Sigma-Aldrich and used as received. 8-Hydroxy-1,3,6-pyrenetrisulfonate (HPTS) was from Fluka. Egg yolk phosphatidylcholine (EYPC) and a Mini-Extruder used for vesicle preparation were purchased from Avanti Polar Lipids. Column chromatography was carried out on silica gel (SiliaFlash® P60, SILICYCLE, 230-400 mesh). Analytical (TLC) and preparative thin layer chromatography (PTLC) were performed on silica gel 60 F254 (Merck) and silica gel (SiliCycle, $1000 \mu \mathrm{m}$ ), respectively. Melting points (Mp) were measured on a Melting Point M-565 (BUCHI). IR spectra were recorded on a Perkin Elmer Spectrum One FT-IR spectrometer (ATR, Golden Gate) and are reported as wavenumbers $v$ in $\mathrm{cm}^{-1}$ with band intensities indicated as $\mathrm{s}$ (strong), m (medium), w (weak). ${ }^{1} \mathrm{H}$ and ${ }^{13} \mathrm{C}$ spectra were recorded (as indicated) either on a Bruker $300 \mathrm{MHz}, 400 \mathrm{MHz}$ or $500 \mathrm{MHz}$ spectrometer and are reported as chemical shifts $(\delta)$ in ppm relative to TMS $(\delta=0)$. Spin multiplicities are reported as a singlet (s), doublet $(\mathrm{d})$, triplet $(\mathrm{t})$, quartet (q) and nonet (non), with coupling constants $(J)$ given in $\mathrm{Hz}$, or multiplet $(\mathrm{m})$. Broad peaks are marked as br. ${ }^{1} \mathrm{H}$ and ${ }^{13} \mathrm{C}$ resonances were assigned with the aid of additional information from 1D and 2D NMR spectra (H,H-COSY, DEPT 135, HSQC and HMBC). ESI-MS for the characterization of new compounds was performed on an ESI API 150EX and are reported as massper-charge ratio $\mathrm{m} / \mathrm{z}$ (intensity in $\%$, [assignment]). HR ESI-MS for the characterization of new compounds were performed on a QSTAR Pulsar (AB/MDS Sciex) and are reported as mass-percharge ratio $\mathrm{m} / \mathrm{z}$ calculated and observed. Electrochemical measurements were done on an Electrochemical Analyzer with Picoamp booster and Faraday cage (CH Instruments 660C). UV-Vis spectra were recorded on a JASCO V-650 spectrophotometer equipped with a stirrer and a temperature controller. Fluorescence measurements were performed with a FluoroMax-4 
spectrofluorometer (Horiba Scientific) equipped with a stirrer and a temperature controller. Fluorescence spectra were corrected using instrument-supplied correction factors, unless stated otherwise. All measurements were performed at $25^{\circ} \mathrm{C}$.

Abbreviations. AcOH: Acetic acid; BuLi: n-Butyllithium; CF: Carboxyfluorescein; DIBAL-H: Diisobutylaluminium hydride; DMF: $N, N$-Dimethylformamide; DMP: Dess-Martin periodinane; DMSO: Dimethylsulfoxide; DPV: Differential pulse voltammetry; EYPC: Egg yolk La-Phosphatidylcholine; Fc: Ferrocene; HEPES: 4-(2-hydroxyethyl)-1-piperazineethanesulfonic acid; HPTS: 8-Hydroxypyrene-1,3,6-trisulfonic acid, trisodium salt; LDA: Lithium diisopropyl amide; LUVs: Large unilamellar vesicles; mCPBA: 3-Chloroperbenzoic acid; PE: Petroleum ether; rt: Room temperature; SCE: Saturated calomel electrode; TBACl: Tetrabutylammonium chloride; $\mathrm{TBANO}_{3}$ Tetrabutylammonium nitrate; TBAPF 6 : Tetrabutylammonium hexafluorophosphate; TfOH: Trifluoromethansulfonic acid; THF: Tetrahydrofuran. 


\section{Synthesis}

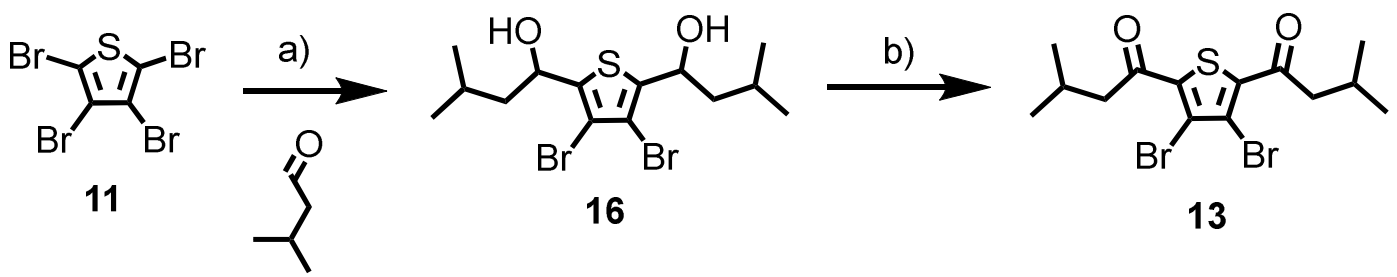

12

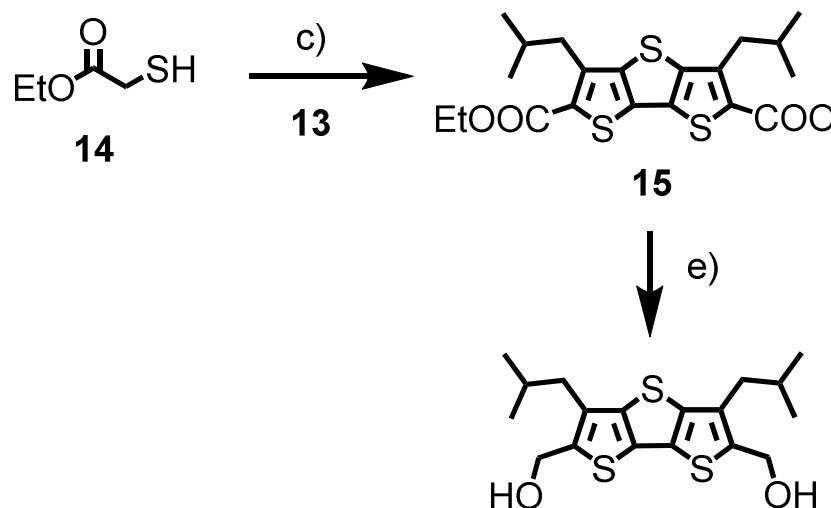

18
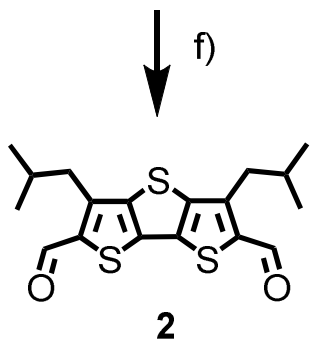

2
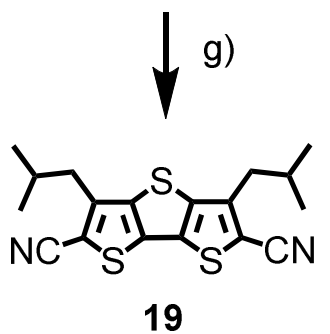

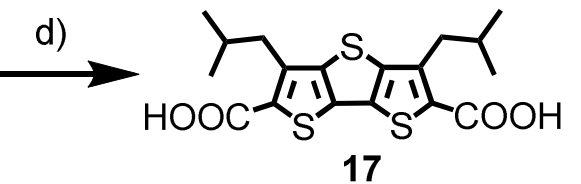

17
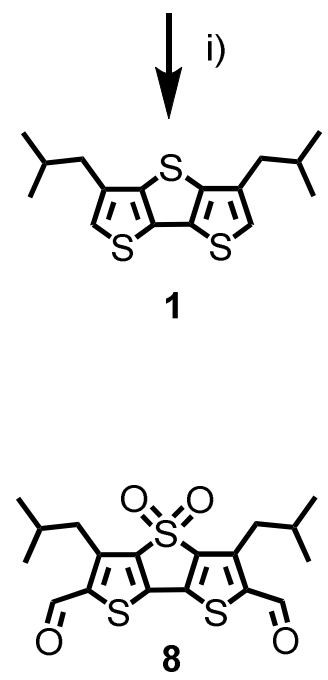

h)

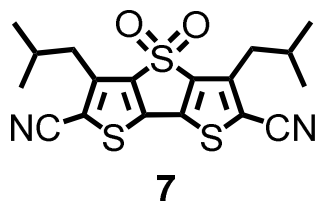

Scheme S1. Reagents and conditions: (a) BuLi, THF, $-78{ }^{\circ} \mathrm{C}, 2 \mathrm{~h}, 69 \%$; (b) $\mathrm{Na}_{2} \mathrm{Cr}_{2} \mathrm{O}_{7}, \mathrm{H}_{2} \mathrm{SO}_{4}, \mathrm{H}_{2} \mathrm{O}$, acetone, rt, 16 h, 68\%; (c) EtONa, EtOH, reflux, 2 h, 86\%; (d) LiOH, EtOH, reflux, 16 h, 95\%; (e) DIBAL-H, THF, $-78{ }^{\circ} \mathrm{C}, 30$ min, quant; (f) Dess-Martin periodinane, $\mathrm{CH}_{2} \mathrm{Cl}_{2}, \mathrm{rt}, 2 \mathrm{~h}, 71 \%$; $(\mathrm{g}$ ) $\mathrm{NaN}_{3}, \mathrm{TfOH}, \mathrm{CH}_{3} \mathrm{CN}, 50{ }^{\circ} \mathrm{C}, 1 \mathrm{~h}, 71 \%$; (h) mCPBA, $\mathrm{CHCl}_{3}, \mathrm{rt}, 3 \mathrm{~h}, 77 \%$; (i) $\mathrm{Ag}_{2} \mathrm{CO}_{3}, \mathrm{AcOH}$, DMSO, $120{ }^{\circ} \mathrm{C}, 16 \mathrm{~h}, 73 \%$; (j) mCPBA, $\mathrm{CHCl}_{3}, \mathrm{rt}, 3 \mathrm{~h}, 36 \%$. 


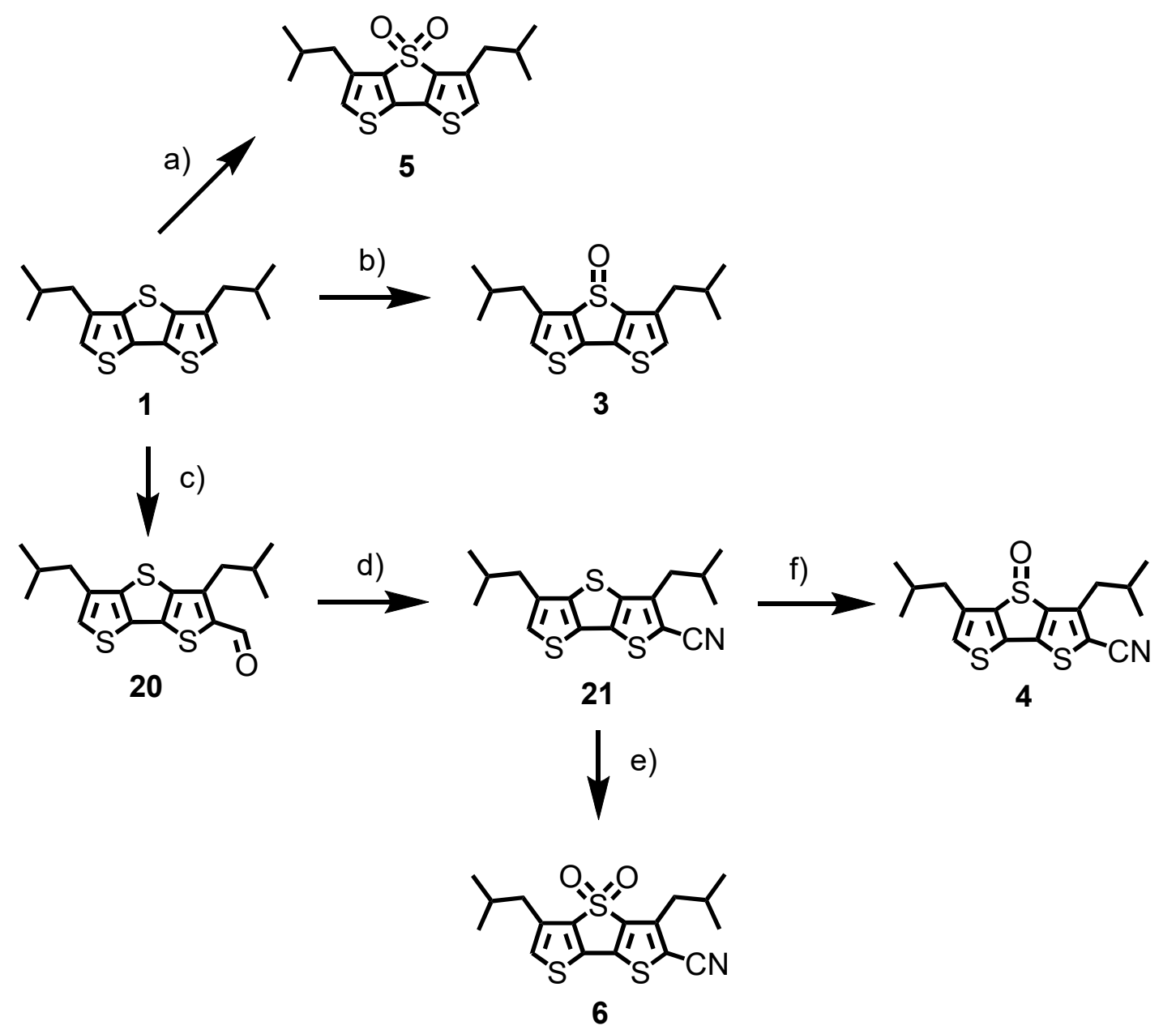

Scheme S2. Reagents and conditions: (a) mCPBA, $\mathrm{CHCl}_{3}, \mathrm{rt}, 2 \mathrm{~h}, 35 \%$; (b) $\mathrm{BF}_{3} \mathrm{OEt}_{2}, \mathrm{mCPBA}$, $\mathrm{CH}_{2} \mathrm{Cl}_{2},-20{ }^{\circ} \mathrm{C}, 2 \mathrm{~h}, 28 \%$; (c) $\mathrm{POCl}_{3}$, DMF, $0{ }^{\circ} \mathrm{C}$ to $50{ }^{\circ} \mathrm{C}, 3 \mathrm{~h}, 88 \%$; (d) $\mathrm{NaN}_{3}, \mathrm{TfOH}, \mathrm{CH}_{3} \mathrm{CN}, 50$ ${ }^{\circ} \mathrm{C}, 1 \mathrm{~h}, 83 \%$; (e) mCPBA, $\mathrm{CHCl}_{3}$, rt, 3 h, $70 \%$; (f) $\mathrm{BF}_{3} \mathrm{OEt}_{2}$, mCPBA, $\mathrm{CH}_{2} \mathrm{Cl}_{2},-20{ }^{\circ} \mathrm{C}, 2 \mathrm{~h}, 42 \%$.

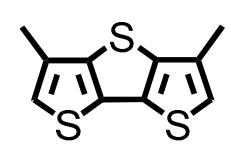

22
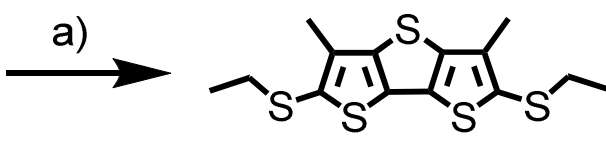

23

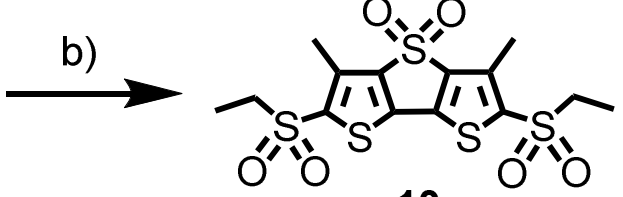

10

Scheme S3. Reagents and conditions: a) 1. LDA, THF, $-78{ }^{\circ} \mathrm{C}, 30 \mathrm{~min}$, 2. diethyldisulfide, THF, rt, 12 h, $54 \%$; (b) mCPBA, $\mathrm{CHCl}_{3}, \mathrm{rt}, 12$ h, $42 \%$. 
Compound 9. Was synthesized according to the procedure reported in ref. S6.

Compound 16. To a solution of $11(6.00 \mathrm{~g}, 15.0 \mathrm{mmol})$ in dry THF (40 mL) under $\mathrm{N}_{2}$ atmosphere, BuLi (26 mL, $42 \mathrm{mmol})$ was added dropwise at $-78{ }^{\circ} \mathrm{C}$. After subsequent dropwise addition of $12(5 \mathrm{~mL}, 45 \mathrm{mmol})$, the mixture was stirred for $2 \mathrm{~h}$ at $-78{ }^{\circ} \mathrm{C}$. The solvent was evaporated in vacuo and the brown crude product was purified by flash column chromatography $\left(\mathrm{SiO}_{2}, \mathrm{PE} / \mathrm{EtOAc} 85: 15\right)$ to afford 16 as a faint yellow solid (4.28 $\left.\mathrm{g}, 69 \%\right)$, mixture of diastereomers. $R_{\mathrm{f}}\left(\mathrm{PE} / \mathrm{EtOAc}\right.$ 85:15): 0.3; Mp: 112-113 ${ }^{\circ} \mathrm{C}$; IR (neat): 3280 (b), 2957 (m), 1740 (w), 1466 (m), 1367 (m), 1329 (m), 1234 (m), 1177 (m), 1067 (s), 981 (w), 847 (m), 766 (m), 679 (b), 595 (m); ${ }^{1} \mathrm{H}$ NMR (400 MHz, $\left.\mathrm{CDCl}_{3}\right)$ : 5.14-5.11 (m, 2H), 1.82-1.57 (m, 6H), 1.01-0.96 (m, 12H); ${ }^{13} \mathrm{C}$ NMR (101 MHz, $\left.\mathrm{CDCl}_{3}\right): 143.1(\mathrm{C}), 110.0(\mathrm{C}), 68.8(\mathrm{CH}), 47.2\left(\mathrm{CH}_{2}\right), 24.9(\mathrm{CH}), 23.3\left(\mathrm{CH}_{3}\right)$, $22.1\left(\mathrm{CH}_{3}\right) ; \mathrm{MS}\left(\mathrm{ESI}, \mathrm{CHCl}_{3}\right): 399 / 397$ / 395 (50 / 100 / 50, [M-OH] $\left.{ }^{+}\right), 343$ / $341 / 339$ (25 / 50 / 25, [M-OH-isobutyl $\left.]^{+}\right)$.

Compound 13. Chromic acid solution was prepared by dissolving $\mathrm{Na}_{2} \mathrm{Cr}_{2} \mathrm{O}_{7} \times 2 \mathrm{H}_{2} \mathrm{O}(10.0$ $\mathrm{g}, 34.0 \mathrm{mmol})$ in water $(30 \mathrm{~mL})$, then $7.4 \mathrm{~mL}$ of concentrated $\mathrm{H}_{2} \mathrm{SO}_{4}$ were added, and the resulting solution is diluted to $50 \mathrm{~mL}$ total volume. To $16(4.54 \mathrm{~g}, 11.0 \mathrm{mmol})$ in acetone $(60 \mathrm{~mL})$ was added dropwise chromic acid solution $(45.5 \mathrm{~mL})$ at room temperature. The reaction mixture was stirred overnight and a considerable amount of precipitate formed. The suspension was then diluted in EtOAc $(70 \mathrm{~mL})$, washed with $\mathrm{H}_{2} \mathrm{O}(3 \times 40 \mathrm{~mL})$, dried over $\mathrm{Na}_{2} \mathrm{SO}_{4}$ and concentrated in vacuo. The crude product was purified by solid/liquid extraction with EtOH to afford $\mathbf{1 3}$ as a faint yellow solid (3.10 g, 68\%). $R_{\mathrm{f}}(\mathrm{PE} / \mathrm{EtOAc} 9: 1): 0.9 ; \mathrm{Mp}: 102-103{ }^{\circ} \mathrm{C}$; IR (neat): $2958(\mathrm{~m}), 1649$ (s), $1470(\mathrm{~m})$, $1363(\mathrm{~s}), 1290(\mathrm{~m}), 1184(\mathrm{~s}), 1120(\mathrm{~m}), 981(\mathrm{w}), 923(\mathrm{w}), 877(\mathrm{~m}), 852(\mathrm{~m}), 768(\mathrm{~m}), 716(\mathrm{w}), 601$ (m); ${ }^{1} \mathrm{H}$ NMR (400 MHz, $\left.\mathrm{CDCl}_{3}\right): 2.92\left(\mathrm{~d},{ }^{3} J=6.8 \mathrm{~Hz}, 4 \mathrm{H}\right), 2.30\left(\right.$ non, $\left.{ }^{3} J=6.8 \mathrm{~Hz}, 2 \mathrm{H}\right), 1.01\left(\mathrm{~d},{ }^{3} J\right.$ $=6.8 \mathrm{~Hz}, 12 \mathrm{H}) ;{ }^{13} \mathrm{C} \mathrm{NMR}\left(101 \mathrm{MHz}, \mathrm{CDCl}_{3}\right): 192.0(\mathrm{C}), 141.9(\mathrm{C}), 119.0(\mathrm{C}), 50.5\left(\mathrm{CH}_{2}\right), 25.2$ (CH), $22.7\left(\mathrm{CH}_{3}\right) ; \mathrm{MS}\left(\mathrm{ESI}, \mathrm{CHCl}_{3}\right): 413 / 411 / 409\left(50 / 100 / 50,[\mathrm{M}+\mathrm{H}]^{+}\right)$. 
Compound 15. To a suspension of $\mathbf{1 3}(910 \mathrm{mg}, 2.22 \mathrm{mmol})$ in EtOH (20 mL) was added $\mathbf{1 4}$ $(681 \mu \mathrm{L}, 6.21 \mathrm{mmol})$ at $\mathrm{rt}$. After addition of freshly prepared NaOEt solution $(7.1 \mathrm{mmol}$ in $2.3 \mathrm{~mL}$ $\mathrm{EtOH}$ ), the reaction mixture was heated at reflux for $2 \mathrm{~h}$. The solution was cooled to room temperature and the $\mathrm{pH}$ was adjusted to 5 using $1 \mathrm{M} \mathrm{HCl}$. The precipitate formed was filtered and washed with $\mathrm{EtOH}$ to afford $\mathbf{1 5}$ as a colorless solid (864 mg, 86\%). $R_{\mathrm{f}}$ (PE/EtOAc 9:1): 0.8; Mp: 111-112 ${ }^{\circ} \mathrm{C}$; IR (neat): 2956 (w), 1695 (s), 1506 (m), 1463 (w), 1384 (m), 1245 (b), 1096 (s), 1023 (m), 904 (w), 861 (w), 753 (m); ${ }^{1} \mathrm{H}$ NMR (400 MHz, CDCl $): 4.37$ (q, $\left.{ }^{3} J=7.1 \mathrm{~Hz}, 4 \mathrm{H}\right), 3.05\left(\mathrm{~d},{ }^{3} J\right.$ $=7.0 \mathrm{~Hz}, 4 \mathrm{H}), 2.19\left(\right.$ non, $\left.{ }^{3} \mathrm{~J}=7.0 \mathrm{~Hz}, 2 \mathrm{H}\right), 1.41\left(\mathrm{t},{ }^{3} \mathrm{~J}=7.1 \mathrm{~Hz}, 6 \mathrm{H}\right), 0.99\left(\mathrm{~d},{ }^{3} \mathrm{~J}=7.0 \mathrm{~Hz}, 12 \mathrm{H}\right) ;{ }^{13} \mathrm{C}$ NMR (101 MHz, $\left.\mathrm{CDCl}_{3}\right)$ : 162.7 (C), 145.7 (C), 143.5 (C), 132.8 (C), 129.0 (C), $61.3\left(\mathrm{CH}_{2}\right), 38.1$ $\left(\mathrm{CH}_{2}\right), 29.5(\mathrm{CH}), 22.8\left(\mathrm{CH}_{3}\right), 14.4\left(\mathrm{CH}_{3}\right) ; \mathrm{MS}\left(\mathrm{ESI}, \mathrm{CHCl}_{3}\right): 453\left(100,[\mathrm{M}+\mathrm{H}]^{+}\right)$.

Compound 17. To a suspension of 15 (722 mg, $1.82 \mathrm{mmol})$ in EtOH (60 mL), KOH (255 $\mathrm{mg}, 4.55 \mathrm{mmol}$ ) was added. After heating at reflux overnight, the solution was cooled down to room temperature and $1 \mathrm{M} \mathrm{HCl}(25 \mathrm{~mL})$ was added. The colorless precipitate was filtered and washed with $\mathrm{H}_{2} \mathrm{O}(2 \times 30 \mathrm{~mL})$ to afford $\mathbf{1 7}$ as a colorless solid $(630 \mathrm{mg}, 95 \%) . R_{\mathrm{f}}(\mathrm{PE} / \mathrm{EtOAc} / \mathrm{AcOH}$ 3:6.9:0.1): 0.7; Mp: 263-264 ${ }^{\circ} \mathrm{C}$; IR (neat): 2958 (m), 2868 (m), 2624 (w), 2505 (w), 1651 (b), 1501 (s), 1449 (w), 1401 (s), 1255 (b), 1129 (m), 897 (b), 762 (w), 735 (m), 695 (w), 620 (w); ${ }^{1} \mathrm{H}$ NMR (400 MHz, DMSO-d6): $13.40(\mathrm{bs}, 2 \mathrm{H}), 3.03\left(\mathrm{~d},{ }^{3} J=7.0 \mathrm{~Hz}, 4 \mathrm{H}\right), 2.12$ (non, $\left.{ }^{3} J=7.0 \mathrm{~Hz}, 2 \mathrm{H}\right), 0.92$ $\left(\mathrm{d},{ }^{3} \mathrm{~J}=7.0 \mathrm{~Hz}, 12 \mathrm{H}\right) ;{ }^{13} \mathrm{C}$ NMR (101 MHz, DMSO-d $)$ : 163.4 (C), 144.4 (C), 141.8 (C), 131.7 (C), $130.3(\mathrm{C}), 36.9\left(\mathrm{CH}_{2}\right), 28.7(\mathrm{CH}), 22.4\left(\mathrm{CH}_{3}\right) ; \mathrm{MS}\left(\mathrm{ESI}, \mathrm{CHCl}_{3}\right)$ : $397\left(100,[\mathrm{M}+\mathrm{H}]^{+}\right)$.

Compound 1. To a solution of $17(250 \mathrm{mg}, 0.63 \mathrm{mmol})$ in DMSO (6.0 mL), $\mathrm{Ag}_{2} \mathrm{CO}_{3}(17$ $\mathrm{mg}, 0.06 \mathrm{mmol})$ and $\mathrm{AcOH}(2 \mu \mathrm{L}, 0.03 \mathrm{mmol})$ were added at room temperature. The reaction mixture was heated to $120{ }^{\circ} \mathrm{C}$ and stirred overnight. After cooling to room temperature, $2 \mathrm{M} \mathrm{HCl}$ (4 $\mathrm{mL})$ was added and the mixture was diluted in EtOAc $(20 \mathrm{~mL})$, washed with $\mathrm{H}_{2} \mathrm{O}(3 \times 20 \mathrm{~mL})$, 
dried over $\mathrm{Na}_{2} \mathrm{SO}_{4}$ and concentrated in vacuo. The crude product was purified by column chromatography $\left(\mathrm{SiO}_{2}, \mathrm{PE}\right)$ to afford compound 1 as a light yellow oil (141 mg, 73\%). $R_{\mathrm{f}}(\mathrm{PE}): 0.6$; IR (neat): 2960 (s), 2923 (m), 1462 (m), 1376 (m), 1260 (m), 1167 (w), 1096 (m), 1020 (m), 973 (w), 799 (m), 726 (m); ${ }^{1} \mathrm{H}$ NMR (400 MHz, $\left.\mathrm{CDCl}_{3}\right): 6.93$ (s, 2H), $2.60\left(\mathrm{~d},{ }^{3} \mathrm{~J}=6.9 \mathrm{~Hz}, 4 \mathrm{H}\right), 2.16$ (non, $\left.{ }^{3} J=6.9 \mathrm{~Hz}, 2 \mathrm{H}\right), 0.97\left(\mathrm{~d},{ }^{3} J=6.9 \mathrm{~Hz}, 12 \mathrm{H}\right) ;{ }^{13} \mathrm{C} \mathrm{NMR}\left(101 \mathrm{MHz}, \mathrm{CDCl}_{3}\right): 141.8(\mathrm{C}), 135.3$ (C), $130.8(\mathrm{C}), 121.1(\mathrm{CH}), 39.3\left(\mathrm{CH}_{2}\right), 28.3(\mathrm{CH}), 22.7\left(\mathrm{CH}_{3}\right)$; MS (ESI, $\left.\mathrm{CHCl}_{3}\right)$ : 309 (100, $\left.[\mathrm{M}+\mathrm{H}]^{+}\right)$.

Compound 3. To a solution of $1(27 \mathrm{mg}, 0.08 \mathrm{mmol})$ in dry $\mathrm{CH}_{2} \mathrm{Cl}_{2}(1.5 \mathrm{~mL})$ under $\mathrm{N}_{2}$ atmosphere, $\mathrm{BF}_{3} \mathrm{OEt}_{2}(31 \mu \mathrm{L}, 0.26 \mathrm{mmol})$ was added dropwise at $-20{ }^{\circ} \mathrm{C}$. After subsequent addition of mCPBA (24 mg, $0.11 \mathrm{mmol})$ in dry $\mathrm{CH}_{2} \mathrm{Cl}_{2}(800 \mu \mathrm{L})$, the mixture was stirred at $-20{ }^{\circ} \mathrm{C}$ for $2 \mathrm{~h}$. After completion, monitored by TLC, the solution was diluted in $\mathrm{CH}_{2} \mathrm{Cl}_{2}(10 \mathrm{~mL})$ washed with aq. $\mathrm{NaHSO}_{3}(10 \%, 10 \mathrm{~mL})$, aq. $\mathrm{NaHCO}_{3}$ (sat. $\left.10 \mathrm{~mL}\right), \mathrm{H}_{2} \mathrm{O}(10 \mathrm{~mL})$, dried over $\mathrm{Na}_{2} \mathrm{SO}_{4}$ and concentrated in vacuo. The crude product was purified by PTLC (PE/EtOAc 9:1) to afford 3 as a yellow solid (13 mg, 28\%). $R_{\mathrm{f}}$ (PE/EtOAc 9:1): 0.3; IR (neat): $2953(\mathrm{~m}), 2923(\mathrm{~m}), 2867(\mathrm{w}), 1462$ (m), $1382(w), 1300(w), 1260(w), 1166(w), 1054($ s), 1025 (s), $888(w), 800(b), 742(m), 606$ (m); ${ }^{1} \mathrm{H}$ NMR (400 MHz, $\left.\mathrm{CDCl}_{3}\right): 6.87(\mathrm{~s}, 2 \mathrm{H}), 2.73-2.61(\mathrm{~m}, 4 \mathrm{H}), 2.20-2.10(\mathrm{~m}, 2 \mathrm{H}), 0.98\left(\mathrm{~d},{ }^{3} J=\right.$ $6.6 \mathrm{~Hz}, 12 \mathrm{H}) ;{ }^{13} \mathrm{C} \mathrm{NMR}\left(101 \mathrm{MHz}, \mathrm{CDCl}_{3}\right): 149.1(\mathrm{C}), 140.3(\mathrm{C}), 138.4(\mathrm{C}), 123.5(\mathrm{CH}), 38.0$ $\left(\mathrm{CH}_{2}\right), 29.2(\mathrm{CH}), 22.7\left(\mathrm{CH}_{3}\right)$; MS (ESI, $\left.\mathrm{CHCl}_{3}\right): 325\left(90,[\mathrm{M}+\mathrm{H}]^{+}\right), 308\left(80,[\mathrm{M}-\mathrm{O}]^{+}\right), 266(100$, [M-isobutyl $]^{+}$); HRMS (ESI, +ve) calcd for $\mathrm{C}_{16} \mathrm{H}_{20} \mathrm{OS}_{3}$ : 325.0749, found: 325.0748 .

Compound 5. To a solution of $\mathbf{1}(38 \mathrm{mg}, 0.12 \mathrm{mmol})$ in $\mathrm{CHCl}_{3}(3.5 \mathrm{~mL}), \mathrm{mCPBA}(106 \mathrm{mg}$, $0.37 \mathrm{mmol}$ ) was added and stirred at room temperature for $2 \mathrm{~h}$. The mixture was diluted in $\mathrm{CH}_{2} \mathrm{Cl}_{2}$ $(10 \mathrm{~mL})$ and washed with aq. $\mathrm{Na}_{2} \mathrm{SO}_{3}(10 \%, 3$ x $10 \mathrm{~mL})$, aq. $\mathrm{NaHCO}_{3}$ (sat. 2 x $\left.10 \mathrm{~mL}\right), \mathrm{H}_{2} \mathrm{O}(10$ $\mathrm{mL}$ ), dried over $\mathrm{Na}_{2} \mathrm{SO}_{4}$ and concentrated in vacuo. The crude product was purified by PTLC (PE/EtOAc 9:1) to afford 5 as a yellow solid (14 mg, 35\%). $R_{\mathrm{f}}(\mathrm{PE} / \mathrm{EtOAc} 9: 1): 0.6 ; \mathrm{Mp}: 85-86{ }^{\circ} \mathrm{C}$; 
IR (neat): 3096 (w), 2959 (m), 2926 (w), 1699 (w), 1515 (w), 1462 (w), 1409 (w), 1385 (w), 1295 (s), $1225(\mathrm{w}), 1140(\mathrm{~s}), 1095(\mathrm{~m}), 1070(\mathrm{~m}), 955(\mathrm{w}), 892(\mathrm{w}), 827(\mathrm{~m}), 747$ (m), 618 (s), 557 (s); ${ }^{1} \mathrm{H}$ NMR (400 MHz, $\left.\mathrm{CDCl}_{3}\right): 6.87(\mathrm{~s}, 2 \mathrm{H}), 2.62\left(\mathrm{~d},{ }^{3} \mathrm{~J}=7.0 \mathrm{~Hz}, 4 \mathrm{H}\right), 2.12$ (non, $\left.{ }^{3} J=7.0 \mathrm{~Hz}, 2 \mathrm{H}\right)$, $0.97\left(\mathrm{~d},{ }^{3} \mathrm{~J}=7.0 \mathrm{~Hz}, 12 \mathrm{H}\right) ;{ }^{13} \mathrm{C}$ NMR $\left(101 \mathrm{MHz}, \mathrm{CDCl}_{3}\right): 142.8(\mathrm{C}), 138.1(\mathrm{C}), 136.1(\mathrm{C}), 124.7$ (CH), $37.7\left(\mathrm{CH}_{2}\right), 29.3(\mathrm{CH}), 22.5\left(\mathrm{CH}_{3}\right)$; MS (ESI, $\left.\mathrm{CHCl}_{3} / \mathrm{MeOH} 1: 1+0.5 \% \mathrm{HCOOH}\right): 341$ (100, $\left.[\mathrm{M}+\mathrm{H}]^{+}\right)$.

Compound 20. To a solution of 1 (372 mg, $1.21 \mathrm{mmol})$ in freshly distilled DMF (12 mL) under $\mathrm{N}_{2}$ atmosphere, $\mathrm{POCl}_{3}(150 \mu \mathrm{L}, 1.57 \mathrm{mmol})$ was added dropwise at $0{ }^{\circ} \mathrm{C}$. After addition, the solution was heated at $50{ }^{\circ} \mathrm{C}$ for $3 \mathrm{~h}$, cooled to room temperature and poured into a solution of aq. sodium acetate (sat. $200 \mathrm{~mL}$ ), and stirred for an additional $2 \mathrm{~h}$. The mixture was extracted with $\mathrm{CH}_{2} \mathrm{Cl}_{2}(3 \times 20 \mathrm{~mL})$ and washed with aq. $\mathrm{LiCl}(5 \%, 3 \times 10 \mathrm{~mL})$, dried over $\mathrm{Na}_{2} \mathrm{SO}_{4}$ and concentrated under vacuum. The yellow crude product was purified by flash column chromatography $\left(\mathrm{SiO}_{2}, \mathrm{CH}_{2} \mathrm{Cl}_{2} / \mathrm{PE} 1: 1\right)$ to afford 20 as a faint yellow solid $(357 \mathrm{mg}, 88 \%) . R_{\mathrm{f}}$ ( $\mathrm{CH}_{2} \mathrm{Cl}_{2} / \mathrm{PE}$ 1:1): 0.4; Mp: 127-128 ${ }^{\circ} \mathrm{C}$; IR (neat): 2955 (m), 2866 (w), 1632 (s), 1504 (w), 1445 (m), 1405 (w), $1379(\mathrm{~m}), 1339(\mathrm{w}), 1299$ (w), 1228 (b), 1165 (w), $1103(\mathrm{w}), 1046(\mathrm{w}), 888(\mathrm{w}), 826$ (w), 769 (w), 737 (m), 662 (m), 647 (m), 605 (w), 572 (w); ${ }^{1} \mathrm{H}$ NMR (400 MHz, CDCl $)$ ) 10.05 (s, 1H), $7.14(\mathrm{~s}, 1 \mathrm{H}), 2.97\left(\mathrm{~d},{ }^{3} J=7.4 \mathrm{~Hz}, 2 \mathrm{H}\right), 2.62\left(\mathrm{~d},{ }^{3} J=7.3 \mathrm{~Hz}, 2 \mathrm{H}\right), 2.26-2.07(\mathrm{~m}, 2 \mathrm{H}), 1.02\left(\mathrm{~d},{ }^{3} J\right.$ $=6.6 \mathrm{~Hz}, 6 \mathrm{H}), 0.98\left(\mathrm{~d},{ }^{3} \mathrm{~J}=6.6 \mathrm{~Hz}, 6 \mathrm{H}\right) ;{ }^{13} \mathrm{C} \mathrm{NMR}\left(101 \mathrm{MHz}, \mathrm{CDCl}_{3}\right): 182.2(\mathrm{CH}), 146.1(\mathrm{C})$, 145.5 (C), 142.9 (C), 138.2 (C), 137.4 (C), 135.6 (C), 130.6 (C), $125.3(\mathrm{CH}), 39.1\left(\mathrm{CH}_{2}\right), 37.3$ $\left(\mathrm{CH}_{2}\right), 29.8(\mathrm{CH}), 28.3(\mathrm{CH}), 22.9\left(\mathrm{CH}_{3}\right), 22.7\left(\mathrm{CH}_{3}\right) ; \mathrm{MS}\left(\mathrm{ESI}, \mathrm{CHCl}_{3}\right)$ : $337\left(100,[\mathrm{M}+\mathrm{H}]^{+}\right)$.

Compound 21. To a suspension of $20(70 \mathrm{mg}, 0.21 \mathrm{mmol})$ and $\mathrm{NaN}_{3}(21 \mathrm{mg}, 0.31 \mathrm{mmol})$ in $\mathrm{CH}_{3} \mathrm{CN}(5 \mathrm{~mL}), \mathrm{TfOH}(55 \mu \mathrm{L}, 0.62 \mathrm{mmol})$ was added dropwise, and the reaction mixture was heated at $50{ }^{\circ} \mathrm{C}$ for $1 \mathrm{~h}$. After cooling to room temperature, the reaction was extracted with $\mathrm{CH}_{2} \mathrm{Cl}_{2}$ (3 $\times 20 \mathrm{~mL})$ and the organic layer was washed with $\mathrm{H}_{2} \mathrm{O}(3 \times 20 \mathrm{~mL})$, dried over $\mathrm{Na}_{2} \mathrm{SO}_{4}$ and 
concentrated under vacuum. The deep red crude product was purified by filtration over silica

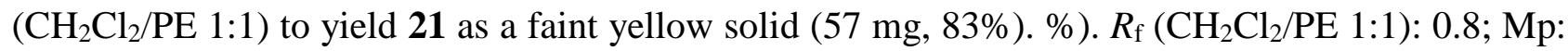
105-106 ${ }^{\circ} \mathrm{C}$; IR (neat): 3091 (w), 2957 (m), 2926 (m), 2206 (m), 1503 (w), 1444 (m), 1381 (m), $1337(w), 1301(w), 1260(\mathrm{~m}), 1224(w), 1182(w), 1165(w), 1099(b), 1017$ (b), $866(w), 798$ (b), 754 (s), 679 (w), 611 (w), 556 (w); ${ }^{1} \mathrm{H}$ NMR (400 MHz, $\left.\mathrm{CDCl}_{3}\right): 7.11$ (s, 1H), 2.82 (d, ${ }^{3} \mathrm{~J}=7.0 \mathrm{~Hz}$, 2H), $2.62\left(\mathrm{~d},{ }^{3} J=7.3 \mathrm{~Hz}, 2 \mathrm{H}\right), 2.26\left(\right.$ non, $\left.{ }^{3} J=7.0 \mathrm{~Hz}, 1 \mathrm{H}\right), 2.21\left(\right.$ non, $\left.{ }^{3} J=7.3 \mathrm{~Hz}, 1 \mathrm{H}\right), 1.02\left(\mathrm{~d},{ }^{3} J\right.$ $=7.0 \mathrm{~Hz}, 6 \mathrm{H}), 0.98\left(\mathrm{~d},{ }^{3} \mathrm{~J}=7.3 \mathrm{~Hz}, 6 \mathrm{H}\right) ;{ }^{13} \mathrm{C} \mathrm{NMR}\left(101 \mathrm{MHz}, \mathrm{CDCl}_{3}\right): 146.9(\mathrm{C}), 145.7(\mathrm{C}), 140.5$ (C), $135.5(\mathrm{C}), 134.4(\mathrm{C}), 129.9(\mathrm{C}), 124.5(\mathrm{CH}), 114.9(\mathrm{C}), 104.6(\mathrm{C}), 39.1\left(\mathrm{CH}_{2}\right), 38.8\left(\mathrm{CH}_{2}\right), 28.9$ (CH), $28.3(\mathrm{CH}), 22.7\left(\mathrm{CH}_{3}\right)$; MS (ESI, $\left.\mathrm{CHCl}_{3}\right): 334\left(100,[\mathrm{M}+\mathrm{H}]^{+}\right)$.

Compound 4. To a solution of $21(57 \mathrm{mg}, 0.17 \mathrm{mmol})$ in dry $\mathrm{CH}_{2} \mathrm{Cl}_{2}(2 \mathrm{~mL})$ under $\mathrm{N}_{2}$ atmosphere, $\mathrm{BF}_{3} \mathrm{OEt}_{2}(65 \mu \mathrm{L}, 0.51 \mathrm{mmol})$ was added dropwise at $-20{ }^{\circ} \mathrm{C}$. After subsequent addition of mCPBA (47 mg, $0.21 \mathrm{mmol})$ in dry $\mathrm{CH}_{2} \mathrm{Cl}_{2}(1 \mathrm{~mL})$ at $-20{ }^{\circ} \mathrm{C}$, the mixture was stirred for $2 \mathrm{~h}$ at $-20{ }^{\circ} \mathrm{C}$. After completion, monitored by TLC, the solution was diluted with $\mathrm{CH}_{2} \mathrm{Cl}_{2}(10 \mathrm{~mL})$ and washed with aq. $\mathrm{NaHSO}_{3}(10 \%, 10 \mathrm{~mL})$, aq. $\mathrm{NaHCO}_{3}$ (sat. $\left.10 \mathrm{~mL}\right), \mathrm{H}_{2} \mathrm{O}(10 \mathrm{~mL}$ ), dried over $\mathrm{Na}_{2} \mathrm{SO}_{4}$ and concentrated in vacuo. The crude product was purified by PTLC (PE/EtOAc 9:1) to afford 4 as a yellow solid (25 mg, 42\%). $R_{\mathrm{f}}(\mathrm{PE} / \mathrm{EtOAc} 9: 1): 0.4 ; \mathrm{Mp}: 148-149{ }^{\circ} \mathrm{C}$; IR (neat): 3114 (w), 2953 (m), 2924 (w), 2865 (w), 2205 (m), 1503 (w), 1463 (m), $1419(\mathrm{~m}), 1386(\mathrm{~m}), 1366$ (m), 1331 (w), 1294 (m), 1223 (w), 1164 (w), 1044 (s), 891 (w), 834 (m), 756 (m), 699 (w), 605 (w); ${ }^{1} \mathrm{H}$ NMR (400 MHz, $\left.\mathrm{CDCl}_{3}\right): 7.07$ (s, 1H), 2.91-2.80 (m, 2H), 2.74-2.63 (m, 2H), 2.33-2.23 (m, 1H), 2.17-2.07 (m, 1H), $1.03\left(\mathrm{~d},{ }^{3} J=6.6 \mathrm{~Hz}, 6 \mathrm{H}\right), 0.98\left(\mathrm{~d},{ }^{3} J=6.6 \mathrm{~Hz}, 6 \mathrm{H}\right) ;{ }^{13} \mathrm{C}$ NMR $(101 \mathrm{MHz}$, $\left.\mathrm{CDCl}_{3}\right): 152.0(\mathrm{C}), 151.2(\mathrm{C}), 148.5(\mathrm{C}), 143.1(\mathrm{C}), 140.9$ (C), $136.4(\mathrm{C}), 126.9$ (CH) 113.6 (C), $107.4(\mathrm{C}), 37.9\left(\mathrm{CH}_{2}\right), 37.6\left(\mathrm{CH}_{2}\right), 29.8(\mathrm{CH}), 29.2(\mathrm{CH}), 22.6\left(\mathrm{CH}_{3}\right), 22.4\left(\mathrm{CH}_{3}\right)$; MS (ESI, $\mathrm{CHCl} / \mathrm{MeOH}$ 1:1 + 0.5\% HCOOH): $350\left(30,[\mathrm{M}+\mathrm{H}]^{+}\right), 291\left(60,[\mathrm{M}-\mathrm{O}-\text { isopropyl }]^{+}\right), 248(100,[\mathrm{M}-$ isobutyl-isopropyl] ${ }^{+}$); HRMS (ESI, +ve) calcd for $\mathrm{C}_{17} \mathrm{H}_{19} \mathrm{OS}_{3}$ : 372.0521, found: 372.0517. 
Compound 6. To a solution of $21(12 \mathrm{mg}, 0.03 \mathrm{mmol})$ in $\mathrm{CHCl}_{3}(1.5 \mathrm{~mL}), \mathrm{mCPBA}(31 \mathrm{mg}$, $0.11 \mathrm{mmol}$ ) was added, and the mixture was stirred at room temperature for $3 \mathrm{~h}$. The mixture was diluted in $\mathrm{CH}_{2} \mathrm{Cl}_{2}(10 \mathrm{~mL})$ and washed with aq. $\mathrm{Na}_{2} \mathrm{SO}_{3}\left(10 \%, 3 \times 10 \mathrm{~mL}\right.$ ), aq. $\mathrm{NaHCO}_{3}$ (sat. 2 x 10 $\mathrm{mL}), \mathrm{H}_{2} \mathrm{O}(10 \mathrm{~mL})$, dried over $\mathrm{Na}_{2} \mathrm{SO}_{4}$ and concentrated in vacuo. The crude product was purified by PTLC $\left(\mathrm{CH}_{2} \mathrm{Cl}_{2} / \mathrm{PE} / 1: 1\right)$ to afford 6 as a yellow sticky solid (9 mg, $\left.70 \%\right) . R_{\mathrm{f}}\left(\mathrm{CH}_{2} \mathrm{Cl}_{2} / \mathrm{PE} 1: 1\right)$ : 0.5; IR (neat): 2956 (m), 2924 (m), 2869 (w), 2212 (w), 1721 (w), 1464 (m), 1432 (m), 1384 (w), 1304 (s), 1227 (w), 1169 (w), 1139 (s), 1100 (s), $1066(w), 1025$ (w), $996(w), 747$ (m), $689(\mathrm{~s}), 635$ (s), 612 (m), 554 (s); ${ }^{1} \mathrm{H}$ NMR (400 MHz, $\left.\mathrm{CDCl}_{3}\right): 7.08$ (s, 1H), 2.79 (d, $\left.{ }^{3} J=7.1 \mathrm{~Hz}, 2 \mathrm{H}\right), 2.64$ (d, $\left.{ }^{3} J=7.0 \mathrm{~Hz}, 2 \mathrm{H}\right), 2.28\left(\right.$ non, $\left.{ }^{3} J=7.1 \mathrm{~Hz}, 1 \mathrm{H}\right), 2.13\left(\right.$ non, $\left.{ }^{3} J=7.0 \mathrm{~Hz}, 1 \mathrm{H}\right), 1.03\left(\mathrm{~d},{ }^{3} J=7.1 \mathrm{~Hz}, 6 \mathrm{H}\right)$, $0.98\left(\mathrm{~d},{ }^{3} \mathrm{~J}=7.0 \mathrm{~Hz}, 6 \mathrm{H}\right) ;{ }^{13} \mathrm{C} \mathrm{NMR}\left(101 \mathrm{MHz}, \mathrm{CDCl}_{3}\right): 148.7$ (C), 145.0 (C), 142.1 (C), 140.5 (C), $138.7(\mathrm{C}), 133.9(\mathrm{C}), 128.0(\mathrm{CH}), 113.0(\mathrm{C}), 108.7(\mathrm{C}), 37.6\left(\mathrm{CH}_{2}\right), 37.5\left(\mathrm{CH}_{2}\right), 29.8(\mathrm{CH}), 29.4$ (CH), $22.5\left(\mathrm{CH}_{3}\right), 22.4\left(\mathrm{CH}_{3}\right)$; MS (ESI, CHCl3/MeOH 1:1 + 0.5\% HCOOH): 295 (100, [M-CNisopropyl $]^{+}$), $217\left(90,[\mathrm{M}-2 \text { isobutyl-O }]_{2}^{+}\right.$); HRMS (ESI, +ve) calcd for $\mathrm{C}_{17} \mathrm{H}_{19} \mathrm{NO}_{2} \mathrm{~S}_{3}: 366.0651$, found: 366.0650 .

Compound 18. To a solution of $\mathbf{1 5}(300 \mathrm{mg}, 0.66 \mathrm{mmol})$ in $\mathrm{CH}_{2} \mathrm{Cl}_{2}$ (35 mL), DIBAL-H (3.1 $\mathrm{mL}$ of $1 \mathrm{M}$ in toluene, $3.1 \mathrm{mmol}$ ) was added dropwise at $-78{ }^{\circ} \mathrm{C}$ under argon atmosphere. The mixture was stirred for $4 \mathrm{~h}$ at $-78^{\circ} \mathrm{C}$ before the addition of $1 \mathrm{~mL} \mathrm{MeOH}$. The jellified mixture was warmed to $0{ }^{\circ} \mathrm{C}$, where it liquefied again. Aq. $\mathrm{KOH}(4 \mathrm{M}, 0.5 \mathrm{~mL})$ was slowly added and the resulting mixture was stirred for $30 \mathrm{~min}$. After addition of $\mathrm{Na}_{2} \mathrm{SO}_{4}$, the mixture was diluted with $\mathrm{CH}_{2} \mathrm{Cl}_{2}$, filtered and concentrated under reduced pressure to yield $\mathbf{1 8}$ as a colorless solid (243 mg, quant). $R_{\mathrm{f}}\left(\mathrm{CH}_{2} \mathrm{Cl}_{2} / \mathrm{MeOH}\right.$ 9:1): 0.5; Mp: 162-163 ${ }^{\circ} \mathrm{C}$; IR (neat): 2953 (m), 2924 (m), 2866 (w), 1461 (m), 1376 (m), 1290 (w), 1227 (w), 1168 (m), 1101 (m), 906 (m), 731 (s), 649 (w); ${ }^{1} \mathrm{H}$ NMR $\left(400 \mathrm{MHz}, \mathrm{CDCl}_{3}\right): 4.77\left(\mathrm{~d},{ }^{3} J=5.5 \mathrm{~Hz}, 4 \mathrm{H}\right), 2.55\left(\mathrm{~d},{ }^{3} J=7.1 \mathrm{~Hz}, 4 \mathrm{H}\right), 2.08\left(\right.$ non, $\left.{ }^{3} J=7.1 \mathrm{~Hz}, 2 \mathrm{H}\right)$, $1.62\left(\mathrm{t},{ }^{3} \mathrm{~J}=5.5 \mathrm{~Hz}, 2 \mathrm{H}\right), 0.90\left(\mathrm{~d},{ }^{3} \mathrm{~J}=7.1 \mathrm{~Hz}, 12 \mathrm{H}\right) ;{ }^{13} \mathrm{C} \mathrm{NMR}\left(101 \mathrm{MHz}, \mathrm{CDCl}_{3}\right): 142.0(\mathrm{C}), 138.4$ 
(C), $132.8(\mathrm{C}), 129.2(\mathrm{C}), 58.9\left(\mathrm{CH}_{2}\right), 37.2\left(\mathrm{CH}_{2}\right), 28.7(\mathrm{CH}), 22.9\left(\mathrm{CH}_{3}\right) ; \mathrm{MS}\left(\mathrm{ESI}, \mathrm{CHCl}_{3}\right): 367$ $\left(100,[\mathrm{M}+\mathrm{H}]^{+}\right)$.

Compound 2. To a solution of $\mathbf{1 8}(320 \mathrm{mg}, 0.87 \mathrm{mmol})$ in $\mathrm{CH}_{2} \mathrm{Cl}_{2}(60 \mathrm{~mL})$ was added DMP (884 mg, $2.01 \mathrm{mmol}$ ) at $0{ }^{\circ} \mathrm{C}$. After addition, the temperature was raised to room temperature and the turbid mixture was stirred for $1 \mathrm{~h}$. Aq. $\mathrm{Na}_{2} \mathrm{~S}_{2} \mathrm{O}_{3}(10 \%, 20 \mathrm{~mL})$ was added and stirred vigorously until a clear solution was obtained. The organic layer was separated and washed with $1 \mathrm{M} \mathrm{KOH}$, dried over $\mathrm{Na}_{2} \mathrm{SO}_{4}$ and concentrated under vacuum to ca. $1 \mathrm{~mL}$. Pentane was added to the mixture and the formed precipitate was filtered to give 2 as a colorless solid (225 mg, 71\%). $R_{\mathrm{f}}\left(\mathrm{CH}_{2} \mathrm{Cl}_{2}\right)$ : 0.5; Mp: 254-255 ${ }^{\circ} \mathrm{C}$; IR (neat): 2956 (m), 2924 (w), 2867 (w), 1647 (s), 1507 (w), 1462 (w), 1406 (m), 1364 (m), 1342 (w), 1259 (w), 1230 (m), 1205 (s), 1103 (m), 1058 (m), 1020 (w), 799 (b), 737 (w), 655 (s); ${ }^{1} \mathrm{H}$ NMR (400 MHz, $\mathrm{CDCl}_{3}$ ): 10.11 (s, 2H), $3.00\left(\mathrm{~d},{ }^{3} J=7.0 \mathrm{~Hz}, 4 \mathrm{H}\right), 2.18$ (non, ${ }^{3} J=$ $7.0 \mathrm{~Hz}, 2 \mathrm{H}), 1.04\left(\mathrm{~d},{ }^{3} \mathrm{~J}=7.0 \mathrm{~Hz}, 12 \mathrm{H}\right) ;{ }^{13} \mathrm{C} \mathrm{NMR}\left(101 \mathrm{MHz}, \mathrm{CDCl}_{3}\right): 182.5(\mathrm{CH}), 146.3(\mathrm{C}), 144.8$ (C), $141.1(\mathrm{C}), 136.3(\mathrm{C}), 37.3\left(\mathrm{CH}_{2}\right), 29.9(\mathrm{CH}), 22.9\left(\mathrm{CH}_{3}\right)$; MS (ESI, $\left.\mathrm{CHCl}_{3}\right)$ : 365 (100, $\left.[\mathrm{M}+\mathrm{H}]^{+}\right)$

Compound 8. To a solution of $2(25 \mathrm{mg}, 0.07 \mathrm{mmol})$ in $\mathrm{CHCl}_{3}(3 \mathrm{~mL}), \mathrm{mCPBA}(36 \mathrm{mg}$, $0.21 \mathrm{mmol}$ ) was added and the reaction was stirred at room temperature for $3 \mathrm{~h}$. The mixture was diluted in $\mathrm{CH}_{2} \mathrm{Cl}_{2}(10 \mathrm{~mL})$ and washed with aq. $\mathrm{Na}_{2} \mathrm{SO}_{3}\left(10 \%, 3\right.$ x $10 \mathrm{~mL}$ ), aq. $\mathrm{NaHCO}_{3}$ (sat. 2 × 10 $\mathrm{mL}), \mathrm{H}_{2} \mathrm{O}(10 \mathrm{~mL})$, dried over $\mathrm{Na}_{2} \mathrm{SO}_{4}$ and concentrated in vacuo. The crude product was purified by flash column chromatography (PE/EtOAc 9:1) to afford $\mathbf{8}$ as a yellow solid (11 mg, 36\%). $R_{\mathrm{f}}$ (PE/EtOAc 9:1): 0.3; IR (neat): 2959 (w), 2868 (w), 1654 (s), 1463 (w), 1418 (w), 1372 (w), 1314 (m), 1286 (w), 1228 (w), 1211 (m), 1138 (s), 1063 (m), 804 (w), 661 (m), 615 (m); ${ }^{1}$ H NMR (400 $\left.\mathrm{MHz}, \mathrm{CDCl}_{3}\right): 10.00$ (s, 2H), $2.97\left(\mathrm{~d},{ }^{3} J=7.0 \mathrm{~Hz}, 4 \mathrm{H}\right), 2.23\left(\mathrm{non},{ }^{3} J=7.0 \mathrm{~Hz}, 2 \mathrm{H}\right), 1.05\left(\mathrm{~d},{ }^{3} J=7.0\right.$ $\mathrm{Hz}, 12 \mathrm{H}) ;{ }^{13} \mathrm{C} \mathrm{NMR}\left(101 \mathrm{MHz}, \mathrm{CDCl}_{3}\right): 181.5(\mathrm{CH}), 145.7$ (C), $145.6(\mathrm{C}), 144.2$ (C), 140.7 (C), 
$35.9\left(\mathrm{CH}_{2}\right), 30.7(\mathrm{CH}), 22.6\left(\mathrm{CH}_{3}\right)$; MS (ESI, $\left.\mathrm{CHCl} 3 / \mathrm{MeOH} 1: 1+0.5 \% \mathrm{HCOOH}\right): 397(100$, $\left.[\mathrm{M}+\mathrm{H}]^{+}\right)$.

Compound 19. To a suspension of $2(132 \mathrm{mg}, 0.36 \mathrm{mmol})$ and $\mathrm{NaN}_{3}(71 \mathrm{mg}, 1.1 \mathrm{mmol})$ in $\mathrm{CH}_{3} \mathrm{CN}(18 \mathrm{~mL})$, TfOH $(191 \mu \mathrm{L}, 2.17 \mathrm{mmol})$ was added at room temperature. The mixture was heated to $50{ }^{\circ} \mathrm{C}$ for $1 \mathrm{~h}$, cooled to room temperature and diluted with $\mathrm{CH}_{2} \mathrm{Cl}_{2}(60 \mathrm{~mL})$. The organic layer was washed with $\mathrm{H}_{2} \mathrm{O}(3 \times 20 \mathrm{~mL})$, dried over $\mathrm{Na}_{2} \mathrm{SO}_{4}$ and concentrated under vacuum. The deep red crude product was purified by filtration over silica $\left(\mathrm{CH}_{2} \mathrm{Cl}_{2} / \mathrm{PE} 1: 1\right)$ to afford 19 as a light yellow solid (92 mg, 71\%). $R_{\mathrm{f}}$ (PE/EtOAc 9:1): 0.8; Mp: 178-179 ${ }^{\circ} \mathrm{C}$; IR (neat): 2958 (m), 2927 (m), 2870 (w), 2214 (s), 1508 (w), 1464 (m), 1415 (m), 1387 (w), 1369 (w), 1314 (s), 1283 (m), $1198(w), 1166(w), 1138(\mathrm{~s}), 1035(\mathrm{~m}), 895(\mathrm{w}), 802(\mathrm{~m}), 718(\mathrm{w}), 660(\mathrm{~m}), 620(\mathrm{w}), 600(\mathrm{w}), 554$ (s); ${ }^{1} \mathrm{H}$ NMR $\left(400 \mathrm{MHz}, \mathrm{CDCl}_{3}\right): 2.84\left(\mathrm{~d},{ }^{3} \mathrm{~J}=7.0 \mathrm{~Hz}, 4 \mathrm{H}\right), 2.18\left(\right.$ non, $\left.{ }^{3} \mathrm{~J}=7.0 \mathrm{~Hz}, 2 \mathrm{H}\right), 1.02\left(\mathrm{~d},{ }^{3} \mathrm{~J}\right.$ $=7.0 \mathrm{~Hz}, 12 \mathrm{H}) ;{ }^{13} \mathrm{C} \mathrm{NMR}\left(101 \mathrm{MHz}, \mathrm{CDCl}_{3}\right): 146.8$ (C), 143.9 (C), 133.0 (C), 114.1 (C), 107.9 (C), $38.8\left(\mathrm{CH}_{2}\right), 28.9(\mathrm{CH}), 22.7\left(\mathrm{CH}_{3}\right)$; $\mathrm{MS}\left(\mathrm{ESI}, \mathrm{CHCl}_{3}\right)$ : $376\left(100,\left[\mathrm{M}+\mathrm{NH}_{4}{ }^{+}\right]^{+}\right)$.

Compound 7. To a solution of $\mathbf{1 9}(66 \mathrm{mg}, 0.18 \mathrm{mmol})$ in $\mathrm{CHCl}_{3}(7 \mathrm{~mL})$ was added $\mathrm{mCPBA}$ (117 $\mathrm{mg}, 0.55 \mathrm{mmol}$ ), and the mixture was stirred at room temperature. Aliquots of mCPBA (in total $2.1 \mathrm{~g}, 5.6 \mathrm{mmol}$ ) were added during $3 \mathrm{~h}$ until the consumption of the starting material was complete. The mixture was diluted in $\mathrm{CH}_{2} \mathrm{Cl}_{2}(10 \mathrm{~mL})$ and washed with aq. $\mathrm{Na}_{2} \mathrm{SO}_{3}(10 \%, 3$ x 10 $\mathrm{mL}$ ), aq. $\mathrm{NaHCO}_{3}$ (sat. 2 x $\left.10 \mathrm{~mL}\right), \mathrm{H}_{2} \mathrm{O}(10 \mathrm{~mL})$, dried over $\mathrm{Na}_{2} \mathrm{SO}_{4}$ and concentrated under vacuum. The crude product was purified by filtration over silica $\left(\mathrm{CH}_{2} \mathrm{Cl}_{2}\right)$ to afford 7 as a yellow solid (55 mg, 77\%). $R_{\mathrm{f}}\left(\mathrm{CH}_{2} \mathrm{Cl}_{2}\right)$ : 0.8; Mp: 186-187 ${ }^{\circ} \mathrm{C}$; IR (neat): 2953 (m), 2871 (m), 2207 (s), $1737(\mathrm{w}), 1500$ (w), 1464 (m), 1384 (s), 1334 (m), 1231 (w), 1180 (m), 1166 (m), 1107 (m), 1039 (w), 942 (w), 922 (w), 897 (w), 795 (w), 723 (w), 640 (w), 572 (w); ${ }^{1} \mathrm{H}$ NMR (400 MHz, CDCl $)$ : $2.81\left(\mathrm{~d},{ }^{3} J=7.1 \mathrm{~Hz}, 4 \mathrm{H}\right), 2.26\left(\right.$ non, $\left.{ }^{3} J=7.1 \mathrm{~Hz}, 2 \mathrm{H}\right), 1.03\left(\mathrm{~d},{ }^{3} J=7.1 \mathrm{~Hz}, 12 \mathrm{H}\right) ;{ }^{13} \mathrm{C}$ NMR $(101$ $\left.\mathrm{MHz}, \mathrm{CDCl}_{3}\right)$ : $148.8(\mathrm{C}), 144.0(\mathrm{C}), 137.9(\mathrm{C}), 112.3(\mathrm{C}), 111.7(\mathrm{C}), 37.5\left(\mathrm{CH}_{2}\right), 29.9(\mathrm{CH}), 22.4$ 
$\left(\mathrm{CH}_{3}\right) ; \mathrm{MS}(\mathrm{ESI}, \mathrm{CHCl} / \mathrm{MeOH} 1: 1+0.5 \% \mathrm{HCOOH}): 408\left(100,\left[\mathrm{M}+\mathrm{NH}_{4}{ }^{+}\right]^{+}\right) ; \mathrm{HRMS}(\mathrm{ESI},+\mathrm{ve})$ calcd for $\mathrm{C}_{17} \mathrm{H}_{19} \mathrm{NO}_{2} \mathrm{~S}_{3}: 391.0603$, found: 391.0603 .

Compound 22. Was synthesized according to the procedure reported in ref. S7.

Compound 23. To a solution of $22(210 \mathrm{mg}, 0.94 \mathrm{mmol})$ in dry THF $(10 \mathrm{~mL})$ at $-78{ }^{\circ} \mathrm{C}$ under Ar atmosphere, LDA (1.4 mL, $2 \mathrm{M}$, in THF/heptane/ethylbenzene, $2.8 \mathrm{mmol})$ was added dropwise. After stirring for $45 \mathrm{~min}$, diethyl disulfide (284 $\mathrm{mg}, 2.32 \mathrm{mmol}$ ) was added and the reaction mixture was allowed to warm to $\mathrm{rt}$ and stirred overnight. The mixture was diluted with EtOAc $(50 \mathrm{~mL})$ and washed with water $(30 \mathrm{~mL})$, brine $(30 \mathrm{~mL})$, dried over $\mathrm{Na}_{2} \mathrm{SO}_{4}$ and concentrated under reduced pressure. The crude product was purified by flash column chromatography (PE) to afford 23 as a colorless solid $(173 \mathrm{mg}, 54 \%) . R_{\mathrm{f}}(\mathrm{PE}): 0.4 ; \mathrm{Mp}: 79-80{ }^{\circ} \mathrm{C}$; IR (neat): 2957 (w), 2917 (m), 1419 (w), 1374 (s), 1301 (s), 1253 (m), 1137 (s), 1108 (s), 1035 (s), 965 (m), 928 (m), 788 (w), $762(\mathrm{~m}), 722$ (s), 643 (s); ${ }^{1} \mathrm{H}$ NMR (400 MHz, $\left.\mathrm{CDCl}_{3}\right): 2.80$ (q, ${ }^{3} J=7.3$ $\mathrm{Hz}, 4 \mathrm{H}), 2.43$ (s, 6H), $1.27\left(\mathrm{t},{ }^{3} \mathrm{~J}=7.3 \mathrm{~Hz}, 6 \mathrm{H}\right) ;{ }^{13} \mathrm{C} \mathrm{NMR}\left(126 \mathrm{MHz}, \mathrm{CDCl}_{3}\right): 141.5$ (C), 136.5 (C), $131.2(\mathrm{C}), 129.5(\mathrm{C}), 33.2\left(\mathrm{CH}_{2}\right), 15.0\left(\mathrm{CH}_{3}\right), 13.9\left(\mathrm{CH}_{3}\right)$; $\mathrm{MS}\left(\mathrm{ESI}, \mathrm{CH}_{2} \mathrm{Cl}_{2} / \mathrm{MeOH}\right.$ 9:1): 344 (10, $\left.[\mathrm{M}+\mathrm{H}]^{+}\right), 315\left(100,[\mathrm{M}-\mathrm{Et}]^{+}\right), 287\left(10,[\mathrm{M}-\mathrm{EtS}]^{+}\right)$.

Compound 10. To a solution of $23(116 \mathrm{mg}, 0.34 \mathrm{mmol})$ in $\mathrm{CHCl}_{3}(10 \mathrm{~mL}), \mathrm{mCPBA}(755$ $\mathrm{mg}, 3.37 \mathrm{mmol}$ ) was added in several portions, and the mixture was stirred overnight at rt. The reaction was diluted by $\mathrm{CH}_{2} \mathrm{Cl}_{2}(30 \mathrm{~mL})$ and washed with aq. $\mathrm{NaHCO}_{3}$ (sat. 3 x $30 \mathrm{~mL}$ ), and the aqueous layers were extracted with $\mathrm{CH}_{2} \mathrm{Cl}_{2}(3 \times 30 \mathrm{~mL})$. The combined organic phase was washed with $\mathrm{H}_{2} \mathrm{O}(20 \mathrm{~mL})$, brine $(20 \mathrm{~mL})$, dried over $\mathrm{Na}_{2} \mathrm{SO}_{4}$, and concentrated in vacuo. The crude product was purified by flash column chromatography $\left(\mathrm{CH}_{2} \mathrm{Cl}_{2}\right)$ to afford $\mathbf{1 0}$ as a colorless solid (61 mg, 42\%). $R_{\mathrm{f}}\left(\mathrm{CH}_{2} \mathrm{Cl}_{2}\right): 0.2 ; \mathrm{Mp}: \operatorname{dec}>269{ }^{\circ} \mathrm{C}$; IR (neat): 2983 (w), $2941(\mathrm{w}), 151(\mathrm{w}), 1375(\mathrm{w}), 1304$ (s), 1136 (s), 1115 (s), 1043 (m), 997 (m), 929 (m), 786 (m), 719 (s), 646 (s); ${ }^{1} \mathrm{H}$ NMR (500 MHz, 
$\left.\mathrm{CDCl}_{3}\right): 3.28\left(\mathrm{q},{ }^{3} J=7.4 \mathrm{~Hz}, 4 \mathrm{H}\right), 2.69(\mathrm{~s}, 6 \mathrm{H}), 1.42\left(\mathrm{t},{ }^{3} J=7.4 \mathrm{~Hz}, 6 \mathrm{H}\right) ;{ }^{13} \mathrm{C}$ NMR $(126 \mathrm{MHz}$, $\left.\mathrm{CDCl}_{3}\right): 144.5(\mathrm{C}), 140.0(\mathrm{C}), 138.8(\mathrm{C}), 137.7(\mathrm{C}), 52.1\left(\mathrm{CH}_{2}\right), 12.4\left(\mathrm{CH}_{3}\right), 7.74\left(\mathrm{CH}_{3}\right)$; HRMS (ESI, +ve) calcd for $\mathrm{C}_{17} \mathrm{H}_{19} \mathrm{NO}_{2} \mathrm{~S}_{3}: 440.9623$, found: 440.9622 . 


\section{Anion Binding}

Fluorescence emission and absorption spectra were recorded of the transporters $\mathbf{5}(12.5 \mu \mathrm{M}$, $\left.\lambda_{\mathrm{ex}}=361 \mathrm{~nm}\right), \mathbf{6}\left(50 \mu \mathrm{M}, \lambda_{\mathrm{ex}}=366 \mathrm{~nm}\right), 7\left(25 \mu \mathrm{M}, \lambda_{\mathrm{ex}}=375 \mathrm{~nm}\right), \mathbf{8}\left(30 \mu \mathrm{M}, \lambda_{\mathrm{ex}}=386 \mathrm{~nm}\right), 9(33$ $\left.\mu \mathrm{M}, \lambda_{\mathrm{ex}}=364 \mathrm{~nm}\right)$ and $\mathbf{1 0}\left(20 \mu \mathrm{M}, \lambda_{\mathrm{ex}}=361 \mathrm{~nm}\right)$ in THF in the presence of TBACl $(0-20 \mathrm{mM})$, $\mathrm{TBANO}_{3}(0-20 \mathrm{mM})$ or $\mathrm{TBAPF}_{6}(0-20 \mathrm{mM})$. Differences in emission intensities at $\lambda_{\max }, \Delta I$ were plotted versus acceptor concentration and curve-fitted to a 1:1 binding isotherm in order to determine dissociation constants $\left(K_{\mathrm{D}}{ }^{\prime} \mathrm{s}\right)^{\mathrm{S} 8}$ according to eq $\mathrm{S} 1$ :

$$
\begin{gathered}
\Delta I=\left(\Delta I_{\max } /[\mathrm{T}]_{0}\right) \times\left(0.5 \times[\mathrm{A}]+0.5 \times\left([\mathrm{T}]_{0}+K_{\mathrm{D}}\right)-\left(0.5 \times\left(\left([\mathrm{A}]^{2}\right)+\right.\right.\right. \\
\left.\left.\left.\left(2 \times([\mathrm{A}]) \times\left(K_{\mathrm{D}}-[\mathrm{T}]_{0}\right)\right)+\left(K_{\mathrm{D}}+[\mathrm{T}]_{0}\right)^{2}\right)^{0.5}\right)\right)
\end{gathered}
$$

where $\Delta I=\left|I-I_{0}\right|,[\mathrm{A}]=$ concentration of $\mathrm{TBACl}$ or $\mathrm{TBANO}_{3}$, and $[\mathrm{T}]_{0}=$ concentration of transporter $6,7,8,9$ and 10 . The stoichiometry of chloride complex was determined for transporter $7\left([7]+[\mathrm{TBACl}]=2 \mathrm{mM}, \lambda_{\mathrm{ex}}=433 \mathrm{~nm}\right)$, using the continuous variation method $($ Job Plot $),{ }^{\mathrm{S} 9}$ (Figure S3). 


\subsection{TBACl}

Transporters 5, 6, 7, 8, 9 and 10 were titrated with $\mathrm{TBACl}$ in $\mathrm{THF}$ solution and the changes in absorbance and fluorescence were monitored.
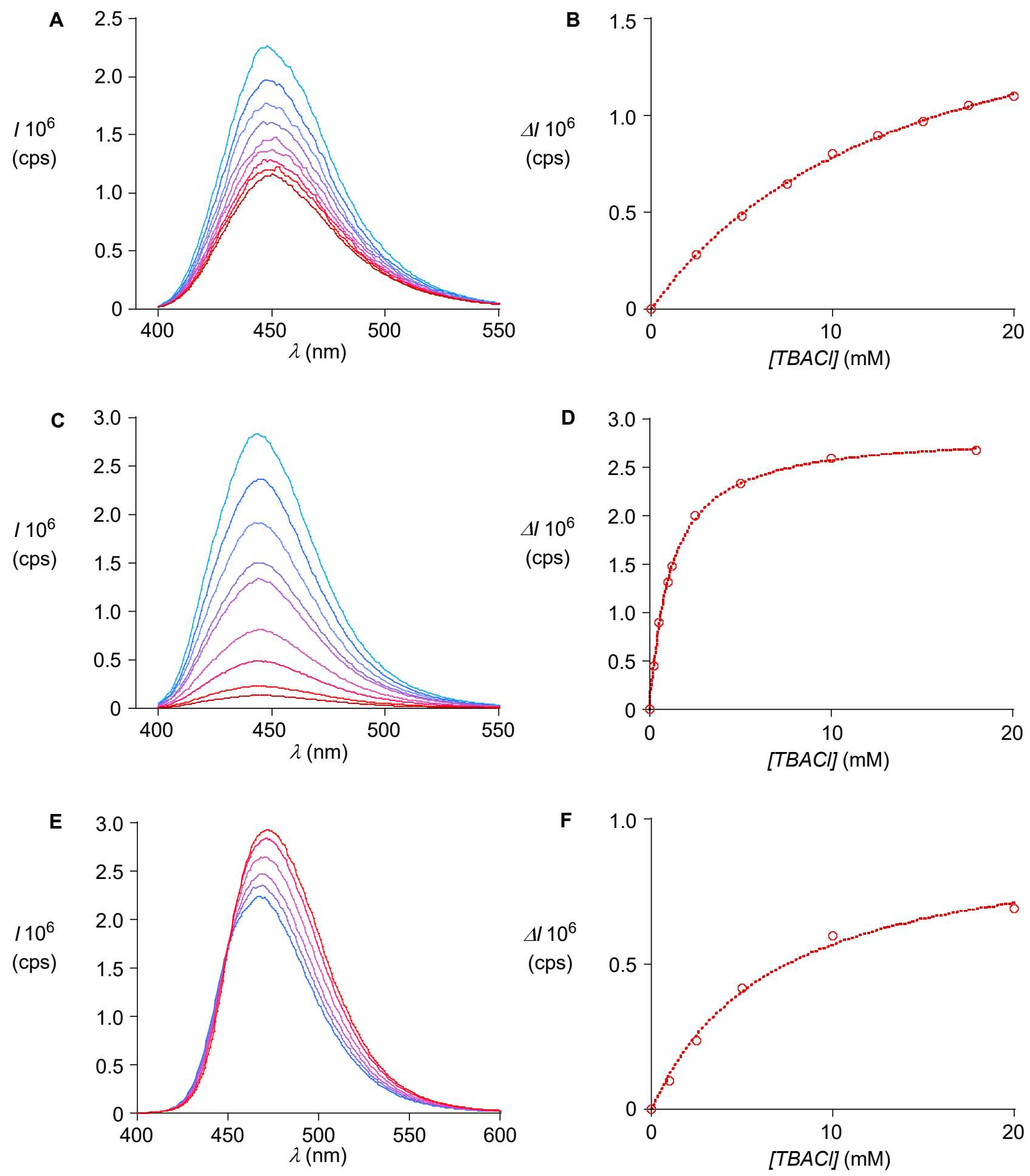

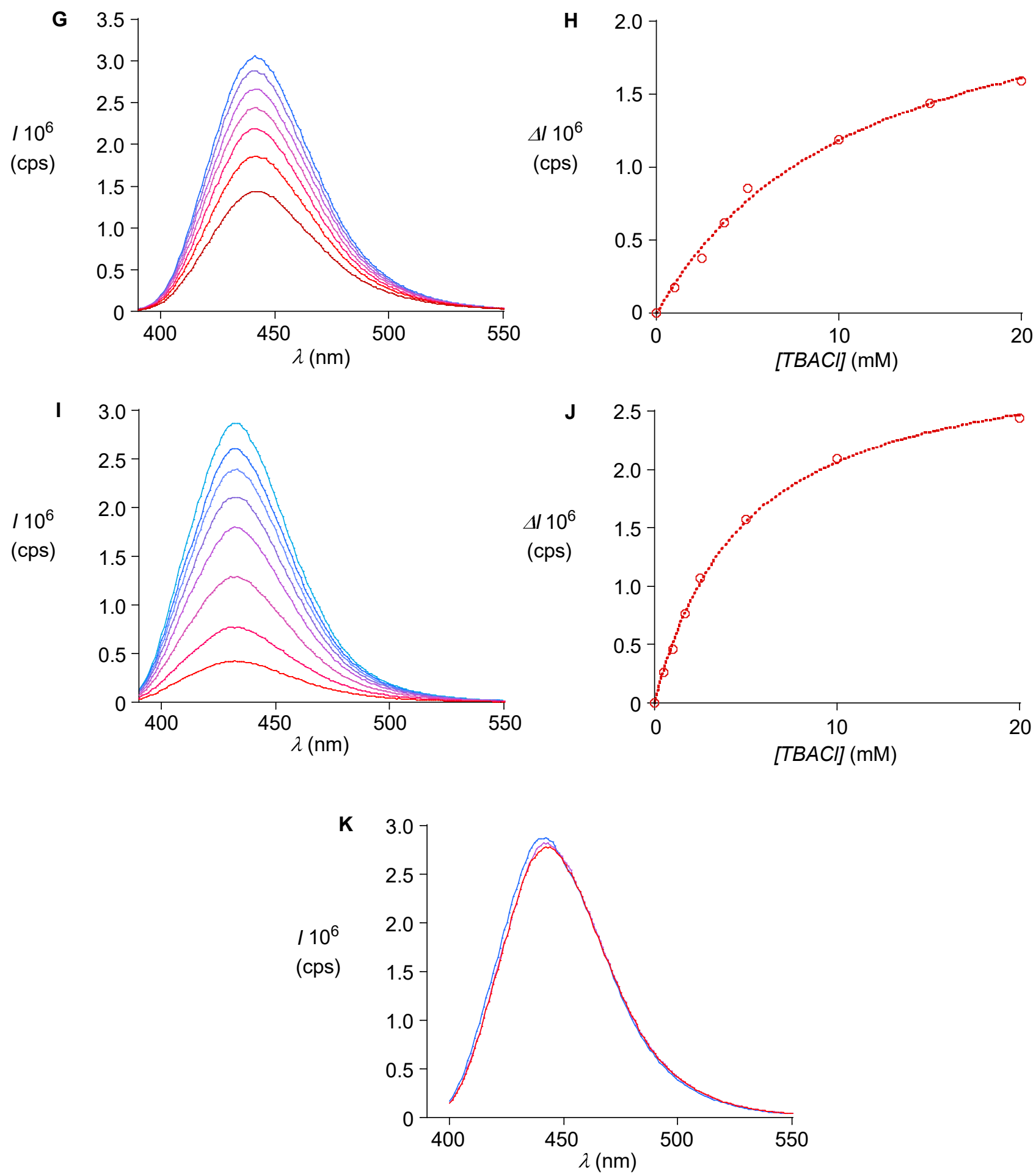

Figure S1. Changes in fluorescence emission of transporters $6(A), 7(C), 8(E), 9(G)$ and 10 (I) with increasing concentration of $\mathrm{TBACl}$ (cyan to red). Nonlinear fitting according to eq S1, of changes in fluorescence taken at $\lambda_{\max }$ versus TBACl concentration, for transporters 6 (B), 7 (D), 8 $(\mathrm{F}), 9(\mathrm{H})$ and $10(\mathrm{~J})$. No significant changes were observed for transporter $\mathbf{5}(\mathrm{K})$ upon the addition of TBACl. 

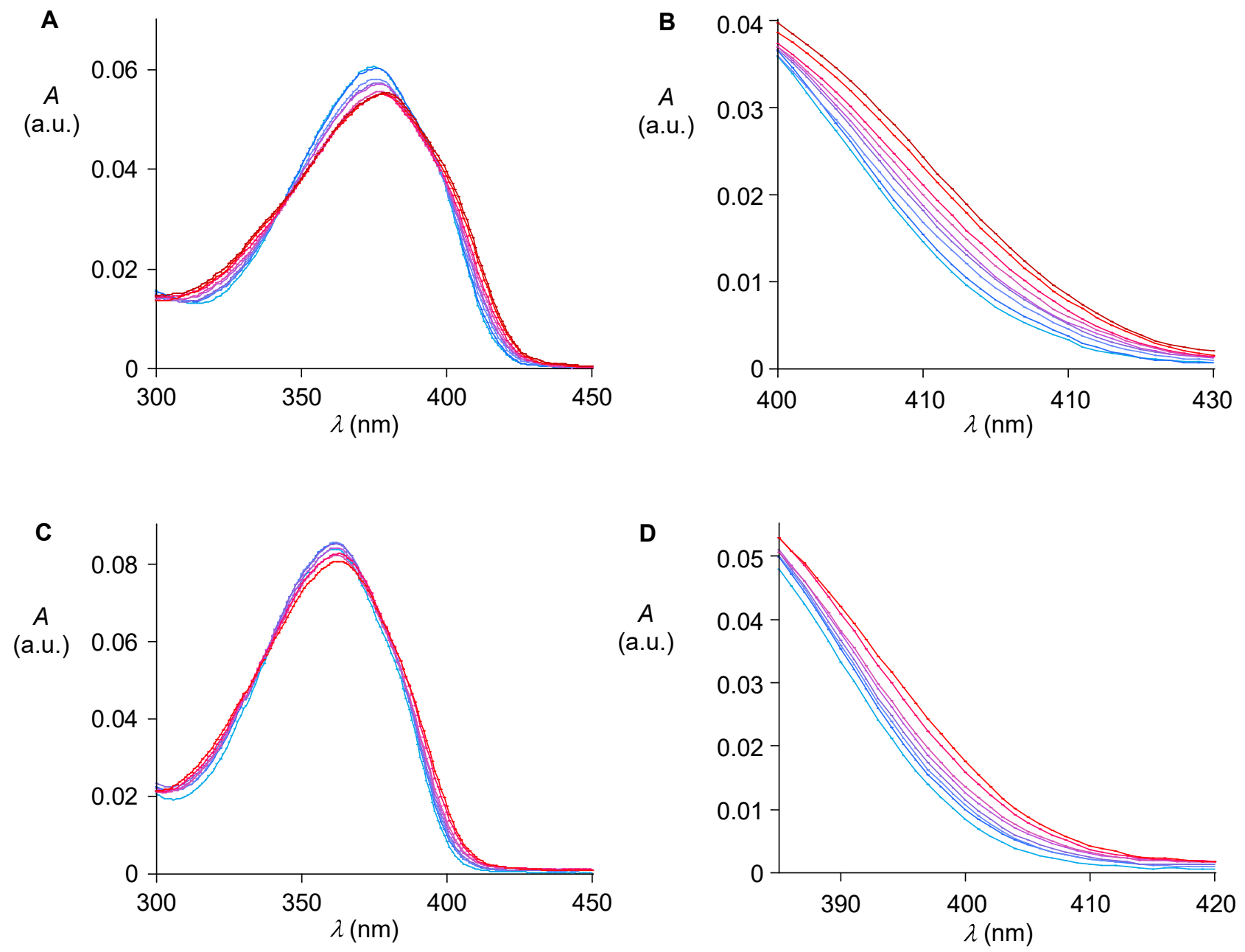

Figure S2. Absorption spectra of transporters $\mathbf{7}(\mathrm{A})$ and $\mathbf{1 0}(\mathrm{C})$ upon titration with $\mathrm{TBACl}$ (cyan to red), zoom of redshifted shoulder for $\mathbf{7}$ (B) and $\mathbf{1 0}$ (D). No significant changes in the absorption spectra with TBACl concentrations from 0 to $20 \mathrm{mM}$ were observed for transporters $\mathbf{5 , 6 , 8}$ and 9 . 
For the most strongly binding transporter 7, the binding stoichiometry was determined using Jobs method. ${ }^{\mathrm{S} 9}$ Maximum differences observed at $x=0.5$ suggested formation of a 1:1 complex.

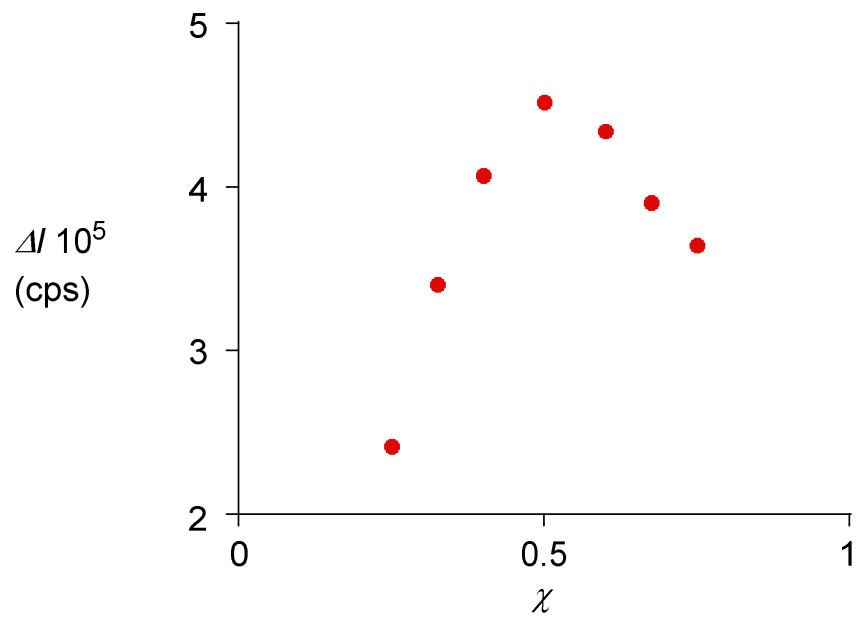

Figure S3. Job plot for $\mathrm{TBACl}$ binding by $\mathbf{7}$, showing fluorescence intensity differences as a function of the mole fraction $(x=[7] /([\mathrm{TBACl}]+[7])$. 


\section{2. $\mathrm{TBANO}_{3}$}

Transporters 6, 7, 9 and 10 were titrated with $\mathrm{TBANO}_{3}$ in $\mathrm{THF}$ solution and the changes in fluorescence were monitored. For all of the transporters no significant changes were observed in the absorption spectra upon the titration with $\mathrm{TBANO}_{3}$.
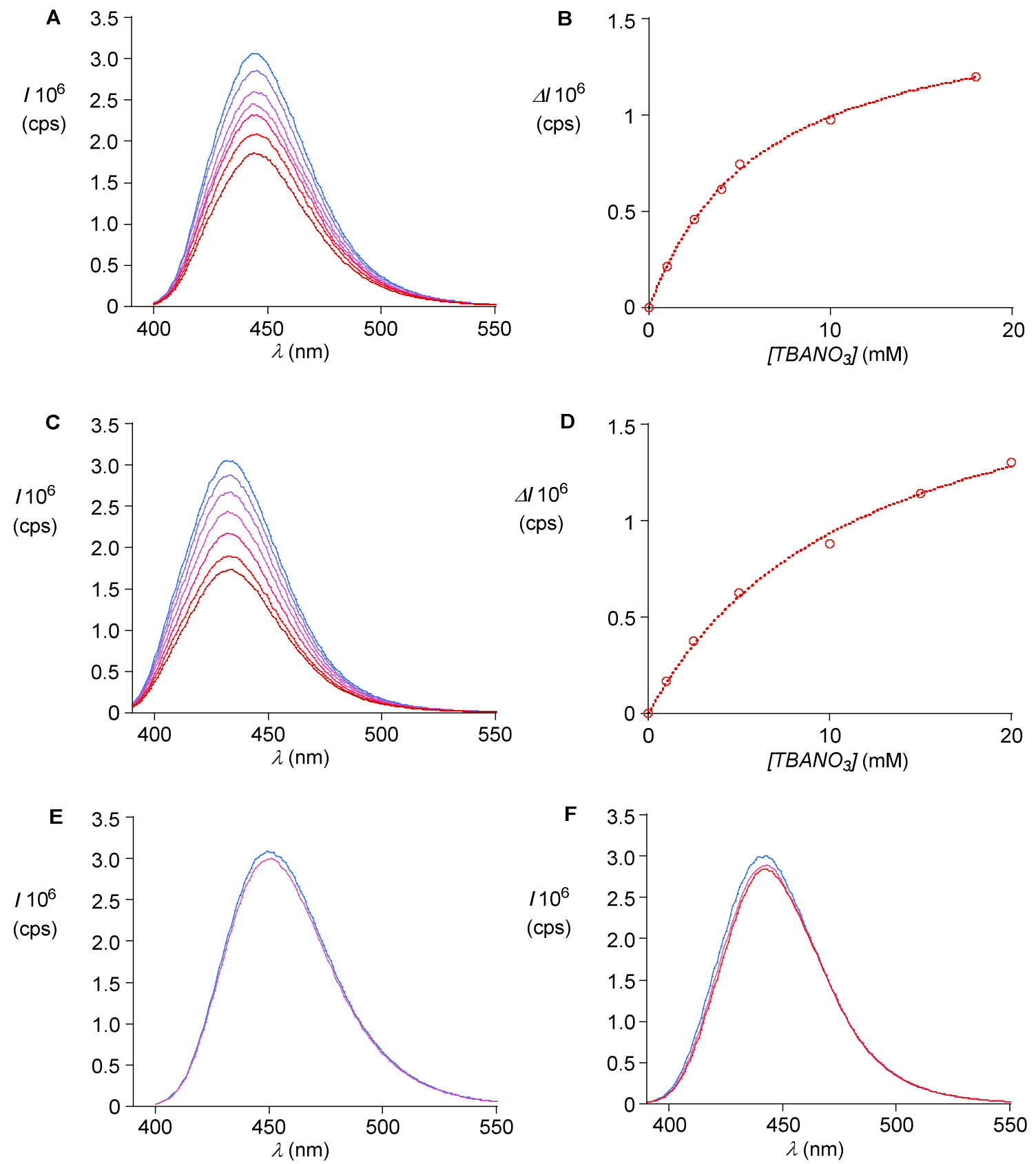

Figure S4. Decrease in fluorescence upon titration with $\mathrm{TBANO}_{3}$ for transporters $\mathbf{7}(\mathrm{A})$ and $\mathbf{1 0}(\mathrm{C})$, nonlinear fitting according to eq $\mathrm{S} 1$, of changes in fluorescence taken at $\lambda_{\max }$ versus $\mathrm{TBANO}_{3}$ concentration for 7 (B) and $\mathbf{1 0}$ (D). No significant changes were observed for transporter $\mathbf{6}(\mathrm{E})$ and 9 (F) upon the addition of $\mathrm{TBANO}_{3}$. 


\subsection{TBAPF 6}

The two strongest chloride binders $\mathbf{7}$ and $\mathbf{1 0}$ were titrated with the bulky anion $\mathrm{PF}_{6}{ }^{-}$.
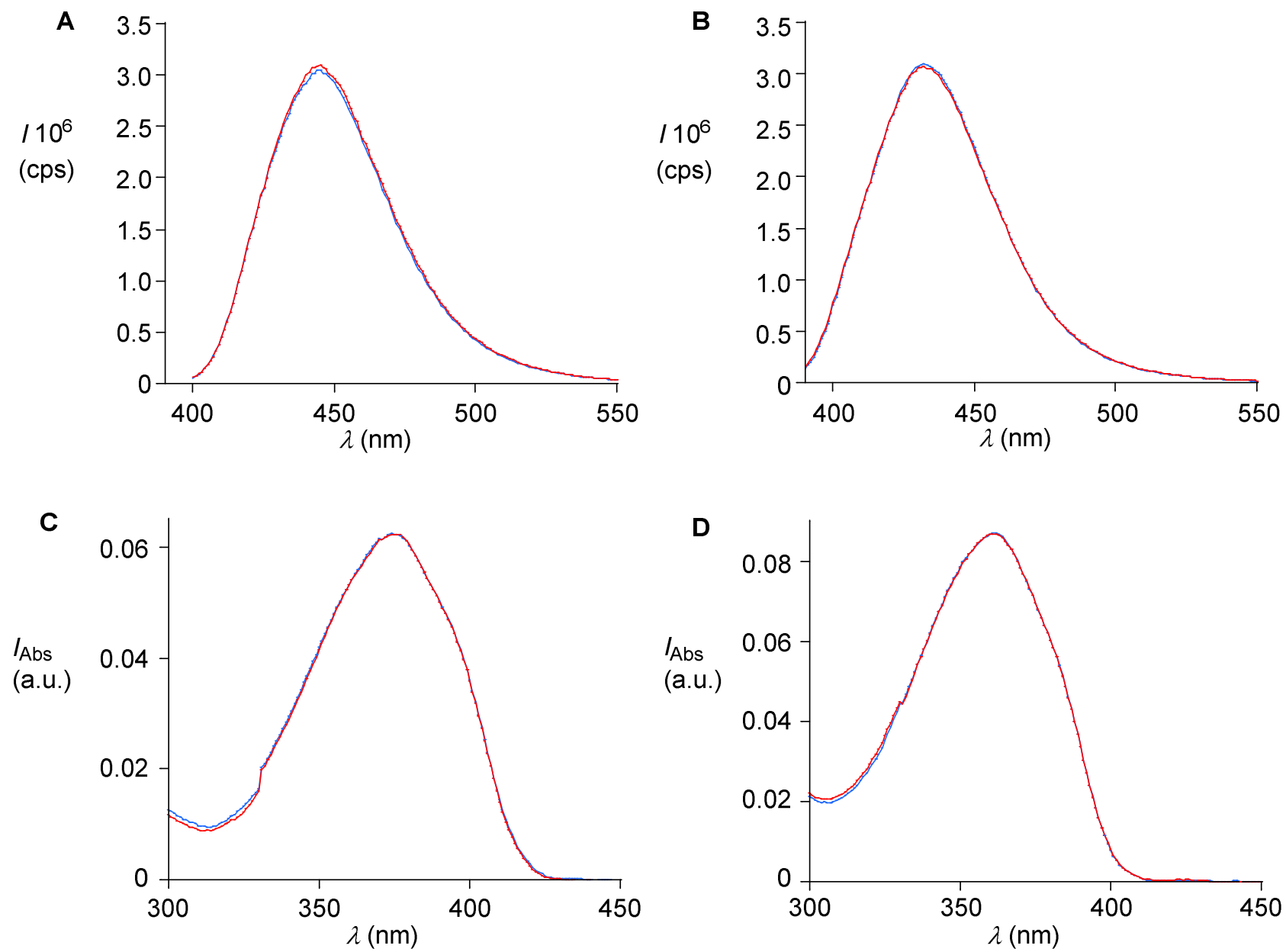

Figure S5. Overlay of the fluorescence spectra with (red) or without (cyan) $20 \mathrm{mM}$ of TBAPF 6 in THF for transporters 7 (A) and 10 (B). No significant changes in fluorescence were observed. Likewise no significant changes in absorption were observed for transporters $\mathbf{7}(\mathrm{C})$ and $\mathbf{1 0}$ (D). 


\section{Anion Transport}

\subsection{Vesicle Preparation}

EYPC-LUVs $\supset$ HPTS. ${ }^{33}$ A thin lipid film was prepared by evaporating a solution of $25 \mathrm{mg}$ EYPC in $2 \mathrm{~mL} \mathrm{MeOH} / \mathrm{CHCl}_{3}(1: 1)$ on a rotary evaporator $\left(40{ }^{\circ} \mathrm{C}\right)$ and then in vacuo overnight. After hydration (> $30 \mathrm{~min}$ ) with $1.0 \mathrm{~mL}$ buffer (10 mM HEPES, $100 \mathrm{mM} \mathrm{NaCl}, 1 \mathrm{mM}$ HPTS, pH 7.0), the resulting suspension was subjected to $>5$ freeze-thaw cycles (liquid $\mathrm{N}_{2}, 37^{\circ} \mathrm{C}$ water bath), and $>15$ times extruded through a polycarbonate membrane (pore size $100 \mathrm{~nm}$ ). Extravesicular components were removed by size exclusion chromatography (Sephadex G-50, Sigma-Aldrich) with $10 \mathrm{mM}$ HEPES, $100 \mathrm{mM} \mathrm{NaCl}$, pH 7.0. Final conditions: $\sim 5 \mathrm{mM}$ EYPC; inside: $10 \mathrm{mM}$ HEPES, 100 mM NaCl, 1 mM HPTS, pH 7.0; outside: 10 mM HEPES, 100 mM NaCl, pH 7.0.

EYPC-LUVs $\supset \mathbf{C F}{ }^{\text {S3 }}$ A thin lipid film was prepared by evaporating a solution of $25 \mathrm{mg}$ EYPC in $2 \mathrm{~mL} \mathrm{MeOH} / \mathrm{CHCl}_{3}(1: 1)$ on a rotary evaporator $\left(40{ }^{\circ} \mathrm{C}\right)$ and then in vacuo overnight. After hydration (> $30 \mathrm{~min}$ ) with $1.0 \mathrm{~mL}$ buffer (10 mM HEPES, $10 \mathrm{mM} \mathrm{NaCl}, 50 \mathrm{mM} \mathrm{CF}, \mathrm{pH} 7.4)$, the resulting suspension was subjected to $>5$ freeze-thaw cycles (liquid $\mathrm{N}_{2}, 37{ }^{\circ} \mathrm{C}$ water bath), and $>15$ times extruded through a polycarbonate membrane (pore size $100 \mathrm{~nm}$ ). Extravesicular components were removed by size exclusion chromatography (Sephadex G-50, Sigma-Aldrich) with $10 \mathrm{mM}$ HEPES, $107 \mathrm{mM} \mathrm{NaCl}, \mathrm{pH}$ 7.4. Final conditions: $~ 5 \mathrm{mM} \mathrm{EYPC}$; inside: $10 \mathrm{mM}$ HEPES, 10 mM NaCl, 50 mM CF, pH 7.0; outside: 10 mM HEPES, 107 NaCl, pH 7.4. 


\subsection{Transport Activity}

Following published procedures, ${ }^{\mathrm{S} 3}$ to a gently stirred, thermostated buffer $\left(1950 \mu \mathrm{L}, 25^{\circ} \mathrm{C}\right.$, $10 \mathrm{mM}$ Hepes, $100 \mathrm{mM} \mathrm{NaCl}, \mathrm{pH}$ 7.0) in a disposable plastic cuvette, $50 \mu \mathrm{L}$ EYPC-LUVs $\mathrm{HPTS}$ were added. The time-dependent change in fluorescence intensity $\left(\lambda_{\mathrm{em}}=510 \mathrm{~nm}\right)$ was monitored at two excitation wavelengths simultaneously $\left(I_{\mathrm{t}}, 450: \lambda_{\mathrm{exc}}=450 \mathrm{~nm}, I_{\mathrm{t}}, 400: \lambda_{\mathrm{exc}}=400 \mathrm{~nm}\right)$, during the addition of base $(20 \mu \mathrm{L}, 0.5 \mathrm{M} \mathrm{NaOH})$ at $t=1 \mathrm{~min}$, transporter $(20 \mu \mathrm{L}$, THF solution $)$ at $t=2 \min$, and gramicidin D $(20 \mu \mathrm{L}, 100 \mu \mathrm{M}$ in DMSO $)$ at $t=7 \mathrm{~min}$. Time courses of fluorescence intensity $I_{\mathrm{t}}$ were obtained first by ratiometric analysis $\left(R=I_{\mathrm{t}}, 450 / I_{\mathrm{t}}, 400\right)$. For transporters 3-7 and 9 which absorb/emit at $I_{\mathrm{t}}, 400$, the signal $R=I_{\mathrm{t}}, 450$ was used without ratiometric analysis. Second, normalization according to eq $\mathrm{S} 2$,

$$
I_{\mathrm{f}}=\left(R_{\mathrm{t}}-R_{0}\right) /\left(R_{\infty}-R_{0}\right)
$$

where $R_{0}=R_{\mathrm{t}}$ at $t=1.5$ min, before addition of transporter and $R_{\infty}=R_{\mathrm{t}}$ at $t=8$ min after addition of gramicidin D. $I_{\mathrm{f}}$ at 6.5 min just before addition of gramicidin D was defined as transmembrane activity $Y$, and analyzed with the Hill equation to give effective concentration $E C_{50}$ and the Hill coefficient $n$,

$$
Y=Y_{\infty}+\left(Y_{0}-Y_{\infty}\right) /\left(1+c / E C_{50}\right)^{n}
$$

where $Y_{0}$ is $Y$ in absence of transporter, $Y_{\infty}$ is $Y$ with excess transporter, and $c$ is the transporter concentration in a cuvette. Complete results for all compounds are shown in Table S1. 

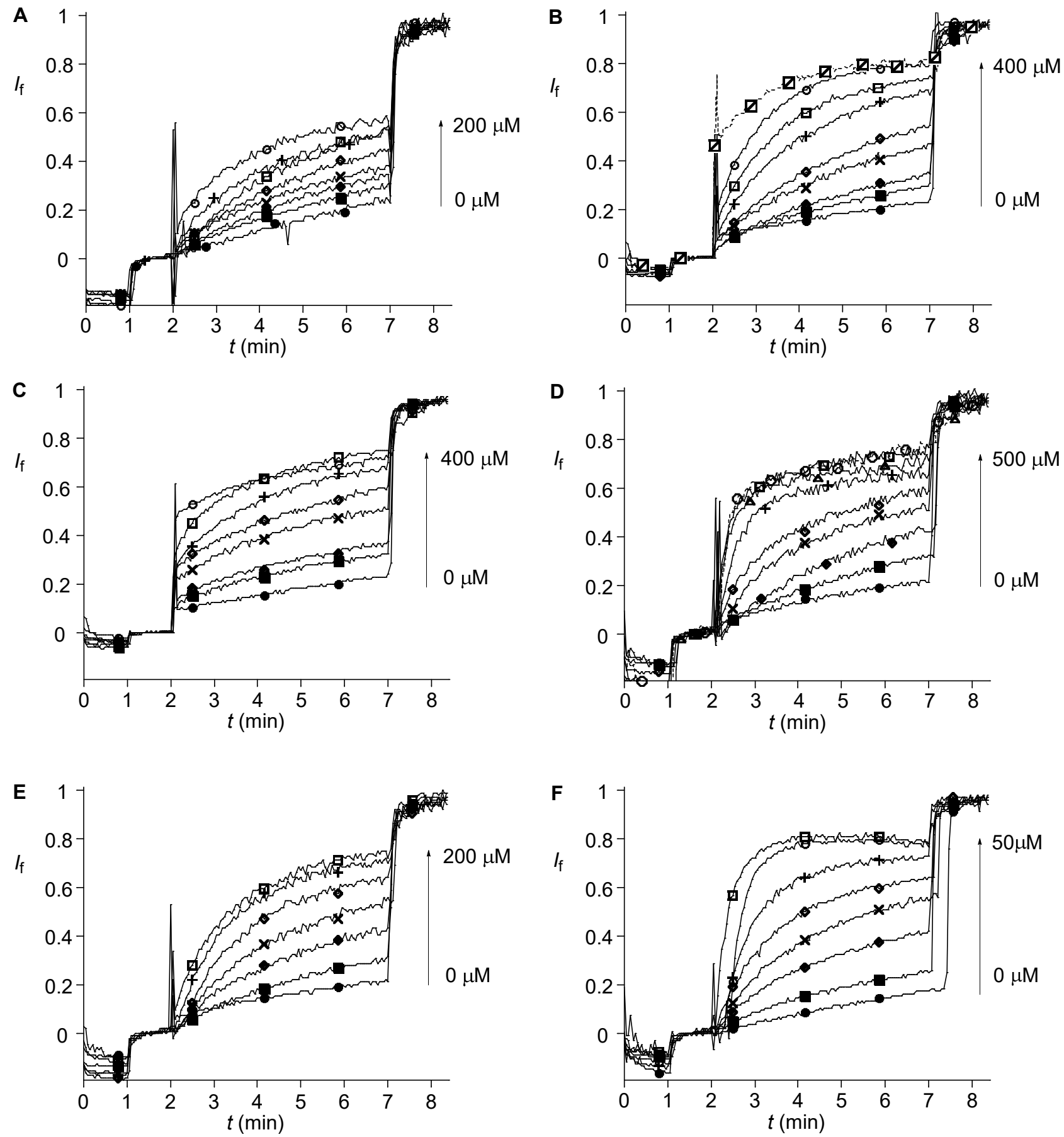

Figure S6. Fluorescence traces for compounds 1 (A), 3 (B), 4 (C), 5 (D), 6 (E) and 7 (F) in the HPTS assay. Fractional emission $I_{\mathrm{F}}$ during the addition of $\mathrm{NaOH}(20 \mu \mathrm{l}$ of $0.5 \mathrm{M}, 1 \mathrm{~min}), 1$ (A), 3 (B), 4 (C), 5 (D), 6 (E) and 7 (F) (with increasing concentration as shown, 2 min) and gramicidin D (20 $\mu \mathrm{l}$ of $100 \mu \mathrm{M}, 7 \mathrm{~min})$ to EYPC-LUVs $\supset$ HPTS in a NaCl buffer (100 mM NaCl, $10 \mathrm{mM}$ HEPES buffer, $\mathrm{pH}$ 7). 


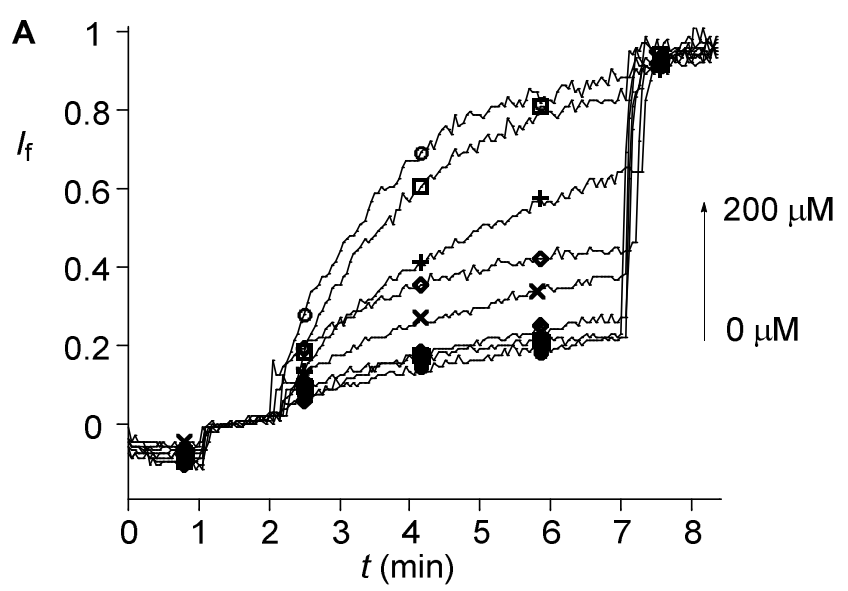

Figure S7. Fluorescence trace for compound 9 (I) in the HPTS assay as in Figure S6 above. 

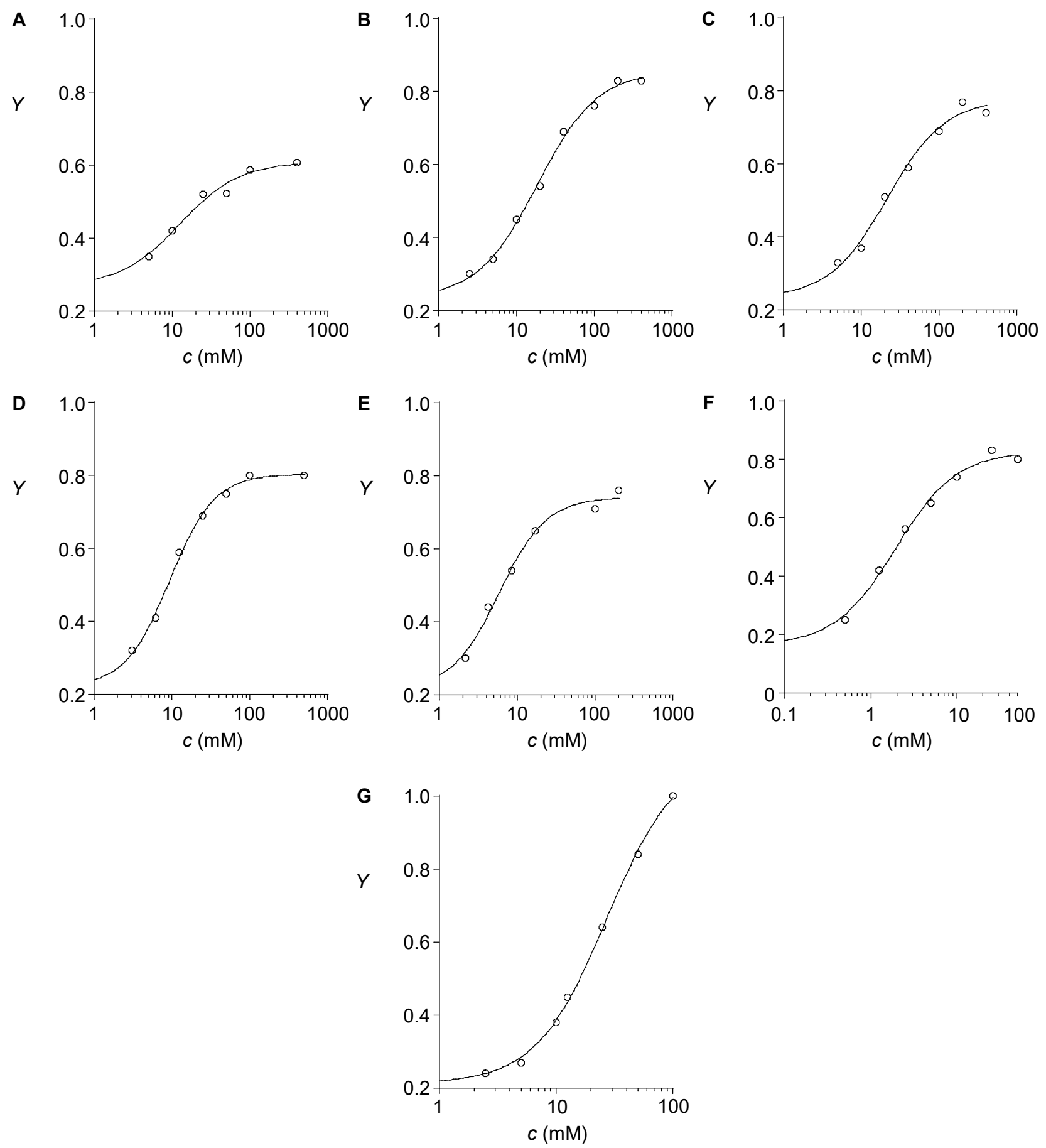

Figure S8. Dose response curves for compounds 1 (A), 3 (B), 4 (C), 5 (D), 6 (E), 7 (F) and 9 (G) in the HPTS assay. 

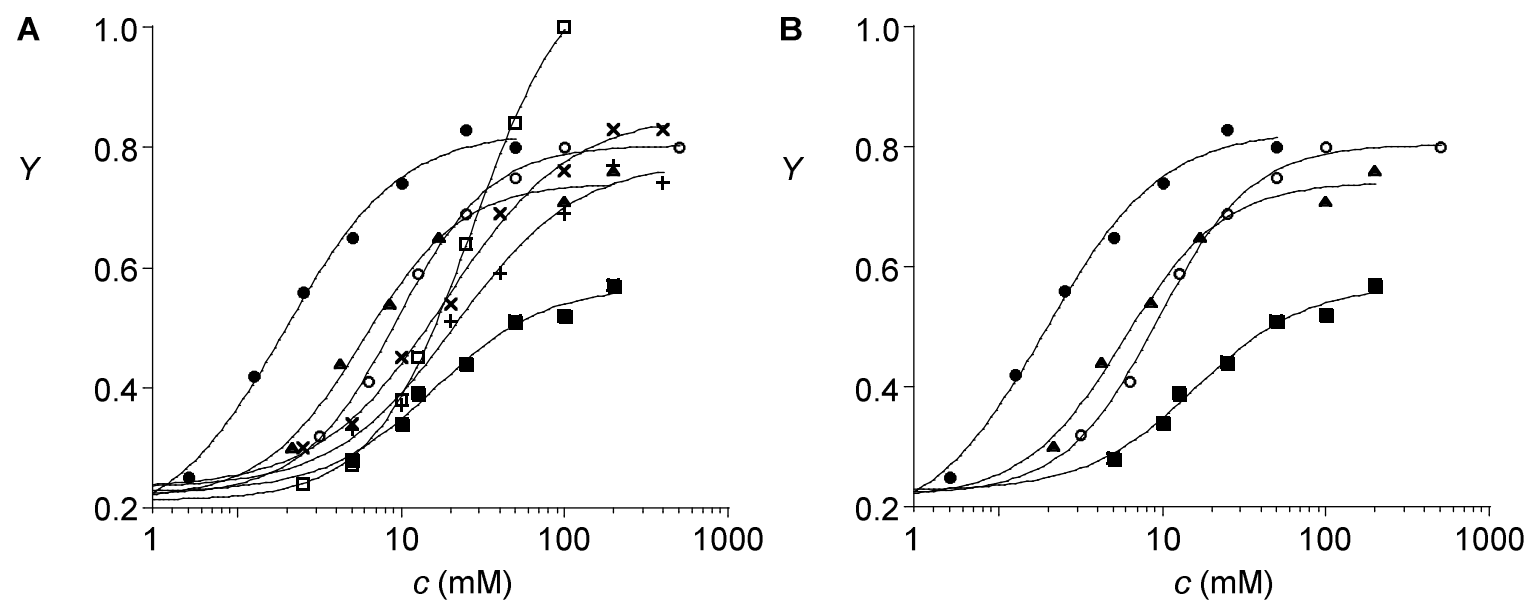

Figure S9. (A) Combined dose response curves for transporters $1(\mathbf{1}), \mathbf{3}(\mathrm{x}), \mathbf{4}(+), \mathbf{5}(\mathrm{\circ}), \mathbf{6}(\mathbf{\Delta}), \mathbf{7}$ $(\bullet)$ and 9 ( $\square$ ) in the HPTS assay. (B) Selected dose response curves for transporters with increasing chloride binding ability $\mathbf{1}<\mathbf{5}<\mathbf{6}<\mathbf{7}$, labels as in (A). 


\subsection{Ion Selectivity}

EYPC-LUVs $\supset$ HPTS $(50 \mu \mathrm{L})$ prepared as described above were added to $1950 \mu \mathrm{L}$ gently stirred, thermostated $\left(25^{\circ} \mathrm{C}\right)$ buffer $\left(10 \mathrm{mM}\right.$ HEPES, $100 \mathrm{mM} \mathrm{M} \mathrm{Cl}^{-}\left(\mathrm{M}^{+}=\mathrm{Li}^{+}, \mathrm{Na}^{+}, \mathrm{K}^{+}, \mathrm{Me}_{4} \mathrm{~N}^{+}\right.$, $\left.\mathrm{Rb}^{+}, \mathrm{Cs}^{+}\right)$or $100 \mathrm{mM} \mathrm{Na}{ }^{+} \mathrm{X}^{-}\left(\mathrm{X}^{-}=\mathrm{F}^{-}, \mathrm{AcO}^{-}, \mathrm{Cl}^{-}, \mathrm{Br}^{-}, \mathrm{NO}_{3}^{-}, \mathrm{I}^{-}, \mathrm{ClO}_{4}^{-}\right), \mathrm{pH}$ 7.0) in a disposable plastic cuvette. The time-dependent change in fluorescence intensity was monitored and analyzed as described above to obtain the fractional transmembrane activity $Y$ dependent on the externally added cation or anion $\mathrm{M}^{+} \mathrm{X}^{-}$. Fractional activities were plotted as a function of the anion dehydration energies (Figure S10).
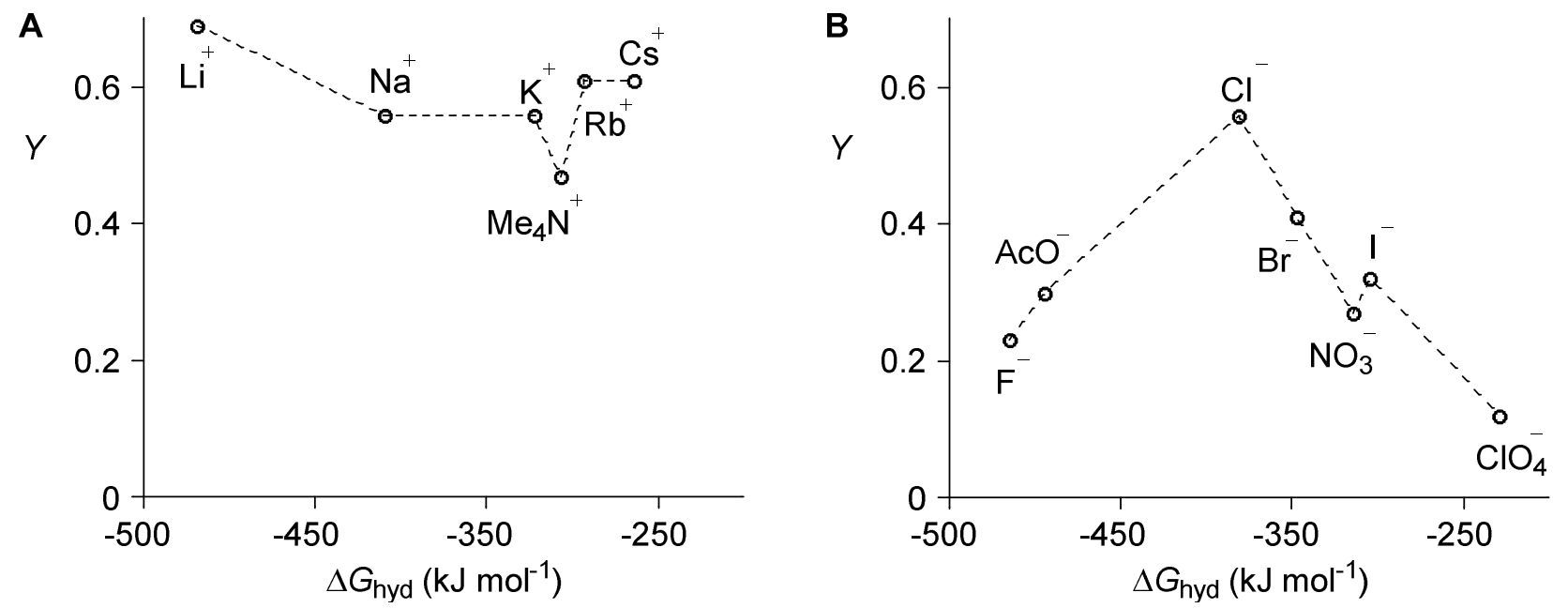

Figure S10. Dependence of fractional activity $Y$ on the extravesicular buffer composition for cations (A) and anions (B) for transporter $7(2.5 \mu \mathrm{M})$ in the HPTS assay. 


\subsection{Non-Specific Leakage}

To $1950 \mu \mathrm{L}$ gently stirred, thermostated buffer $\left(25^{\circ} \mathrm{C}, 10 \mathrm{mM}\right.$ HEPES, $107 \mathrm{mM} \mathrm{NaCl}, \mathrm{pH}$ 7.4) in a disposable plastic cuvette, $50 \mu \mathrm{L}$ EYPC-LUVs $\supset \mathrm{CF}$ were added. The time-dependent changes in fluorescence intensity $I_{\mathrm{t}}\left(\lambda_{\mathrm{ex}}=492 \mathrm{~nm}, \lambda_{\mathrm{em}}=517 \mathrm{~nm}\right)$ were monitored during the addition of the transporter at $t=100 \mathrm{~s}$, and the addition of triton $\mathrm{X}-100(40 \mu \mathrm{L} 1.2 \%$ aq $)$ at $t=400 \mathrm{~s}$. Time courses of $I_{\mathrm{t}}$ were normalized to fractional intensities $I_{\mathrm{f}}$ using eq $\mathrm{S} 4$,

$$
I_{\mathrm{f}}=\left(I_{\mathrm{t}}-I_{0}\right) /\left(I_{\infty}-I_{0}\right)
$$

where $I_{0}=I_{\mathrm{t}}$ right before the transporter addition and $I_{\infty}=I_{\mathrm{t}}$ after lysis (Figure S11). $I_{\mathrm{f}}$ at 6.5 min just before lysis was defined as transmembrane activity $Y$.

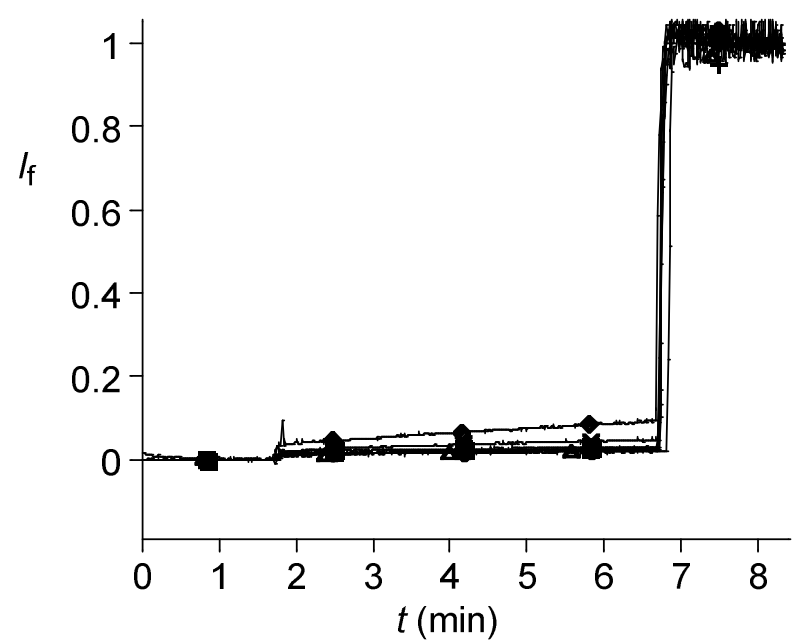

Figure S11. Non-specific leakage (CF assay) for compounds 1-7 and 9. Fluorescence emission during the addition of the transporter at $E C_{50}$ concentrations at $100 \mathrm{~s}$, and triton $\mathrm{X}-100(40 \mu \mathrm{L} 1.2 \%$, 400 s), to EYPC-LUVsつCF in buffer (107 mM NaCl, 10 mM HEPES, pH 7.4). 


\section{Electrochemistry}

The reduction potentials of $\mathbf{3}$ - $\mathbf{1 0}$ were determined using differential pulse voltammetry (DPV, scan rate $100 \mathrm{mV} / \mathrm{s}$ ) $\mathrm{vs}^{\mathrm{F}}{ }^{+} / \mathrm{Fc}$ in $\mathrm{CH}_{2} \mathrm{Cl}_{2}$ (supporting electrolyte: $100 \mathrm{mM} \mathrm{TBAPF}$, working electrode: Glassy carbon, counter electrode: Pt wire, reference electrode: SCE). No reduction was visible for 2 within the solvent limit of $\mathrm{CH}_{2} \mathrm{Cl}_{2}$. LUMO energies vs vacuum were calculated from first reduction peaks in DPV using eq S5.

$$
E_{\mathrm{LUMO}}=-5.1 \mathrm{eV}-E_{\mathrm{DPV}} \mathrm{Vs}\left(\mathrm{Fc}^{+} / \mathrm{Fc}\right)
$$

where $E_{\mathrm{DPV}}$ is the potential measured at the maximum intensity of the first reduction peak in the differential pulse voltammogram, relative to the internal standard ferrocene / ferrocenium. ${ }^{\text {S5 }}$

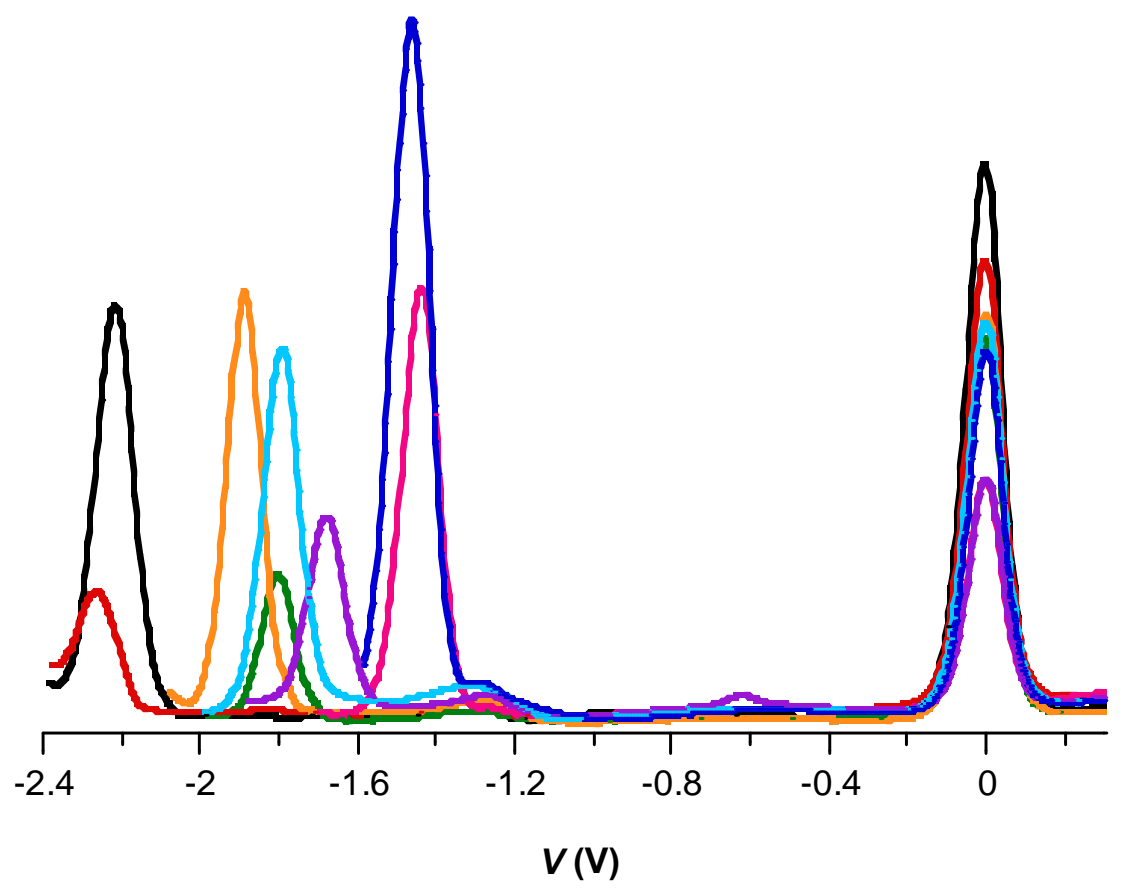

Figure S12. The differential pulse voltammograms relative to the internal $\mathrm{Fc}^{+} / \mathrm{Fc}$ standard, for transporters $\mathbf{3}$ (red), $\mathbf{4}$ (orange), $\mathbf{5}$ (black), $\mathbf{6}$ (green), $\mathbf{7}$ (pink), $\mathbf{8}$ (purple), 9 (light blue) and $\mathbf{1 0}$ (dark blue). 
Table S1. Anion Binding, Anion Transport and Electrochemical Data.

\begin{tabular}{|c|c|c|c|c|c|c|c|c|}
\hline cpd & $\begin{array}{c}\Delta E_{\text {int }} \\
(\mathrm{kcal} / \mathrm{mol})^{a}\end{array}$ & $\begin{array}{l}K_{\mathrm{D}} \mathrm{Cl}^{-} \\
(\mathrm{mM})^{b}\end{array}$ & $\begin{array}{c}K_{\mathrm{D} \mathrm{NO}_{3}{ }^{-}}(\mathrm{mM})^{c}\end{array}$ & $\begin{array}{l}E_{\text {LUMO }} \\
(\mathrm{eV})^{d}\end{array}$ & $\begin{array}{l}E C_{50} \\
(\mu \mathrm{M})^{e}\end{array}$ & $Y_{\max }^{f}$ & $n^{g}$ & $\mathrm{Cl}^{-} / \mathrm{NO}_{3}{ }^{-h}$ \\
\hline 1 & 9.9 & - & - & $>-2.70^{k}$ & $16 \pm 3$ & 0.57 & 1.3 & n.d. \\
\hline 2 & $21.3(14.7)^{i}$ & - & - & - & - & - & - & - \\
\hline 3 & 16.6 & - & - & -2.86 & $19 \pm 2$ & 0.86 & 1.1 & 3.4 \\
\hline 4 & 24.0 & - & - & -3.20 & $22 \pm 4$ & 0.78 & 1.2 & 2.3 \\
\hline 5 & 20.1 & n.d..$^{j}$ & - & -2.88 & $9.4 \pm 0.6$ & 0.80 & 1.5 & 2.2 \\
\hline 6 & 27.4 & $14.4 \pm 0.7$ & n.d. ${ }^{j}$ & -3.30 & $7 \pm 1$ & 0.74 & 1.4 & 2.0 \\
\hline 7 & 37.2 & $1.13 \pm 0.03$ & $6.2 \pm 0.4$ & -3.70 & $1.9 \pm 0.2$ & 0.82 & 1.2 & 2.1 \\
\hline 8 & $30.9(24.8)^{i}$ & $7 \pm 1^{c}$ & - & -3.42 & n.d. ${ }^{l}$ & n.d. ${ }^{l}$ & n.d. ${ }^{l}$ & n.d. ${ }^{l}$ \\
\hline 9 & 26.8 & $11 \pm 2$ & n.d. ${ }^{j}$ & -3.31 & $27 \pm 2$ & 1.1 & 1.4 & 1.2 \\
\hline 10 & 32.7 & $4.9 \pm 0.2$ & $12 \pm 1$ & -3.64 & n.d. & n.d & n.d & n.d \\
\hline
\end{tabular}

${ }^{a}$ Calculated interaction energies for a 1:1 chloride complex, with methyl as alkyl substituent.

${ }^{b}$ Dissociation constant determined in THF for a 1:1 complex by fluorescence titration with TBACl. ${ }^{c}$ same for $\mathrm{TBANO}_{3} .{ }^{d} \mathrm{LUMO}$ energies measured by DPV vs $\mathrm{Fc}^{+} / \mathrm{Fc}$. ${ }^{e}$ Effective transporter concentration needed to reach $50 \%$ of $Y_{\max }$ in the HPTS assay, data from Hill analysis of dose response curves. ${ }^{f}$ Maximum activity in the HPTS assay. ${ }^{g}$ Hill coefficient. ${ }^{h}$ Ratio of transport activity for extravesicular chloride vs. nitrate in the HPTS assay. ${ }^{i}$ Value in parenthesis for conformer $\mathbf{b}$ with competing intramolecular chalcogen bonds (Scheme 1 in the manuscript). ${ }^{j}$ Binding was too weak to be determined. ${ }^{k}$ No reduction observable within the solvent limit. ${ }^{l}$ Not determined due to overlap of absorption/emission of transporter 8 with HPTS. 


\section{Supporting References}

S1. Cotelle, Y.; Benz, S.; Avestro, A. J.; Ward, T. R.; Sakai, N.; Matile, S. Angew. Chem. Int. Ed. 2016, 55, 4275-4279.

S2. Dal Molin, M.; Verolet, Q.; Colom, A.; Letrun, R.; Derivery, E.; Gonzalez-Gaitan, M.; Vauthey, E.; Roux, A.; Sakai, N.; Matile, S. J. Am. Chem. Soc. 2015, 137, 568-571.

S3. Vargas Jentzsch, A.; Emery, D.; Mareda, J.; Metrangolo, P.; Resnati, G.; Matile, S. Angew. Chem. Int. Ed. 2011, 50, 11675-11678.

S4. Vargas Jentzsch, A.; Matile, S. J. Am. Chem. Soc. 2013, 135, 5302-5303.

S5. Zhao, Y.; Huang, G.; Besnard, C.; Mareda, J.; Sakai, N.; Matile, S. Chem. Eur. J. 2015, 21, 6202-6207.

S6. Verolet, Q.; Rosspeintner, A.; Soleimanpour, S.; Sakai, N.; Vauthey, E.; Matile, S. J. Am. Chem. Soc. 2015, 137, 15644-15647.

S7. Barbarella, G.; Favaretto, L.; Sotgiu, G. Chem. Mater. 2001, 13, 4112-4122.

S8. $\quad$ Li, W. S.; Jiang, D. L.; Suna, Y.; Aida, T. J. Am. Chem. Soc. 2005, 127, 7700-7702.

S9. Hirose, K. J. Incl. Phenom. Macrocycl. Chem. 2001, 39, 193-209. 


\section{Computational Data}

Cartesian coordinates $(\AA)$, zero-point energies (Hartree), free energies (Hartree) at 298.15 K and $1 \mathrm{~atm}$, and number of imaginary frequencies (NIMAG) for the optimized structures:

\begin{tabular}{|c|c|c|c|}
\hline & & 1 & \\
\hline & Zero-point Enes & -2040 & 5527 \\
\hline & Free Energy= & -2040 & 498 \\
\hline & & IMAG $=0$ & \\
\hline $\mathrm{C}$ & 0.002817 & 0.000000 & -0.000279 \\
\hline $\mathrm{C}$ & 0.001259 & 0.000000 & 1.363117 \\
\hline C & 1.345192 & 0.000000 & 1.830206 \\
\hline $\mathrm{C}$ & 2.311435 & 0.000000 & 0.837473 \\
\hline $\mathrm{S}$ & 1.579183 & 0.000000 & -0.730510 \\
\hline $\mathrm{C}$ & 3.638807 & 0.000000 & 1.385809 \\
\hline $\mathrm{C}$ & 3.622711 & 0.000000 & 2.771048 \\
\hline S & 5.264192 & 0.000000 & 0.791765 \\
\hline $\mathrm{C}$ & 4.904474 & 0.000000 & 3.388633 \\
\hline $\mathrm{C}$ & 5.865601 & 0.000000 & 2.421635 \\
\hline $\mathrm{H}$ & 6.934756 & 0.000000 & 2.583366 \\
\hline $\mathrm{H}$ & -0.868770 & 0.000000 & -0.640268 \\
\hline $\mathrm{S}$ & 2.009435 & 0.000000 & 3.449300 \\
\hline $\mathrm{Cl}$ & 4.349954 & 0.000000 & -2.216450 \\
\hline $\mathrm{C}$ & -1.202086 & 0.000000 & 2.256695 \\
\hline $\mathrm{H}$ & -1.209084 & -0.881885 & 2.904531 \\
\hline $\mathrm{H}$ & -1.209084 & 0.881885 & 2.904531 \\
\hline $\mathrm{H}$ & -2.121778 & 0.000000 & 1.670023 \\
\hline $\mathrm{C}$ & 5.126333 & 0.000000 & 4.870962 \\
\hline $\mathrm{H}$ & 4.674074 & 0.881885 & 5.334861 \\
\hline $\mathrm{H}$ & 4.674074 & -0.881885 & 5.334861 \\
\hline $\mathrm{H}$ & 6.191939 & 0.000000 & 5.104416 \\
\hline
\end{tabular}

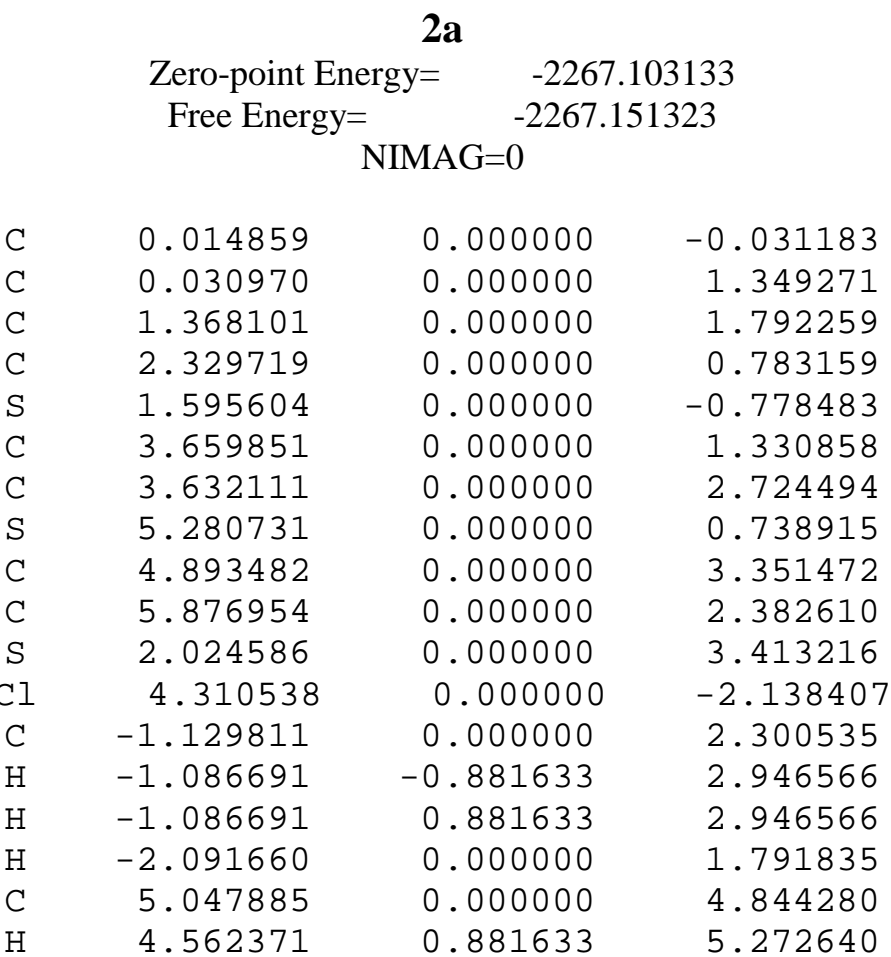




$\begin{array}{rrrr}\mathrm{H} & 4.562371 & -0.881633 & 5.272640 \\ \mathrm{H} & 6.089053 & 0.000000 & 5.160348 \\ \mathrm{C} & -1.173643 & 0.000000 & -0.874347 \\ \mathrm{O} & -1.176897 & 0.000000 & -2.082209 \\ \mathrm{H} & -2.133107 & 0.000000 & -0.318552 \\ \mathrm{C} & 7.314568 & 0.000000 & 2.620783 \\ \mathrm{O} & 8.167383 & 0.000000 & 1.765418 \\ \mathrm{H} & 7.604490 & 0.000000 & 3.691028\end{array}$

2b

$\begin{array}{cc}\text { Zero-point Energy= } & -2267.112379 \\ \text { Free Energy }= & -2267.160345\end{array}$

NIMAG $=0$

$\begin{array}{rrrr}\mathrm{C} & -0.000262 & 0.000000 & 0.002782 \\ \mathrm{C} & 0.011708 & 0.000000 & 1.383255 \\ \mathrm{C} & 1.348609 & 0.000000 & 1.829187 \\ \mathrm{C} & 2.315054 & 0.000000 & 0.824122 \\ \mathrm{~S} & 1.589582 & 0.000000 & -0.732853 \\ \mathrm{C} & 3.641420 & 0.000000 & 1.370270 \\ \mathrm{C} & 3.619950 & 0.000000 & 2.764440 \\ \mathrm{~S} & 5.252878 & 0.000000 & 0.775556 \\ \mathrm{C} & 4.883230 & 0.000000 & 3.389167 \\ \mathrm{C} & 5.863775 & 0.000000 & 2.417374 \\ \mathrm{~S} & 2.009550 & 0.000000 & 3.449733 \\ \mathrm{C} 1 & 4.306444 & 0.000000 & -2.128463 \\ \mathrm{C} & -1.167730 & 0.000000 & 2.308140 \\ \mathrm{H} & -1.135910 & -0.881693 & 2.955392 \\ \mathrm{H} & -1.135910 & 0.881693 & 2.955392 \\ \mathrm{H} & -2.099120 & 0.000000 & 1.749291 \\ \mathrm{C} & 5.069455 & 0.000000 & 4.876381 \\ \mathrm{H} & 4.591105 & 0.881693 & 5.313564 \\ \mathrm{H} & 4.591105 & -0.881693 & 5.313564 \\ \mathrm{H} & 6.124307 & 0.000000 & 5.135392 \\ \mathrm{C} & -1.150423 & 0.000000 & -0.896615 \\ \mathrm{O} & -2.316185 & 0.000000 & -0.565252 \\ \mathrm{H} & -0.880823 & 0.000000 & -1.971982 \\ \mathrm{C} & 7.313761 & 0.000000 & 2.588621 \\ \mathrm{O} & 7.908198 & 0.000000 & 3.644768 \\ \mathrm{H} & 7.879537 & 0.000000 & 1.635208\end{array}$

\section{3}

\section{Zero-point Energy= Free Energy= \\ NIMAG $=0$}

$\begin{array}{lrrr}\mathrm{C} & -0.008072 & 0.059084 & -0.000847 \\ \mathrm{C} & -0.006058 & -0.048027 & 1.361708 \\ \mathrm{C} & 1.335436 & -0.086722 & 1.814299 \\ \mathrm{C} & 2.295043 & -0.025342 & 0.829635 \\ \mathrm{~S} & 1.570100 & 0.081986 & -0.724107 \\ \mathrm{C} & 3.644626 & -0.021498 & 1.386819 \\ \mathrm{C} & 3.630406 & -0.081151 & 2.761744 \\ \mathrm{~S} & 5.253834 & 0.094565 & 0.796872 \\ \mathrm{C} & 4.900260 & -0.034446 & 3.387292 \\ \mathrm{C} & 5.862155 & 0.077279 & 2.422829 \\ \mathrm{C} 1 & 4.320841 & -0.080395 & -2.161427 \\ \mathrm{C} & -1.200842 & -0.083840 & 2.268181 \\ \mathrm{H} & -1.245399 & -1.030563 & 2.814651\end{array}$




$\begin{array}{lr}\mathrm{H} & -1.139954 \\ \mathrm{H} & -2.124814 \\ \mathrm{C} & 5.108243 \\ \mathrm{H} & 4.537531 \\ \mathrm{H} & 4.760418 \\ \mathrm{H} & 6.163677 \\ \mathrm{H} & 6.929105 \\ \mathrm{H} & -0.876590 \\ \mathrm{O} & 1.610228 \\ \mathrm{~S} & 2.000472\end{array}$

$$
\begin{array}{r}
0.716088 \\
0.027392 \\
-0.068514 \\
0.727973 \\
-1.017400 \\
0.049278 \\
0.149884 \\
0.125649 \\
0.792305 \\
-0.325770
\end{array}
$$

3.009272

1.699505

4. 872550

5.354932

5.291515

5.120911

2. 581414

$-0.641216$

4.396975

3. 457819

\section{Zero-point Energy= Free Energy=}

NIMAG $=0$

$\begin{array}{lrrr}\mathrm{C} & 0.010024 & 0.012138 & 0.003073 \\ \mathrm{C} & 0.016966 & 0.004168 & 1.370698 \\ \mathrm{C} & 1.359674 & -0.009033 & 1.815933 \\ \mathrm{C} & 2.315356 & -0.024717 & 0.823648 \\ \mathrm{~S} & 1.580354 & -0.027592 & -0.729348 \\ \mathrm{C} & 3.666403 & 0.023065 & 1.374464 \\ \mathrm{C} & 3.648707 & 0.067372 & 2.754648 \\ \mathrm{~S} & 5.265842 & 0.107502 & 0.761855 \\ \mathrm{C} & 4.903290 & 0.181334 & 3.378886 \\ \mathrm{C} & 5.874834 & 0.231365 & 2.403071 \\ \mathrm{Cl} & 4.318232 & -0.326336 & -2.053336 \\ \mathrm{C} & -1.173245 & 0.041179 & 2.283001 \\ \mathrm{H} & -1.217460 & -0.860940 & 2.900070 \\ \mathrm{H} & -1.107399 & 0.895738 & 2.959739 \\ \mathrm{H} & -2.099269 & 0.110830 & 1.711489 \\ \mathrm{C} & 5.114978 & 0.263295 & 4.858805 \\ \mathrm{H} & 4.500209 & 1.062224 & 5.278231 \\ \mathrm{H} & 4.811688 & -0.671644 & 5.338171 \\ \mathrm{H} & 6.162986 & 0.449695 & 5.093846 \\ \mathrm{H} & -0.861843 & 0.035318 & -0.635903 \\ \mathrm{O} & 1.640606 & 1.075579 & 4.314339 \\ \mathrm{~S} & 2.020449 & -0.119014 & 3.474334 \\ \mathrm{C} & 7.264610 & 0.356861 & 2.656112 \\ \mathrm{~N} & 8.389477 & 0.459091 & 2.889387\end{array}$

\section{5}

\section{Zero-point Energy= Free Energy= \\ NIMAG $=0$}

$\begin{array}{lr}\text { C } & -0.016029 \\ \text { C } & 0.010645 \\ \text { C } & 1.361181 \\ \text { C } & 2.304491 \\ \text { S } & 1.546471 \\ \text { C } & 3.680957 \\ \text { C } & 3.733200 \\ \text { S } & 5.264612 \\ \text { C } & 5.025159 \\ \text { C } & 5.945206 \\ \text { S } & 2.111137 \\ \text { O } & 1.844611 \\ \text { O } & 1.844611\end{array}$

$$
\begin{array}{r}
0.000000 \\
0.000000 \\
0.000000 \\
0.000000 \\
0.000000 \\
0.000000 \\
0.000000 \\
0.000000 \\
0.000000 \\
0.000000 \\
0.000000 \\
1.247513 \\
-1.247513
\end{array}
$$

0.015189

1. 382261

1.800534

0.801286

$-0.737578$

1.318279

2.691451

0.658933

3.265682

2.254194

3.406963

4.116574

4.116574 


$\begin{array}{cccc}\mathrm{C} & 5.294902 & 0.000000 & 4.740782 \\ \mathrm{H} & 4.850476 & 0.880903 & 5.210397 \\ \mathrm{H} & 4.850476 & -0.880903 & 5.210397 \\ \mathrm{H} & 6.367184 & 0.000000 & 4.938727 \\ \mathrm{C} & -1.163486 & 0.000000 & 2.315050 \\ \mathrm{H} & -1.138106 & -0.880903 & 2.961121 \\ \mathrm{H} & -1.138106 & 0.880903 & 2.961121 \\ \mathrm{H} & -2.100947 & 0.000000 & 1.758147 \\ \mathrm{Cl} & 4.234862 & 0.000000 & -2.247346 \\ \mathrm{H} & -0.896640 & 0.000000 & -0.611704 \\ \mathrm{H} & 7.020773 & 0.000000 & 2.362029\end{array}$

\section{6 \\ Zero-point Energy $=\quad-2283.080314$ \\ Free Energy= \\ NIMAG $=0$}

$\begin{array}{lrrr}\text { C } & -0.001426 & 0.000000 & -0.000659 \\ \mathrm{C} & -0.005248 & 0.000000 & 1.377180 \\ \mathrm{C} & 1.328305 & 0.000000 & 1.816174 \\ \mathrm{C} & 2.297461 & 0.000000 & 0.835461 \\ \mathrm{~S} & 1.594873 & 0.000000 & -0.726842 \\ \mathrm{C} & 3.658189 & 0.000000 & 1.391720 \\ \mathrm{C} & 3.669593 & 0.000000 & 2.767466 \\ \mathrm{~S} & 5.262828 & 0.000000 & 0.783036 \\ \mathrm{C} & 4.941303 & 0.000000 & 3.381421 \\ \mathrm{C} & 5.891017 & 0.000000 & 2.396422 \\ \mathrm{~S} & 2.032939 & 0.000000 & 3.444449 \\ \mathrm{O} & 1.746388 & 1.248340 & 4.140605 \\ \mathrm{O} & 1.746388 & -1.248340 & 4.140605 \\ \mathrm{C} & -1.166674 & 0.000000 & -0.809795 \\ \mathrm{~N} & -2.128450 & 0.000000 & -1.445681 \\ \mathrm{C} & 5.166660 & 0.000000 & 4.863915 \\ \mathrm{H} & 4.709149 & 0.881179 & 5.320031 \\ \mathrm{H} & 4.709149 & -0.881179 & 5.320031 \\ \mathrm{H} & 6.232491 & 0.000000 & 5.093099 \\ \mathrm{C} & -1.202208 & 0.000000 & 2.275377 \\ \mathrm{H} & -1.185442 & -0.881473 & 2.920557 \\ \mathrm{H} & -1.185442 & 0.881473 & 2.920557 \\ \mathrm{H} & -2.124499 & 0.000000 & 1.694604 \\ \mathrm{Cl} & 4.249500 & 0.000000 & -2.073646 \\ \mathrm{H} & 6.962896 & 0.000000 & 2.536947\end{array}$

\section{7}

Zero-point Energy $=\quad-2375.325083$

Free Energy $=\quad-2375.374932$

\section{NIMAG $=0$}

$\begin{array}{lrrr}\text { C } & -0.003436 & 0.000000 & -0.001581 \\ \text { C } & 0.031716 & 0.000000 & 1.375937 \\ \text { C } & 1.377888 & 0.000000 & 1.773754 \\ \text { C } & 2.317892 & 0.000000 & 0.764494 \\ \text { S } & 1.567302 & 0.000000 & -0.776012 \\ \text { C } & 3.695091 & 0.000000 & 1.281761 \\ \text { C } & 3.738254 & 0.000000 & 2.660294 \\ \text { S } & 5.274233 & 0.000000 & 0.616290 \\ \text { C } & 5.013461 & 0.000000 & 3.247051 \\ \text { C } & 5.946767 & 0.000000 & 2.233280 \\ \text { S } & 2.119961 & 0.000000 & 3.383470\end{array}$




$\begin{array}{rrrr}\mathrm{O} & 1.856964 & 1.249162 & 4.083686 \\ \mathrm{O} & 1.856964 & -1.249162 & 4.083686 \\ \mathrm{C} & 7.352271 & 0.000000 & 2.431545 \\ \mathrm{~N} & 8.489765 & 0.000000 & 2.617288 \\ \mathrm{C} & -1.191936 & 0.000000 & -0.777608 \\ \mathrm{~N} & -2.170450 & 0.000000 & -1.386626 \\ \mathrm{C} & 5.279389 & 0.000000 & 4.719619 \\ \mathrm{H} & 4.828765 & 0.881697 & 5.181092 \\ \mathrm{H} & 4.828765 & -0.881697 & 5.181092 \\ \mathrm{H} & 6.350405 & 0.000000 & 4.921150 \\ \mathrm{C} & -1.137877 & 0.000000 & 2.309331 \\ \mathrm{H} & -1.102471 & -0.881697 & 2.953355 \\ \mathrm{H} & -1.102471 & 0.881697 & 2.953355 \\ \mathrm{H} & -2.076745 & 0.000000 & 1.755963 \\ \mathrm{Cl} & 4.183177 & 0.000000 & -2.109737\end{array}$

\section{$8 \mathbf{a}$}

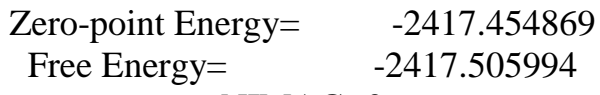

$\mathrm{NIMAG}=0$

$\begin{array}{lrrr}\mathrm{C} & 0.008290 & -0.038252 & -0.004737 \\ \mathrm{C} & 0.001672 & -0.031637 & 1.380613 \\ \mathrm{C} & 1.329533 & -0.016853 & 1.823772 \\ \mathrm{C} & 2.304703 & -0.009631 & 0.840372 \\ \mathrm{~S} & 1.602557 & -0.023416 & -0.712664 \\ \mathrm{C} & 3.662055 & 0.009631 & 1.391308 \\ \mathrm{C} & 3.675970 & 0.016853 & 2.776169 \\ \mathrm{~S} & 5.247974 & 0.023416 & 0.766976 \\ \mathrm{C} & 4.937057 & 0.031637 & 3.383840 \\ \mathrm{C} & 5.897844 & 0.038252 & 2.385778 \\ \mathrm{~S} & 2.033705 & 0.000000 & 3.455570 \\ \mathrm{O} & 1.735793 & 1.248630 & 4.142273 \\ \mathrm{O} & 1.768737 & -1.248630 & 4.155644 \\ \mathrm{C} & 5.184891 & 0.040436 & 4.861540 \\ \mathrm{H} & 5.722345 & 0.945340 & 5.149383 \\ \mathrm{H} & 4.243163 & -0.008986 & 5.408724 \\ \mathrm{H} & 5.814426 & -0.803790 & 5.145054 \\ \mathrm{C} & -1.205949 & -0.040436 & 2.267558 \\ \mathrm{H} & -1.791978 & -0.945340 & 2.099389 \\ \mathrm{H} & -0.911990 & 0.008986 & 3.316296 \\ \mathrm{H} & -1.854993 & 0.803790 & 2.032108 \\ \mathrm{Cl} & 4.281188 & 0.000000 & -2.081594 \\ \mathrm{C} & 7.343934 & 0.055711 & 2.573189 \\ \mathrm{O} & 7.893187 & 0.072072 & 3.652141 \\ \mathrm{H} & 7.938096 & 0.053208 & 1.638029 \\ \mathrm{C} & -1.159335 & -0.055711 & -0.878208 \\ \mathrm{O} & -2.305195 & -0.072072 & -0.487287 \\ \mathrm{H} & -0.933646 & -0.053208 & -1.962928\end{array}$

\section{8b}

\section{Zero-point Energy= $\quad-2417.447963$ \\ Free Energy $=\quad-2417.499468$ \\ NIMAG $=0$}

$\begin{array}{rrrr}\text { C } & -0.000158 & 0.000418 & -0.000082 \\ \mathrm{C} & 0.000096 & -0.000508 & 1.383043 \\ \mathrm{C} & 1.330323 & -0.001037 & 1.821738 \\ \mathrm{C} & 2.301315 & 0.008877 & 0.836440\end{array}$




$\begin{array}{cccr}\mathrm{S} & 1.591864 & 0.010129 & -0.720057 \\ \mathrm{C} & 3.662193 & 0.033117 & 1.397067 \\ \mathrm{C} & 3.657306 & 0.050068 & 2.780333 \\ \mathrm{~S} & 5.262188 & 0.025434 & 0.792119 \\ \mathrm{C} & 4.910483 & 0.050086 & 3.406036 \\ \mathrm{C} & 5.884987 & 0.042128 & 2.424551 \\ \mathrm{~S} & 2.019677 & 0.027934 & 3.451819 \\ \mathrm{O} & 1.705568 & 1.277581 & 4.134979 \\ \mathrm{O} & 1.758762 & -1.217569 & 4.164305 \\ \mathrm{C} & 5.072946 & 0.080909 & 4.898651 \\ \mathrm{H} & 4.840172 & 1.078144 & 5.279988 \\ \mathrm{H} & 4.369987 & -0.618336 & 5.356935 \\ \mathrm{H} & 6.080260 & -0.186196 & 5.212463 \\ \mathrm{C} & -1.166734 & -0.024091 & 2.328134 \\ \mathrm{H} & -1.272234 & -1.018887 & 2.767826 \\ \mathrm{H} & -0.989171 & 0.678942 & 3.145039 \\ \mathrm{H} & -2.102190 & 0.242495 & 1.839914 \\ \mathrm{Cl} & 4.277145 & 0.011679 & -2.027313 \\ \mathrm{C} & 7.328054 & 0.050859 & 2.640179 \\ \mathrm{O} & 8.161929 & 0.051802 & 1.767688 \\ \mathrm{H} & 7.632238 & 0.058672 & 3.705588 \\ \mathrm{C} & -1.176308 & -0.010247 & -0.863547 \\ \mathrm{O} & -1.153548 & -0.017373 & -2.070203 \\ \mathrm{H} & -2.142737 & -0.013286 & -0.321614 \\ & & & \end{array}$

\section{9}

Zero-point Energy= $\quad-2778.658480$

Free Energy $=\quad-2778.711527$

\section{NIMAG $=0$}

$\begin{array}{crrr}\mathrm{C} & 0.102626 & -0.563463 & -0.118372 \\ \mathrm{C} & 0.069701 & -0.143621 & 1.192870 \\ \mathrm{C} & 1.399131 & -0.110421 & 1.652633 \\ \mathrm{C} & 2.379461 & -0.449905 & 0.746059 \\ \mathrm{~S} & 1.699965 & -0.866925 & -0.768566 \\ \mathrm{C} & 3.726251 & -0.417515 & 1.334833 \\ \mathrm{C} & 3.715754 & -0.065867 & 2.664487 \\ \mathrm{~S} & 5.331006 & -0.720426 & 0.810280 \\ \mathrm{C} & 4.971146 & -0.033136 & 3.310586 \\ \mathrm{C} & 5.929635 & -0.384839 & 2.399457 \\ \mathrm{~S} & 2.076589 & 0.260075 & 3.252233 \\ \mathrm{O} & 1.903370 & 1.669088 & 3.585802 \\ \mathrm{O} & 1.660890 & -0.728805 & 4.238823 \\ \mathrm{C} & 5.174129 & 0.330809 & 4.750986 \\ \mathrm{H} & 4.818724 & 1.346086 & 4.942604 \\ \mathrm{H} & 4.608264 & -0.343097 & 5.398615 \\ \mathrm{H} & 6.229032 & 0.272056 & 5.019782 \\ \mathrm{C} & -1.096132 & 0.208317 & 2.070476 \\ \mathrm{H} & -1.321674 & -0.636039 & 2.726248 \\ \mathrm{H} & -0.828143 & 1.058214 & 2.701718 \\ \mathrm{H} & -1.988600 & 0.432789 & 1.492734 \\ \mathrm{Cl} & 4.393017 & -0.961333 & -2.067112 \\ \mathrm{~S} & -1.262389 & -0.650008 & -1.223027 \\ \mathrm{O} & -0.956252 & -1.620951 & -2.259760 \\ \mathrm{O} & -2.493492 & -0.762512 & -0.450763 \\ \mathrm{C} & -1.266535 & 0.965989 & -1.993906 \\ \mathrm{H} & -0.315997 & 1.105107 & -2.506151 \\ \mathrm{H} & -2.093885 & 0.962645 & -2.703176 \\ \mathrm{H} & -1.416712 & 1.717985 & -1.221279\end{array}$




\section{0}

$\begin{array}{lr}\text { Zero-point Energy= } & -3366.48107 \\ \text { Free Energy= } & -3366.539848\end{array}$

\begin{tabular}{lrrr} 
& & \multicolumn{1}{l}{ NIMAG $=0$} & \\
$\mathrm{C}$ & 0.129632 & -0.351976 & -0.285543 \\
$\mathrm{C}$ & 0.138152 & -0.263833 & 1.088050 \\
$\mathrm{C}$ & 1.479934 & -0.113812 & 1.483473 \\
$\mathrm{C}$ & 2.425028 & -0.071345 & 0.481284 \\
$\mathrm{~S}$ & 1.694858 & -0.248428 & -1.058856 \\
$\mathrm{C}$ & 3.794044 & 0.071345 & 1.008350 \\
$\mathrm{C}$ & 3.823074 & 0.113812 & 2.385573 \\
$\mathrm{~S}$ & 5.368512 & 0.248428 & 0.355486 \\
$\mathrm{C}$ & 5.083608 & 0.263833 & 2.992032 \\
$\mathrm{C}$ & 6.011053 & 0.351976 & 1.978782 \\
$\mathrm{~S}$ & 2.203287 & 0.000000 & 3.098733 \\
$\mathrm{O}$ & 1.832937 & 1.244613 & 3.758346 \\
$\mathrm{O}$ & 2.035689 & -1.244613 & 3.836404 \\
$\mathrm{C}$ & 5.262667 & 0.329126 & 4.480790 \\
$\mathrm{H}$ & 4.971983 & 1.320740 & 4.835712 \\
$\mathrm{H}$ & 4.605181 & -0.401626 & 4.956608 \\
$\mathrm{H}$ & 6.294232 & 0.156903 & 4.775705 \\
$\mathrm{C}$ & -0.993033 & -0.329126 & 2.072370 \\
$\mathrm{H}$ & -1.015406 & -1.320740 & 2.530590 \\
$\mathrm{H}$ & -0.824376 & 0.401626 & 2.866250 \\
$\mathrm{H}$ & -1.956041 & -0.156903 & 1.599381 \\
$\mathrm{Cl}$ & 4.307605 & 0.000000 & -2.367082 \\
$\mathrm{~S}$ & -1.298351 & -0.426199 & -1.314147 \\
$\mathrm{O}$ & -0.910551 & -0.997653 & -2.591765 \\
$\mathrm{O}$ & -2.402375 & -0.996349 & -0.553858 \\
$\mathrm{~S}$ & 7.760141 & 0.426199 & 2.173338 \\
$\mathrm{O}$ & 8.329227 & 0.997653 & 0.965514 \\
$\mathrm{O}$ & 8.069286 & 0.996349 & 3.477692 \\
$\mathrm{C}$ & -1.682519 & 1.299417 & -1.594289 \\
$\mathrm{H}$ & -0.831333 & 1.765704 & -2.087283 \\
$\mathrm{H}$ & -2.560738 & 1.313598 & -2.239400 \\
$\mathrm{H}$ & -1.895088 & 1.768965 & -0.635400 \\
$\mathrm{C}$ & 8.232988 & -1.299417 & 2.223143 \\
$\mathrm{H}$ & 7.932158 & -1.765704 & 1.286628 \\
$\mathrm{H}$ & 9.317080 & -1.313598 & 2.333514 \\
$\mathrm{H}$ & 7.747650 & -1.768965 & 3.077017
\end{tabular}

2,5-difluoro-2,6-dimethyl-dithienothiophene-S,S-dioxide (cf. Figure 1(H)) Single Point calcn. based on the geometry of 7

Electronic Energy =-1915.1751212

$\begin{array}{lllr}\text { C } & 0.000000 & 0.000000 & 0.000000 \\ \text { C } & 0.000000 & 0.000000 & 1.377966 \\ \text { C } & 1.335586 & 0.000000 & 1.809995 \\ \text { C } & 2.301030 & 0.000000 & 0.825043 \\ \text { S } & 1.589983 & 0.000000 & -0.734109 \\ \text { C } & 3.664585 & 0.000000 & 1.377275 \\ \text { C } & 3.672567 & 0.000000 & 2.756459 \\ \text { S } & 5.260189 & 0.000000 & 0.752304 \\ \text { C } & 4.932391 & 0.000000 & 3.375557 \\ \text { C } & 5.891255 & 0.000000 & 2.385925 \\ \text { S } & 2.036352 & 0.000000 & 3.438118 \\ \text { O } & 1.755578 & 1.249162 & 4.131397\end{array}$




$\begin{array}{lrrr}\mathrm{O} & 1.755578 & -1.249162 & 4.131397 \\ \mathrm{C} & 7.291244 & 0.000000 & 2.619980 \\ \mathrm{~N} & 8.423629 & 0.000000 & 2.834680 \\ \mathrm{C} & -1.168316 & 0.000000 & -0.806094 \\ \mathrm{~N} & -2.130976 & 0.000000 & -1.439876 \\ \mathrm{C} & 5.160666 & 0.000000 & 4.854429 \\ \mathrm{H} & 4.698418 & 0.881697 & 5.304258 \\ \mathrm{H} & 4.698418 & -0.881697 & 5.304258 \\ \mathrm{H} & 6.226193 & 0.000000 & 5.083217 \\ \mathrm{C} & -1.193023 & 0.000000 & 2.281221 \\ \mathrm{H} & -1.174059 & -0.881697 & 2.925938 \\ \mathrm{H} & -1.174059 & 0.881697 & 2.925938 \\ \mathrm{H} & -2.117469 & 0.000000 & 1.704081\end{array}$

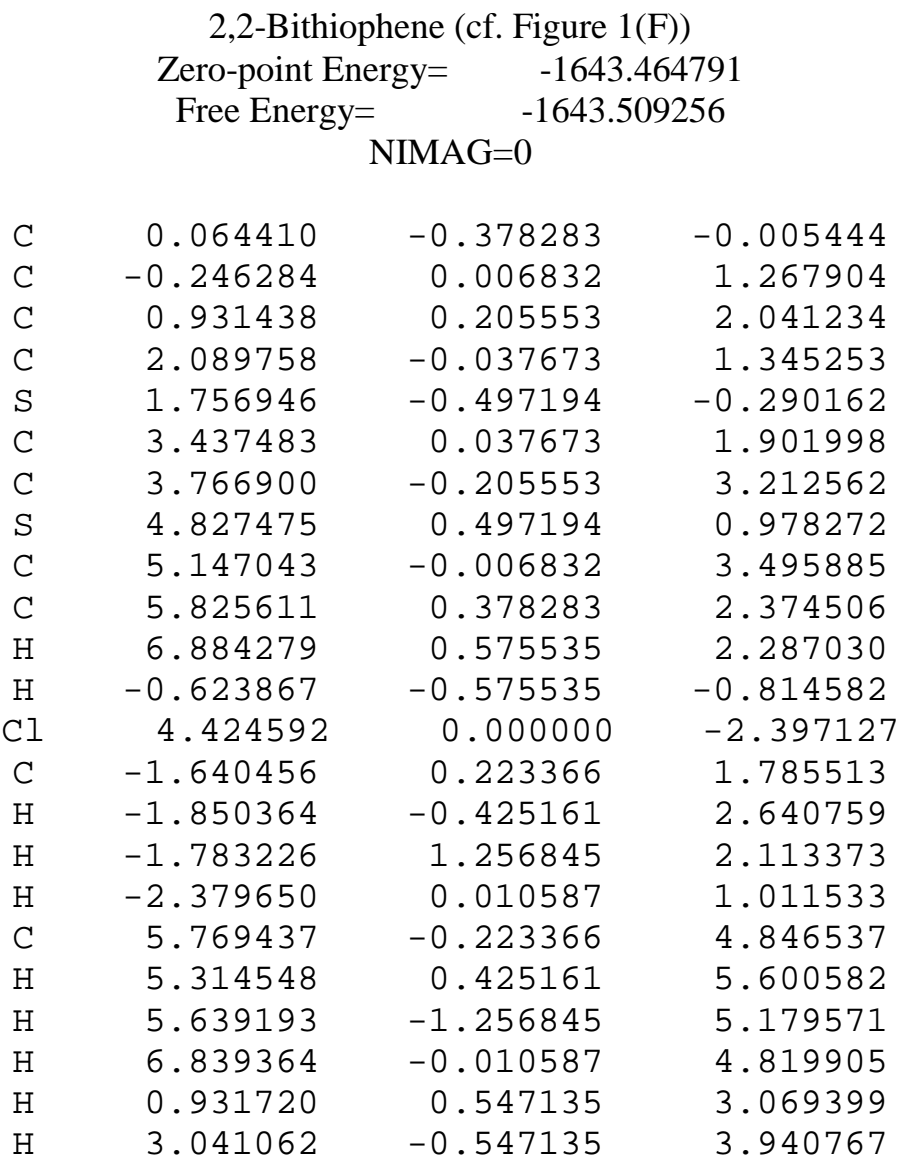

Full reference 9: Gaussian 09, Revision D.01, Frisch, M. J.; Trucks, G. W.; Schlegel, H. B.; Scuseria, G. E.; Robb, M. A.; Cheeseman, J. R.; Scalmani, G.; Barone, V.; Mennucci, B.; Petersson, G. A.; Nakatsuji, H.; Caricato, M.; Li, X.; Hratchian, H. P.; Izmaylov, A. F.; Bloino, J.; Zheng, G.; Sonnenberg, J. L.; Hada, M.; Ehara, M.; Toyota, K.; Fukuda, R.; Hasegawa, J.; Ishida, M.; Nakajima, T.; Honda, Y.; Kitao, O.; Nakai, H.; Vreven, T.; Montgomery, J. A., Jr.; Peralta, J. E.; Ogliaro, F.; Bearpark, M.; Heyd, J. J.; Brothers, E.; Kudin, K. N.; Staroverov, V. N.; Kobayashi, R.; 
Normand, J.; Raghavachari, K.; Rendell, A.; Burant, J. C.; Iyengar, S. S.; Tomasi, J.; Cossi, M.; Rega, N.; Millam, J. M.; Klene, M.; Knox, J. E.; Cross, J. B.; Bakken, V.; Adamo, C.; Jaramillo, J.; Gomperts, R.; Stratmann, R. E.; Yazyev, O.; Austin, A. J.; Cammi, R.; Pomelli, C.; Ochterski, J. W.; Martin, R. L.; Morokuma, K.; Zakrzewski, V. G.; Voth, G. A.; Salvador, P.; Dannenberg, J. J.; Dapprich, S.; Daniels, A. D.; Farkas, Ö.; Foresman, J. B.; Ortiz, J. V.; Cioslowski, J.; Fox, D. J. Gaussian, Inc., Wallingford CT, 2013. 


\section{NMR Spectra}
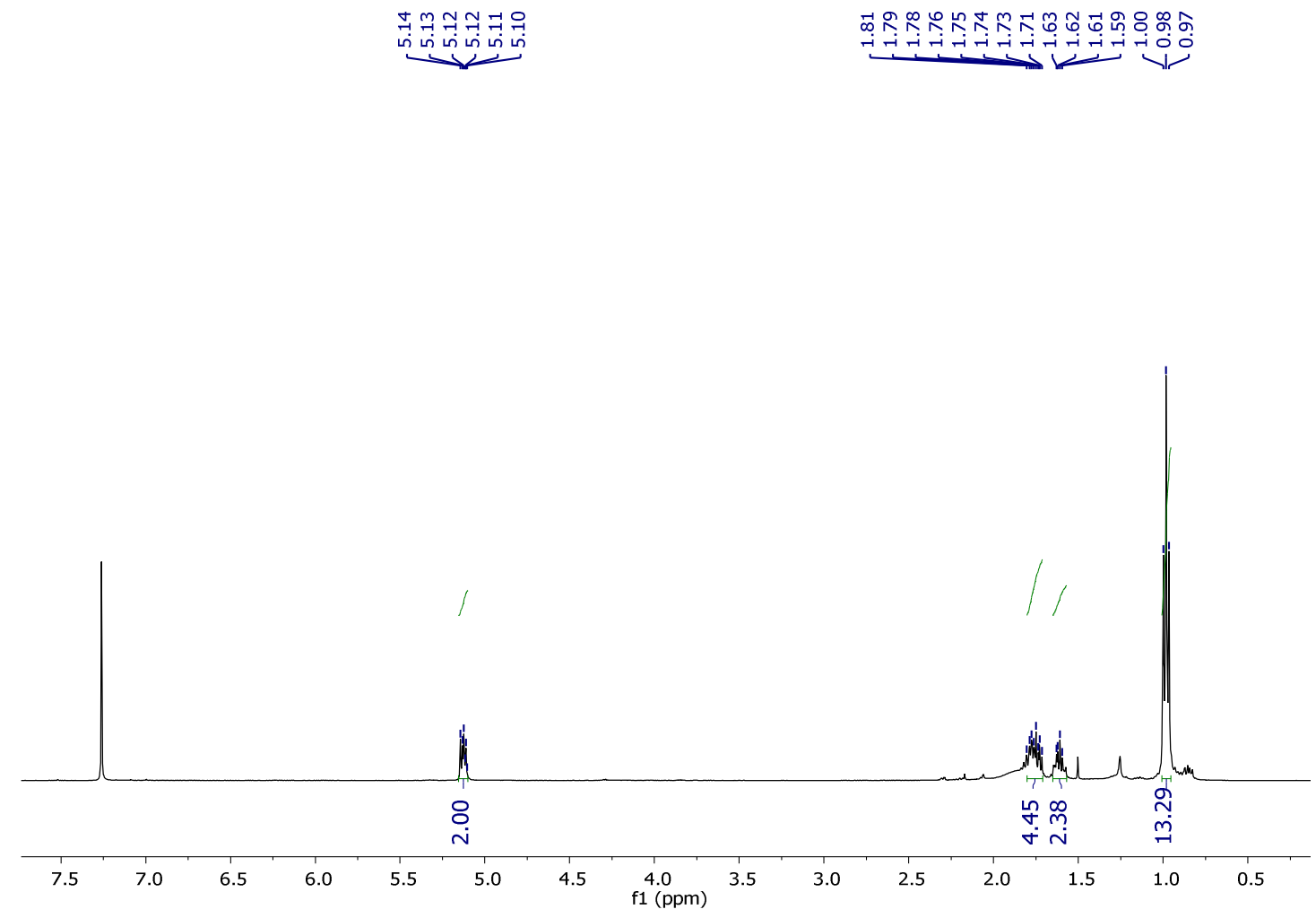

Figure S13. ${ }^{1} \mathrm{H}$ NMR spectrum of 16 in $\mathrm{CDCl}_{3}$.

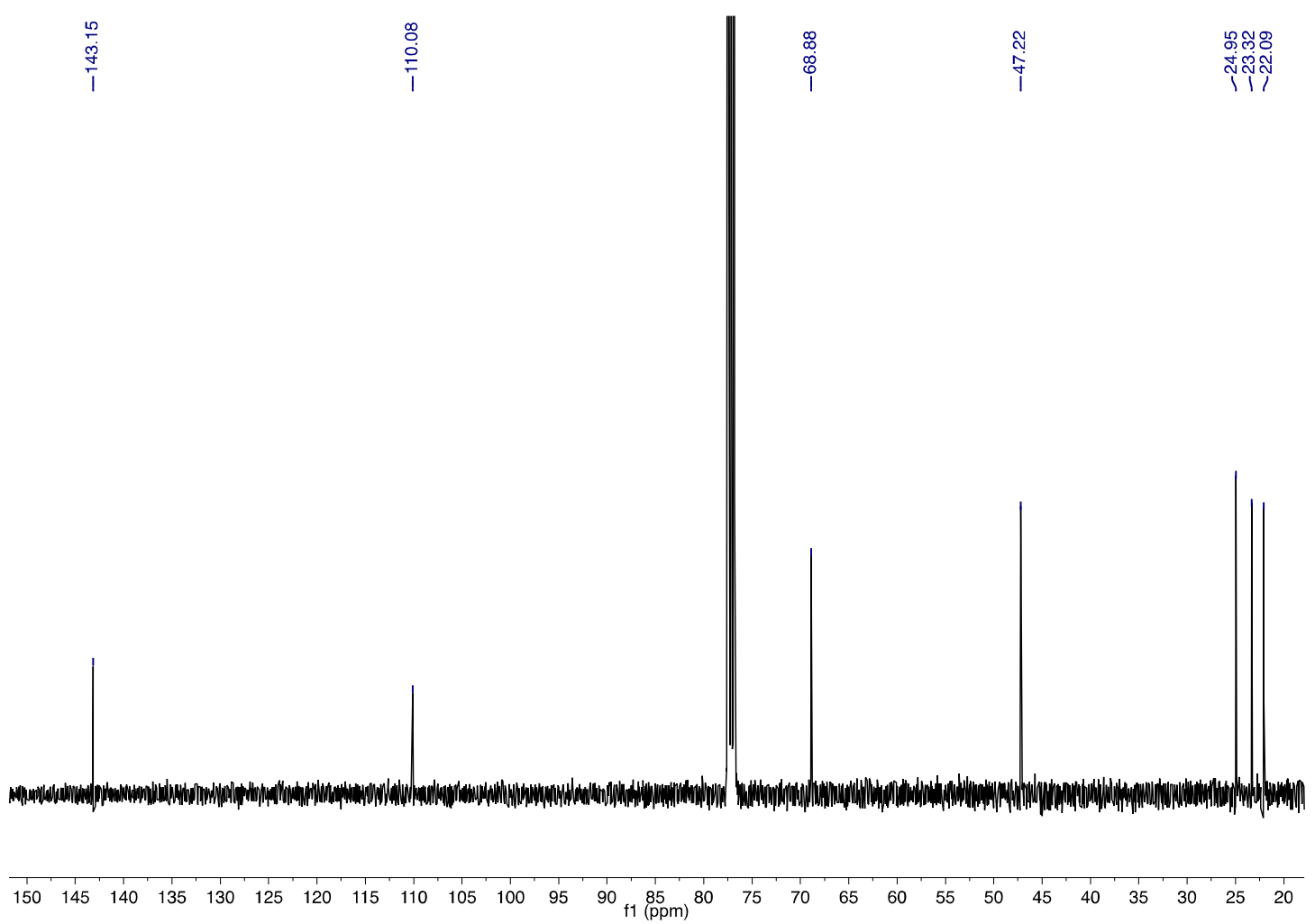

Figure S14. ${ }^{13} \mathrm{C}$ NMR spectrum of 16 in $\mathrm{CDCl}_{3}$. 


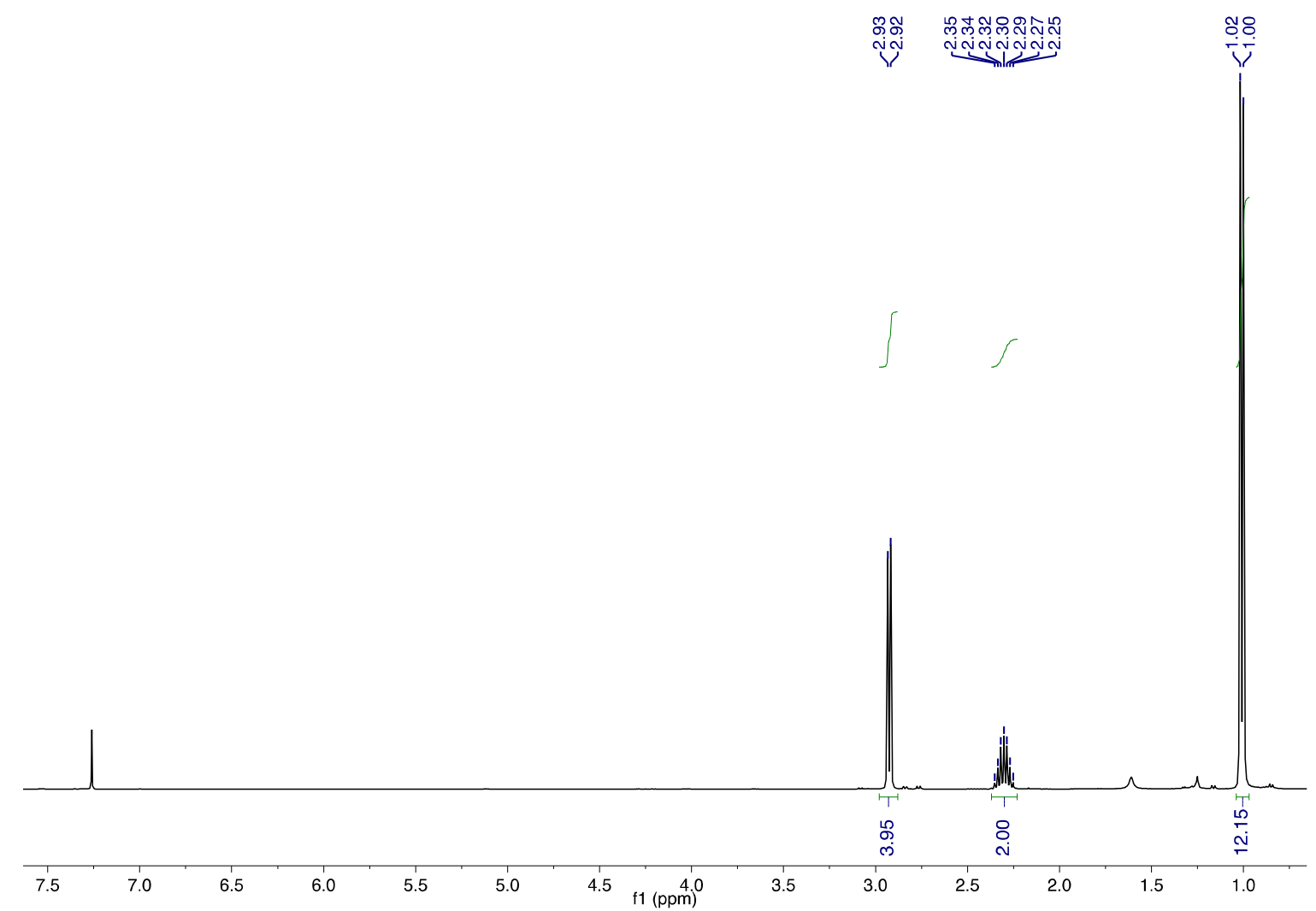

Figure S15. ${ }^{1} \mathrm{H}$ NMR spectrum of 13 in $\mathrm{CDCl}_{3}$.

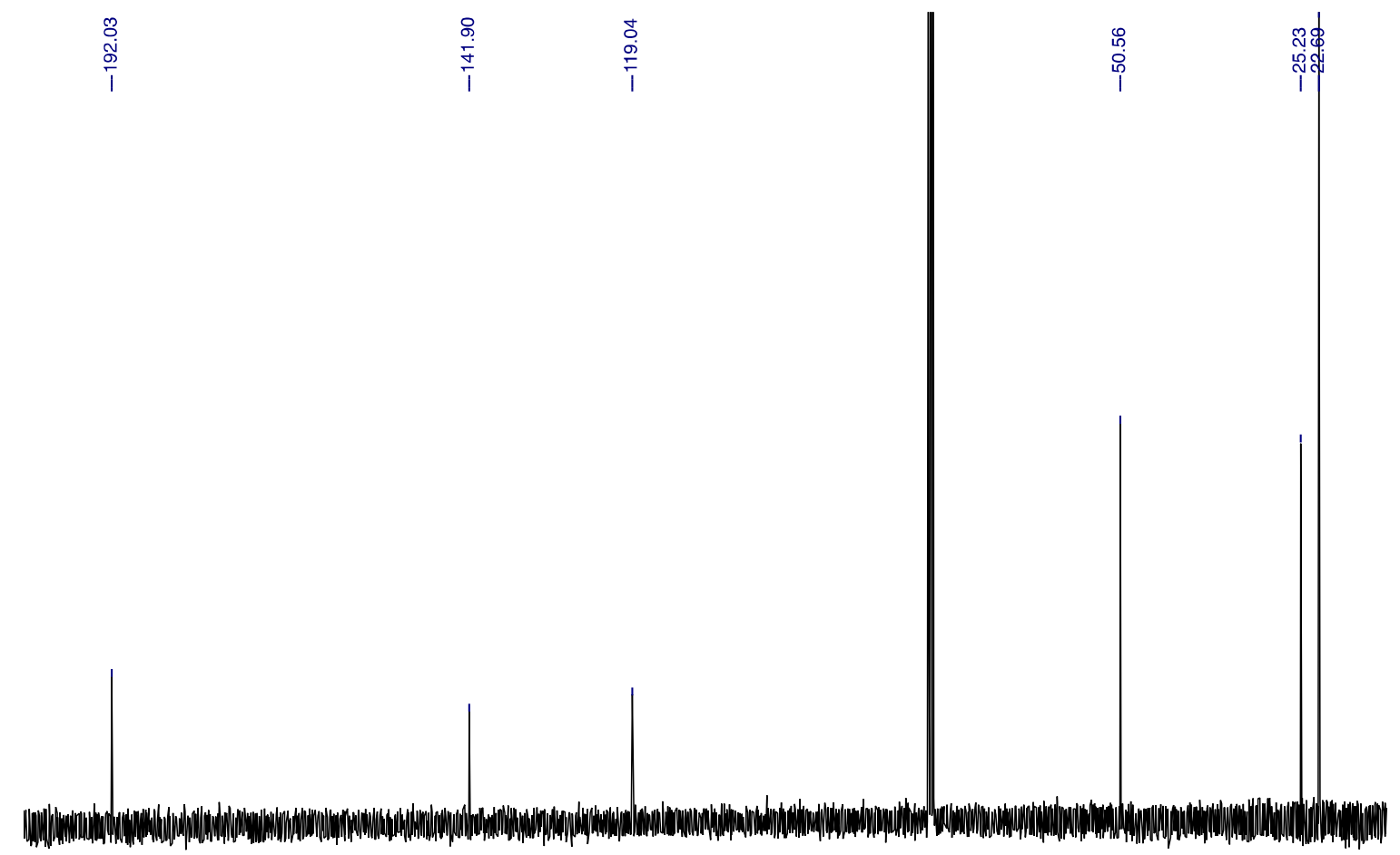

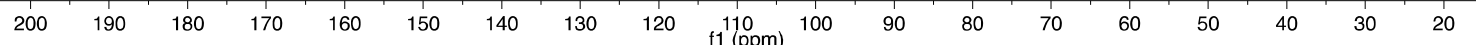

Figure S16. ${ }^{13} \mathrm{C}$ NMR spectrum of 13 in $\mathrm{CDCl}_{3}$. 


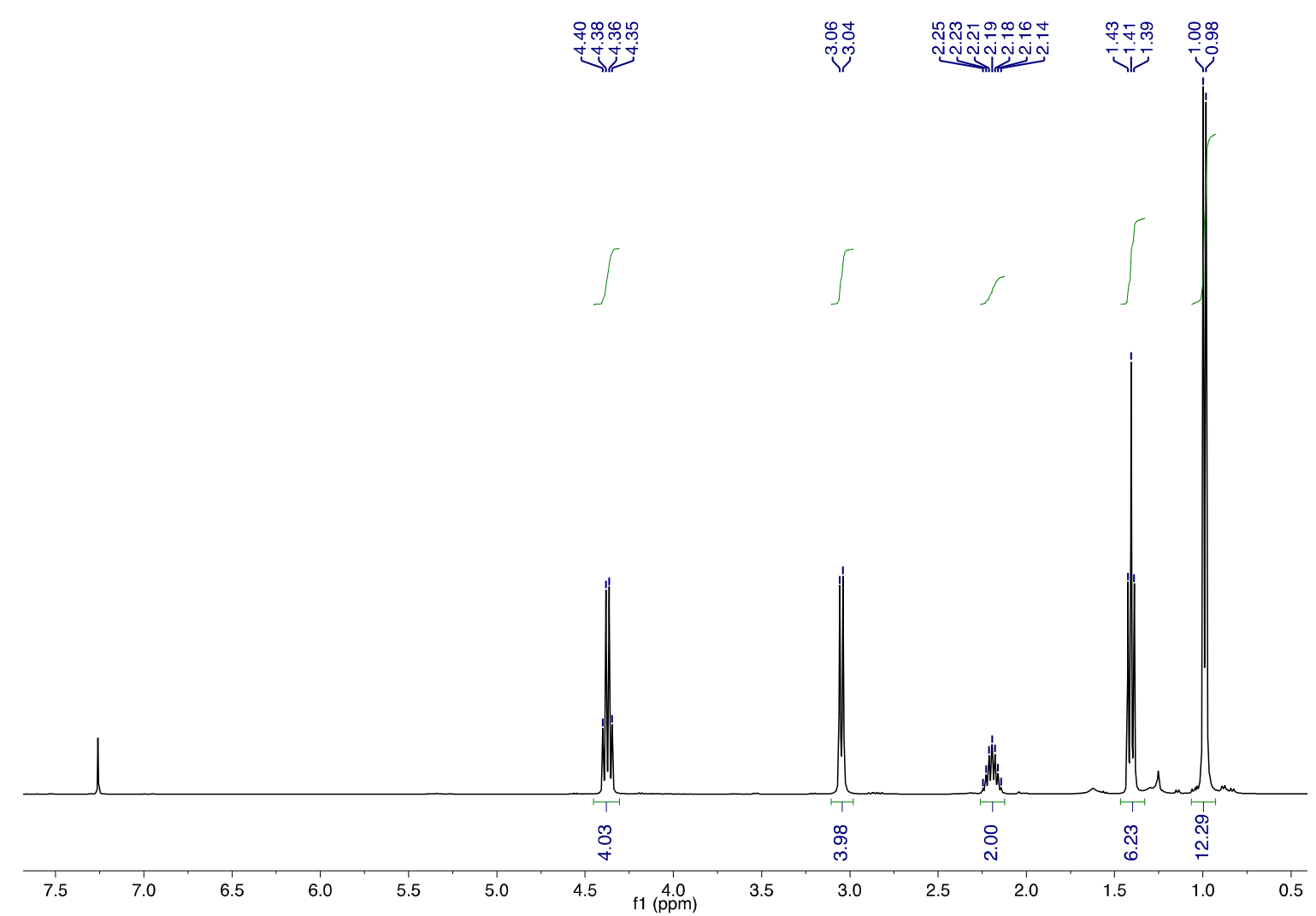

Figure S17. ${ }^{1} \mathrm{H}$ NMR spectrum of 15 in $\mathrm{CDCl}_{3}$.

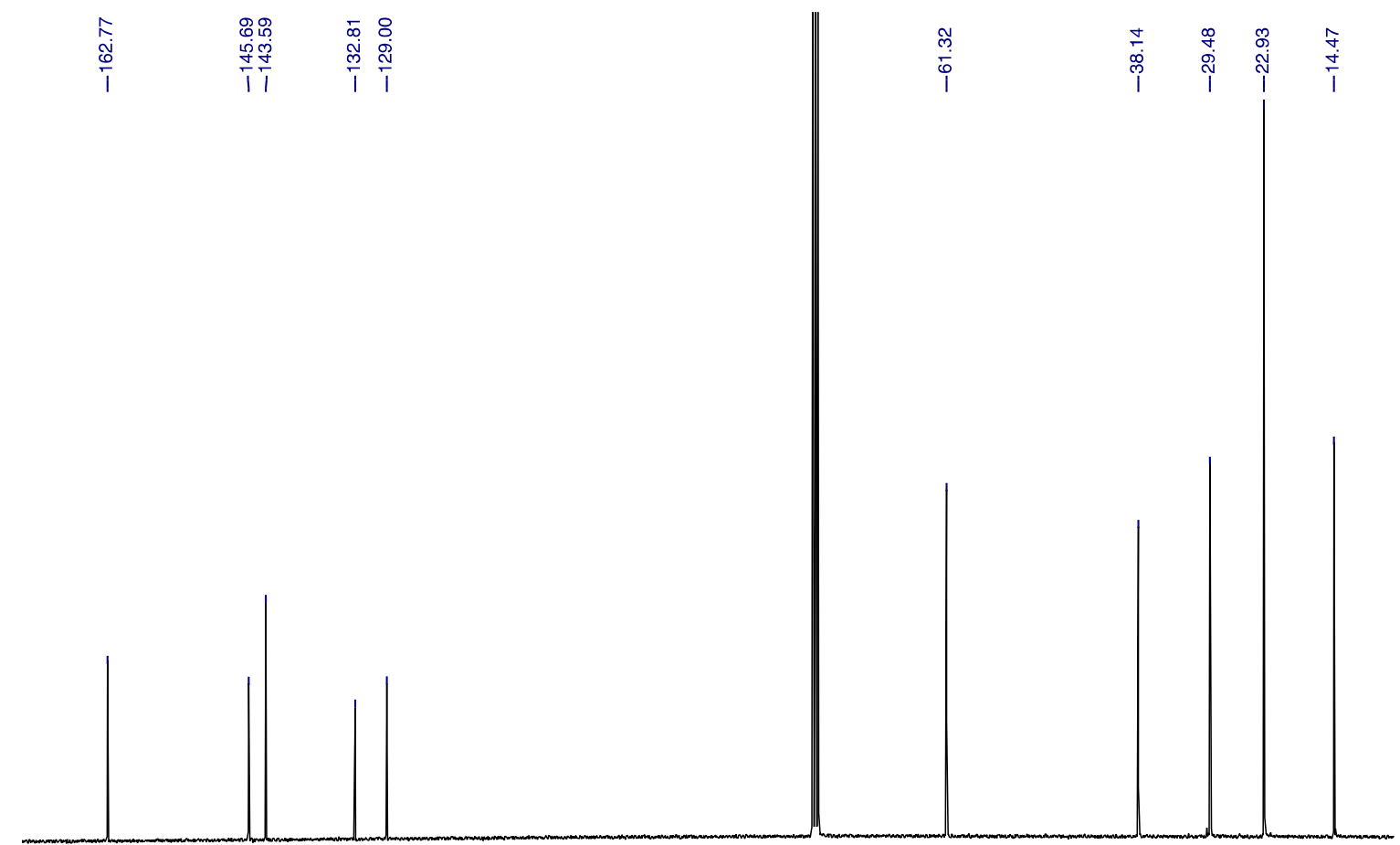

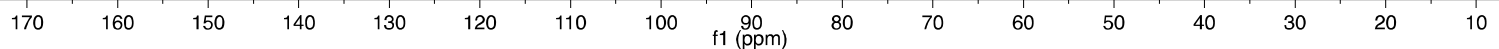

Figure S18. ${ }^{13} \mathrm{C}$ NMR spectrum of 15 in $\mathrm{CDCl}_{3}$. 


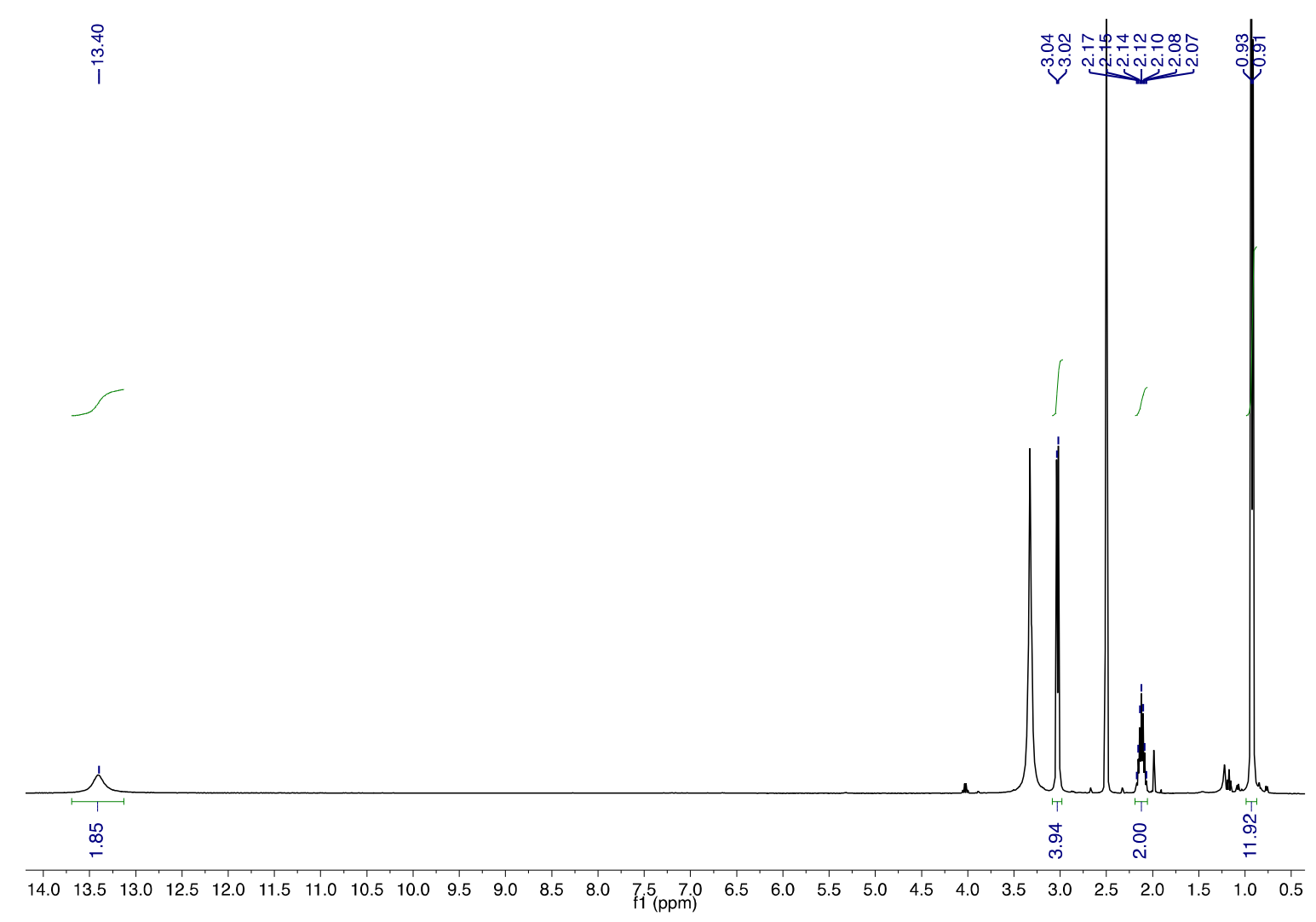

Figure S19. ${ }^{1} \mathrm{H}$ NMR spectrum of 17 in DMSO- $d_{6}$.

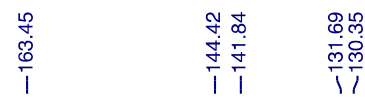

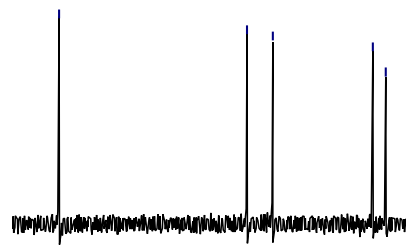

$\begin{array}{lllllllllllllllllllllllllllllllllllll}165 & 160 & 155 & 150 & 145 & 140 & 135 & 130 & 125 & 120 & 115 & 110 & 105 & 100 & \begin{array}{c}95 \\ \mathrm{f1}\end{array}(\mathrm{ppm}) & 85 & 80 & 75 & 70 & 65 & 60 & 55 & 50 & 45 & 40 & 35 & 30 & 25 & 20\end{array}$

Figure S20. ${ }^{13} \mathrm{C}$ NMR spectrum of $\mathbf{1 7}$ in DMSO- $d_{6}$. 

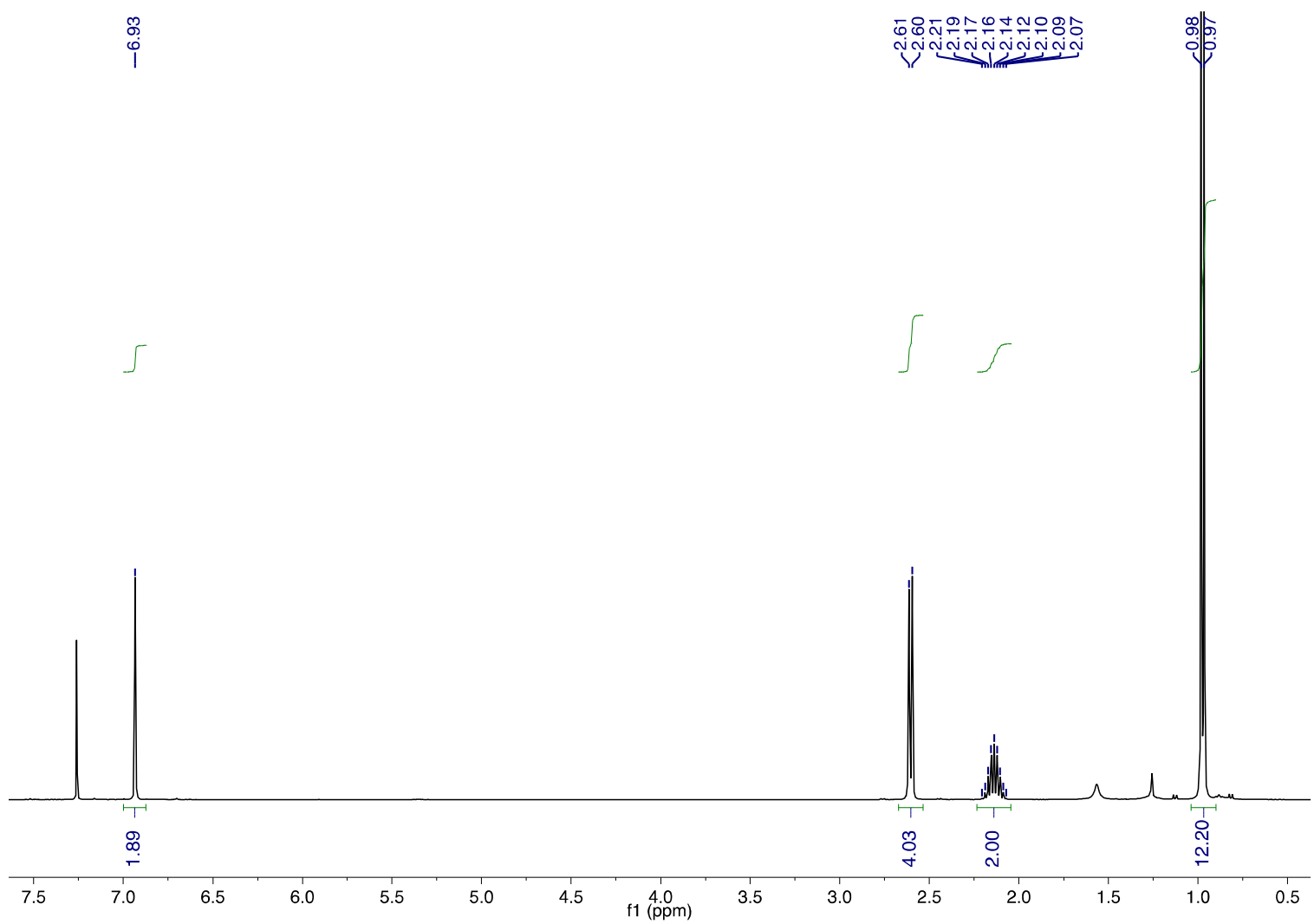

Figure S21. ${ }^{1} \mathrm{H}$ NMR spectrum of $\mathbf{1}$ in $\mathrm{CDCl}_{3}$.

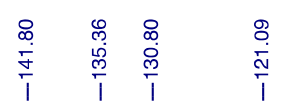
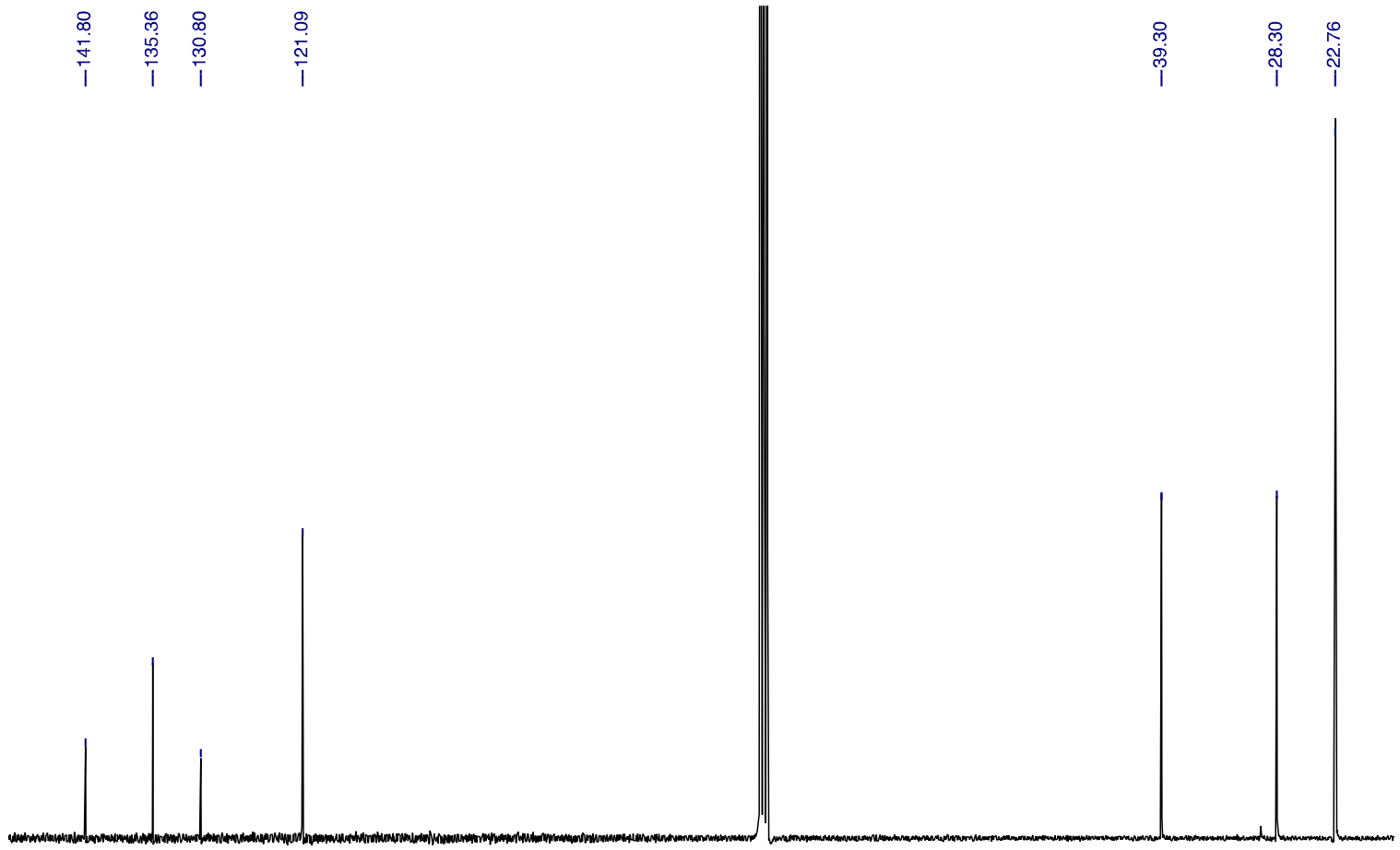

$\begin{array}{llllllllllllllllllllllllllll}145 & 140 & 135 & 130 & 125 & 120 & 115 & 110 & 105 & 100 & 95 & 90 & 85 & 80 & 75 & 70 & 65 & 60 & 55 & 50 & 45 & 40 & 35 & 30 & 25 & 20\end{array}$

Figure S22. ${ }^{13} \mathrm{C}$ NMR spectrum of 1 in $\mathrm{CDCl}_{3}$. 


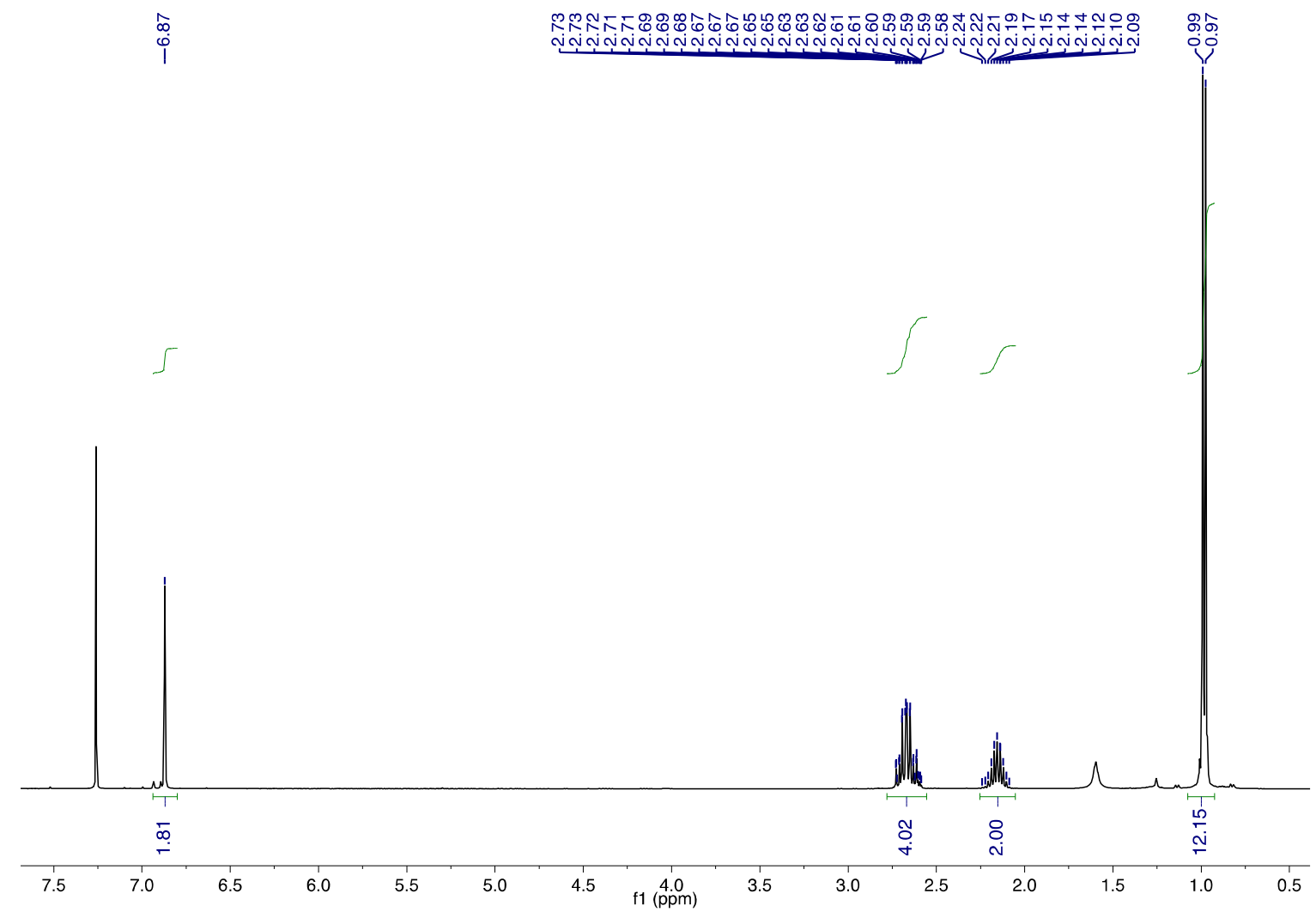

Figure S23. ${ }^{1} \mathrm{H}$ NMR spectrum of 3 in $\mathrm{CDCl}_{3}$.
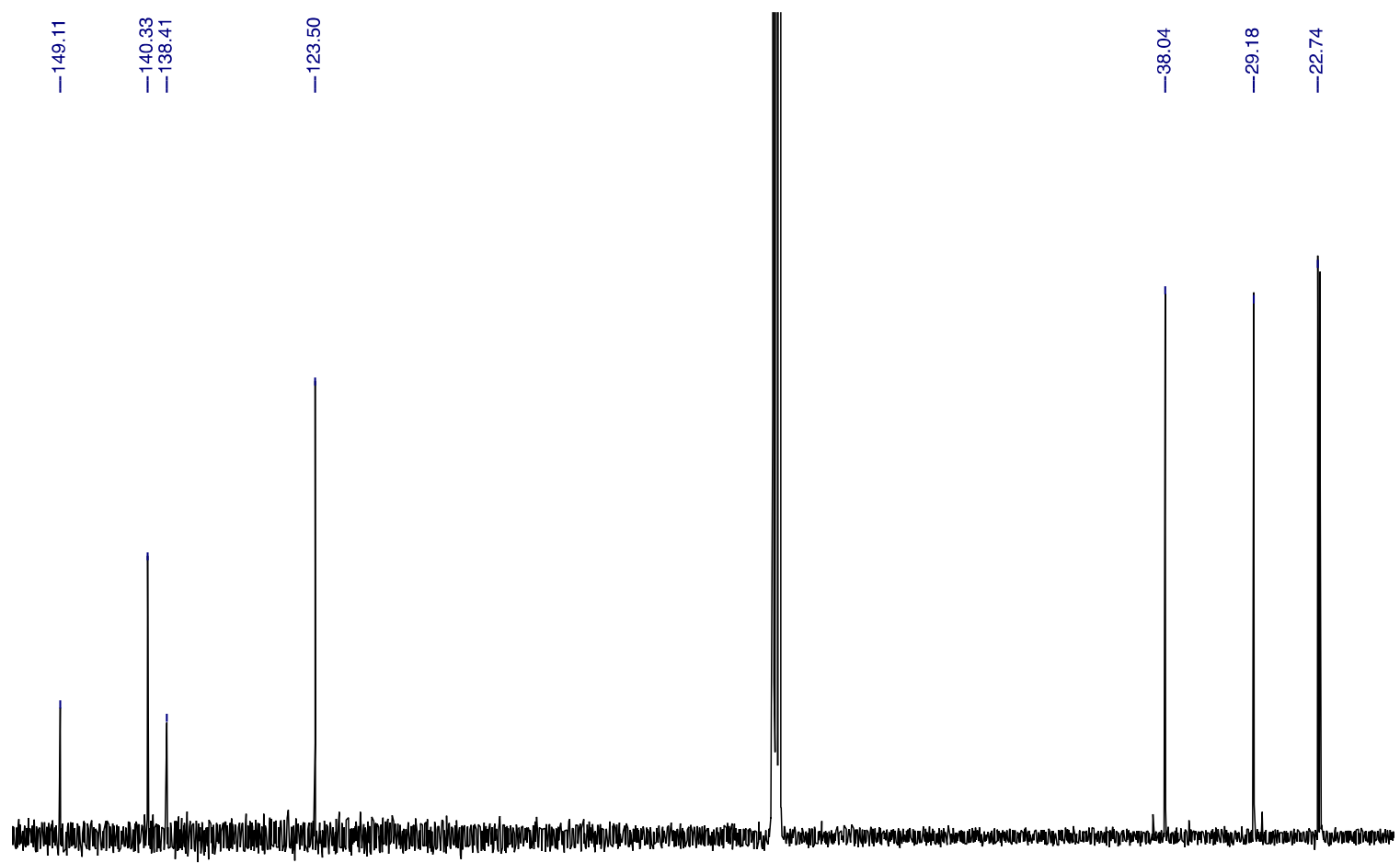

$\begin{array}{lllllllllllllllllllllllllllllll}150 & 145 & 140 & 135 & 130 & 125 & 120 & 115 & 110 & 105 & 100 & 95 & 90 & 85 & 80 & 75 & 70 & 65 & 60 & 55 & 50 & 45 & 40 & 35 & 30 & 25 & 20\end{array}$

Figure S24. ${ }^{13} \mathrm{C}$ NMR spectrum of 3 in $\mathrm{CDCl}_{3}$. 


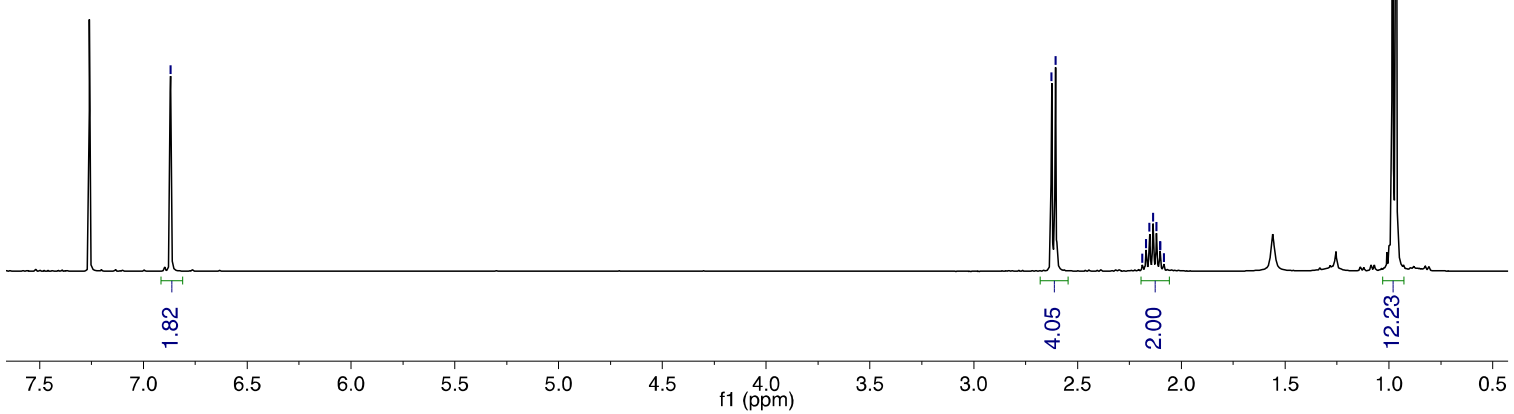

Figure S25. ${ }^{1} \mathrm{H}$ NMR spectrum of 5 in $\mathrm{CDCl}_{3}$.

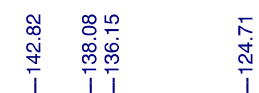
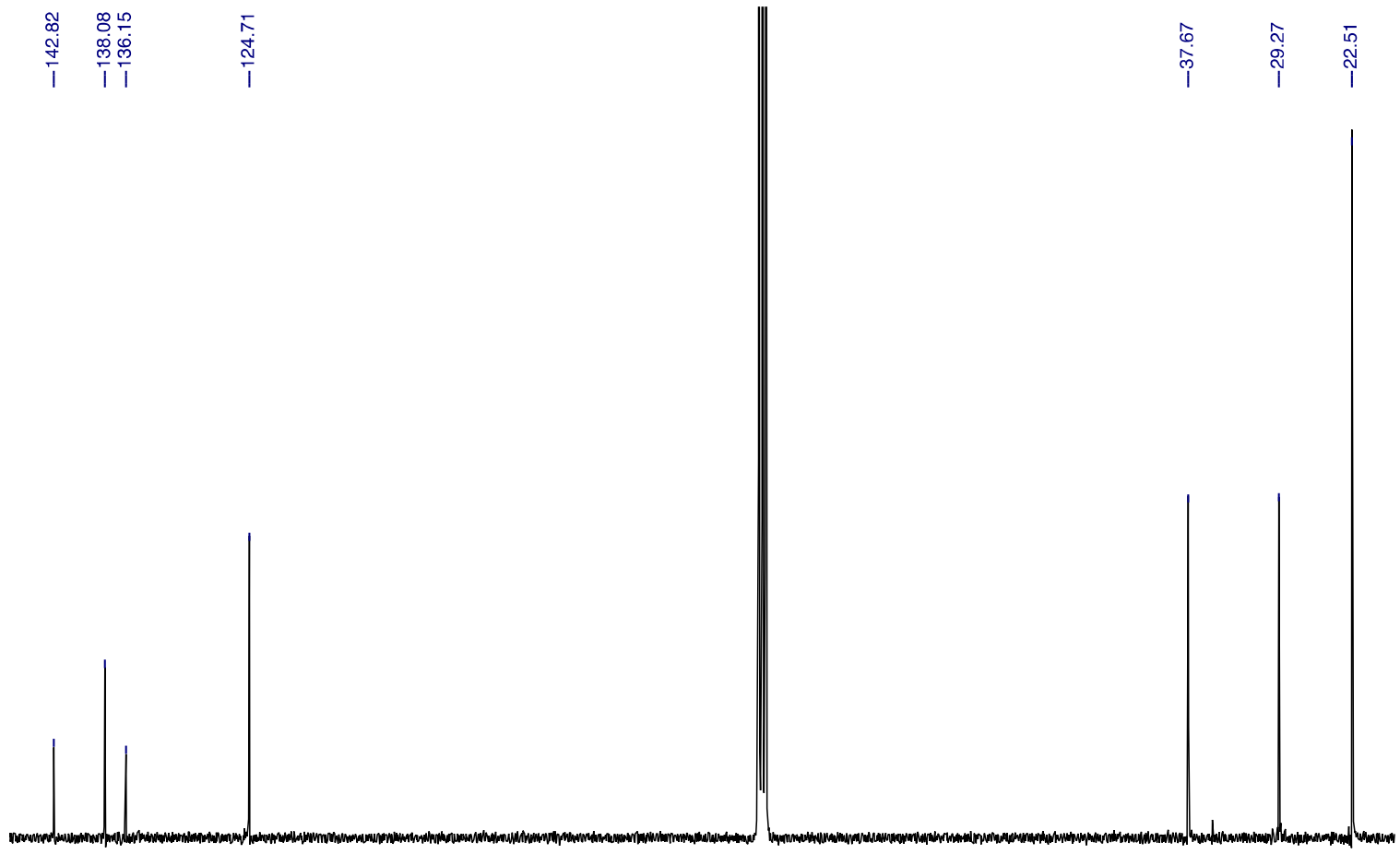

$\begin{array}{lllllllllllll}145 & 140 & 135 & 130 & 125 & 120 & 115 & 110 & 105 & 100 & 95 & 90 & 85\end{array}$

Figure S26. ${ }^{13} \mathrm{C}$ NMR spectrum of 5 in $\mathrm{CDCl}_{3}$. 


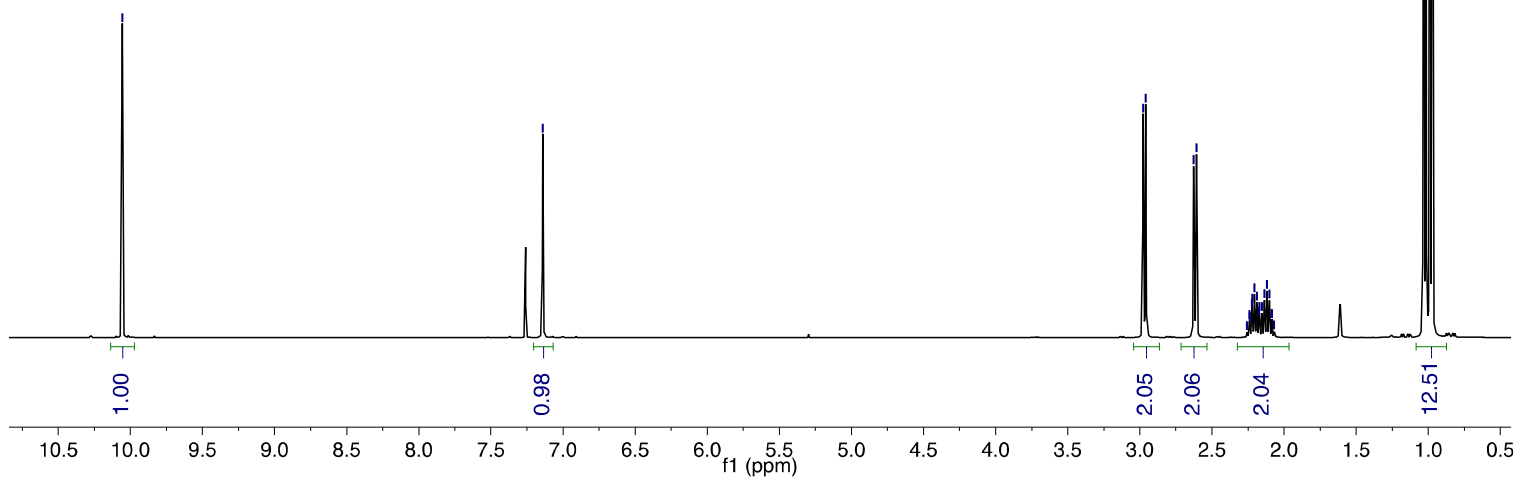

Figure S27. ${ }^{1} \mathrm{H}$ NMR spectrum of 20 in $\mathrm{CDCl}_{3}$.

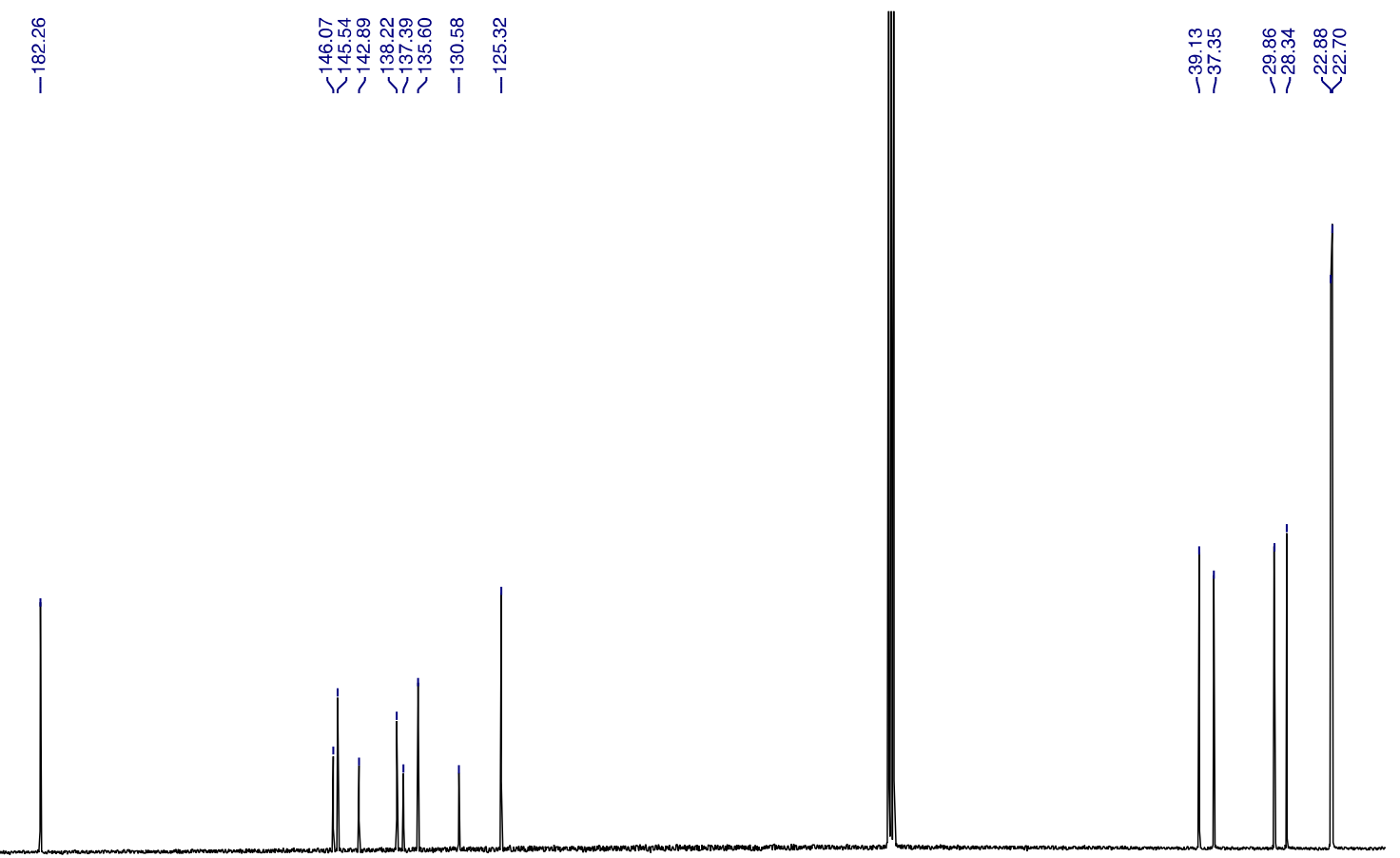

$\begin{array}{llllllll}180 & 170 & 160 & 150 & 140 & 130 & 120 & 110\end{array}$

$80 \quad 70 \quad 60$

50

$40 \quad 30 \quad 20$

Figure S28. ${ }^{13} \mathrm{C}$ NMR spectrum of $\mathbf{2 0}$ in $\mathrm{CDCl}_{3}$. 


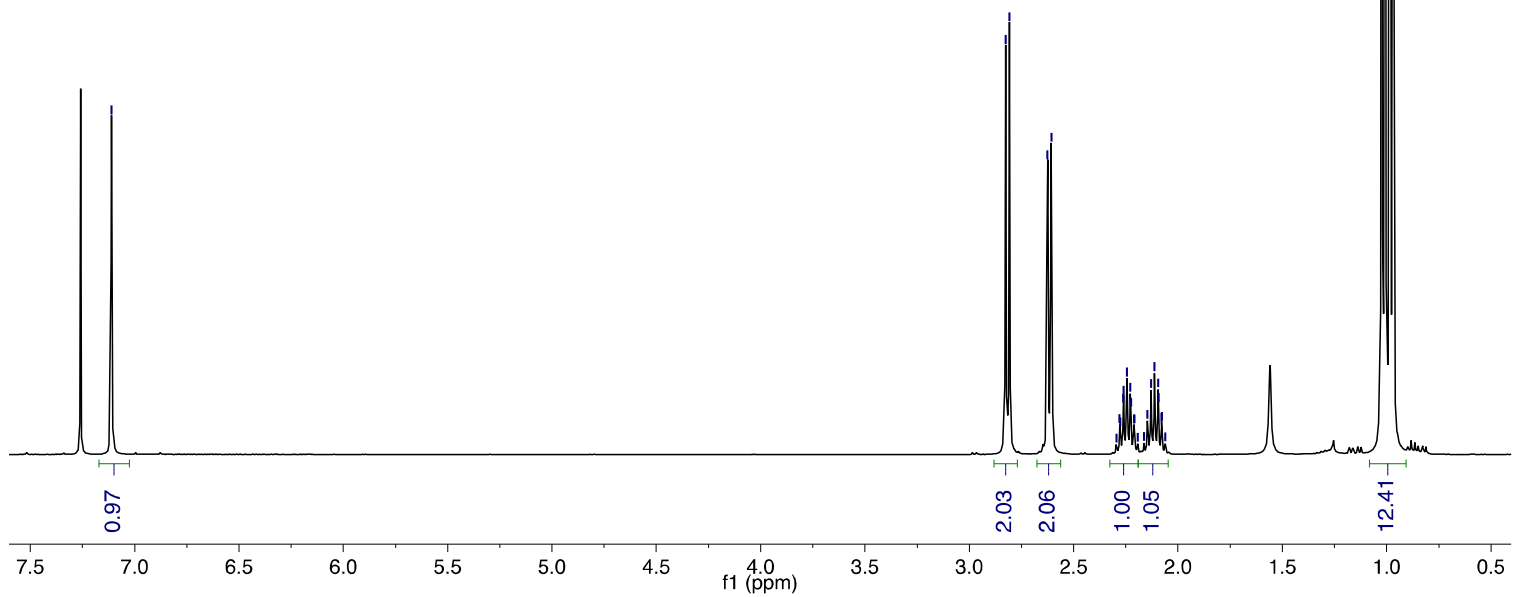

Figure S29. ${ }^{1} \mathrm{H}$ NMR spectrum of 21 in $\mathrm{CDCl}_{3}$.

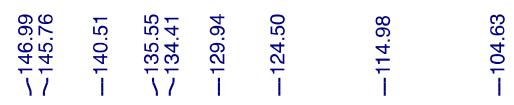
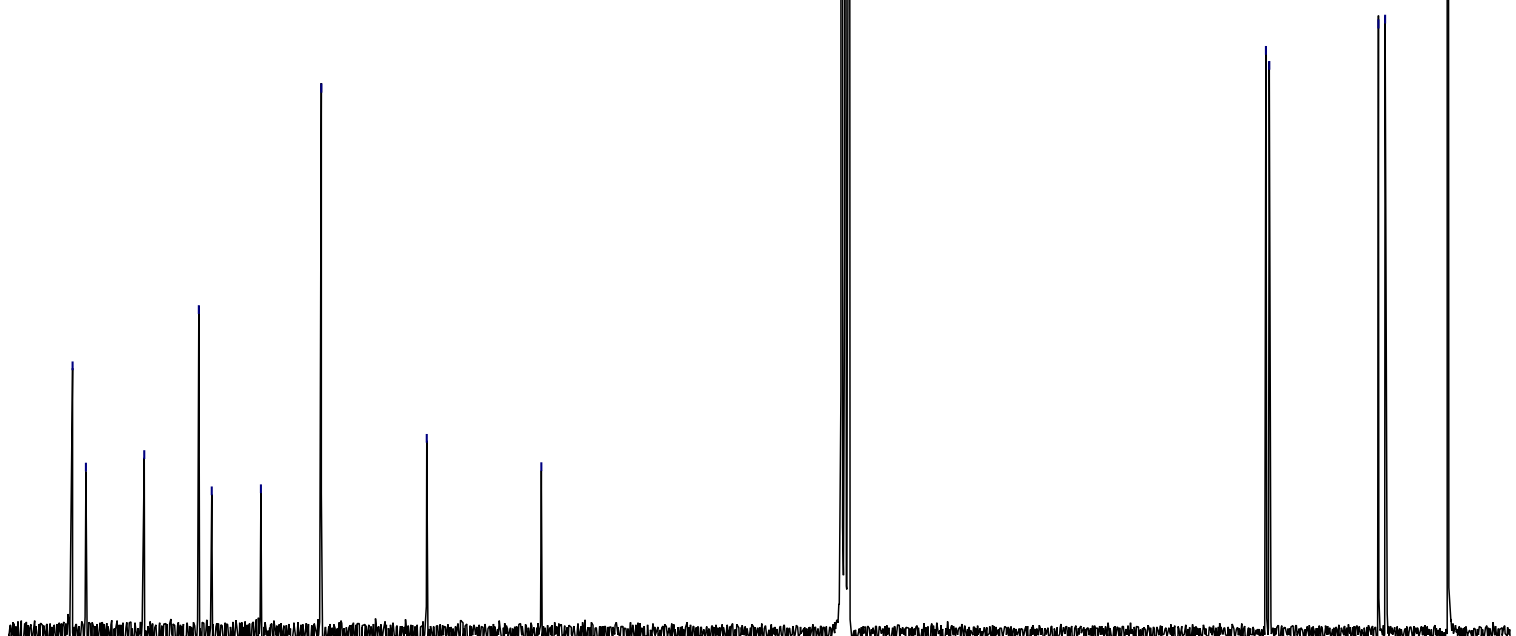

$\begin{array}{lllllllllllll}150 & 145 & 140 & 135 & 130 & 125 & 120 & 115 & 110 & 105 & 100 & 95 & 90 \\ \mathrm{f} 1(\mathrm{ppm}) & 80\end{array}$

Figure S30. ${ }^{13} \mathrm{C}$ NMR spectrum of 21 in $\mathrm{CDCl}_{3}$. 


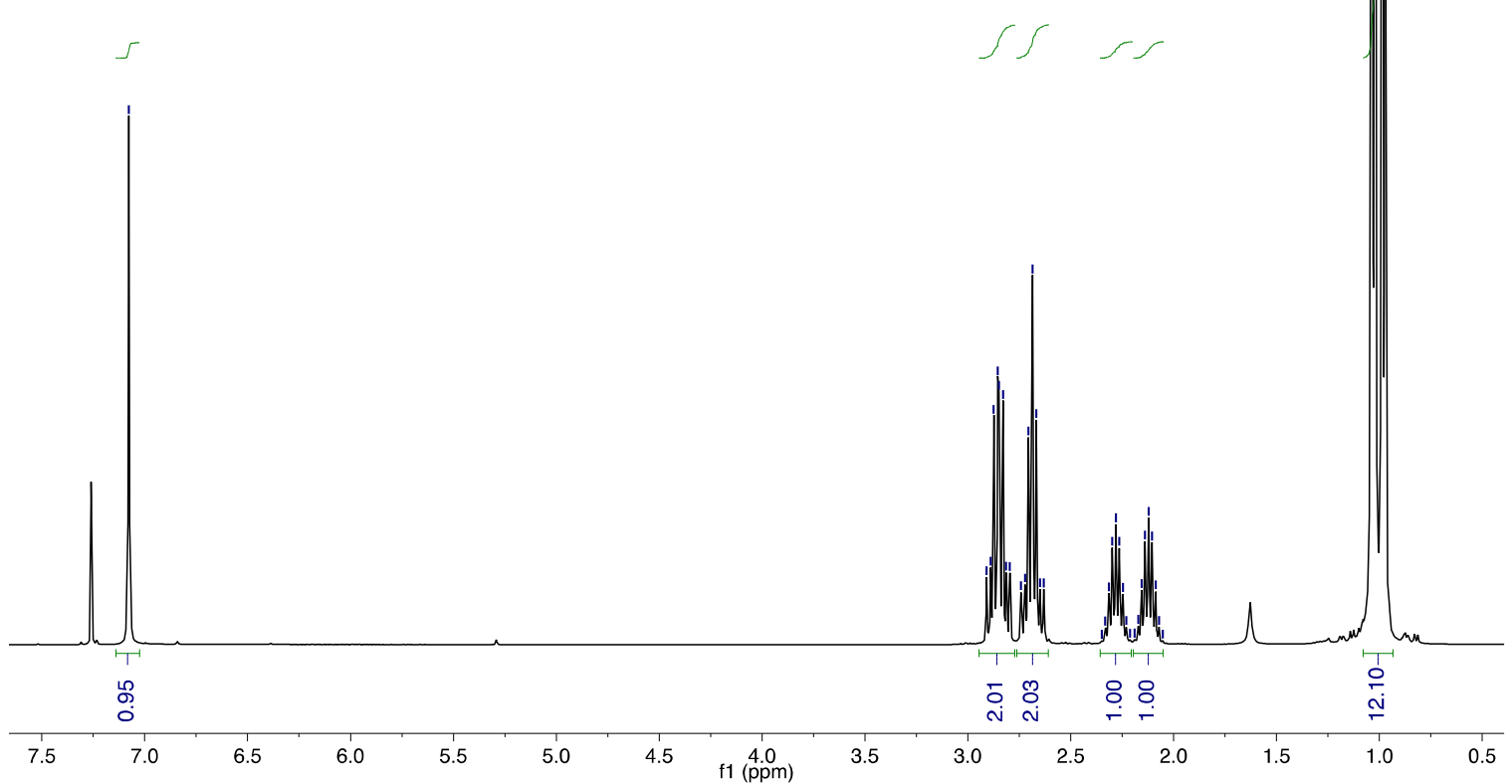

Figure S31. ${ }^{1} \mathrm{H}$ NMR spectrum of 4 in $\mathrm{CDCl}_{3}$.

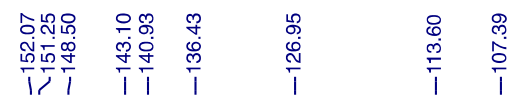

Figure S32. ${ }^{13} \mathrm{C}$ NMR spectrum of 4 in $\mathrm{CDCl}_{3}$. 


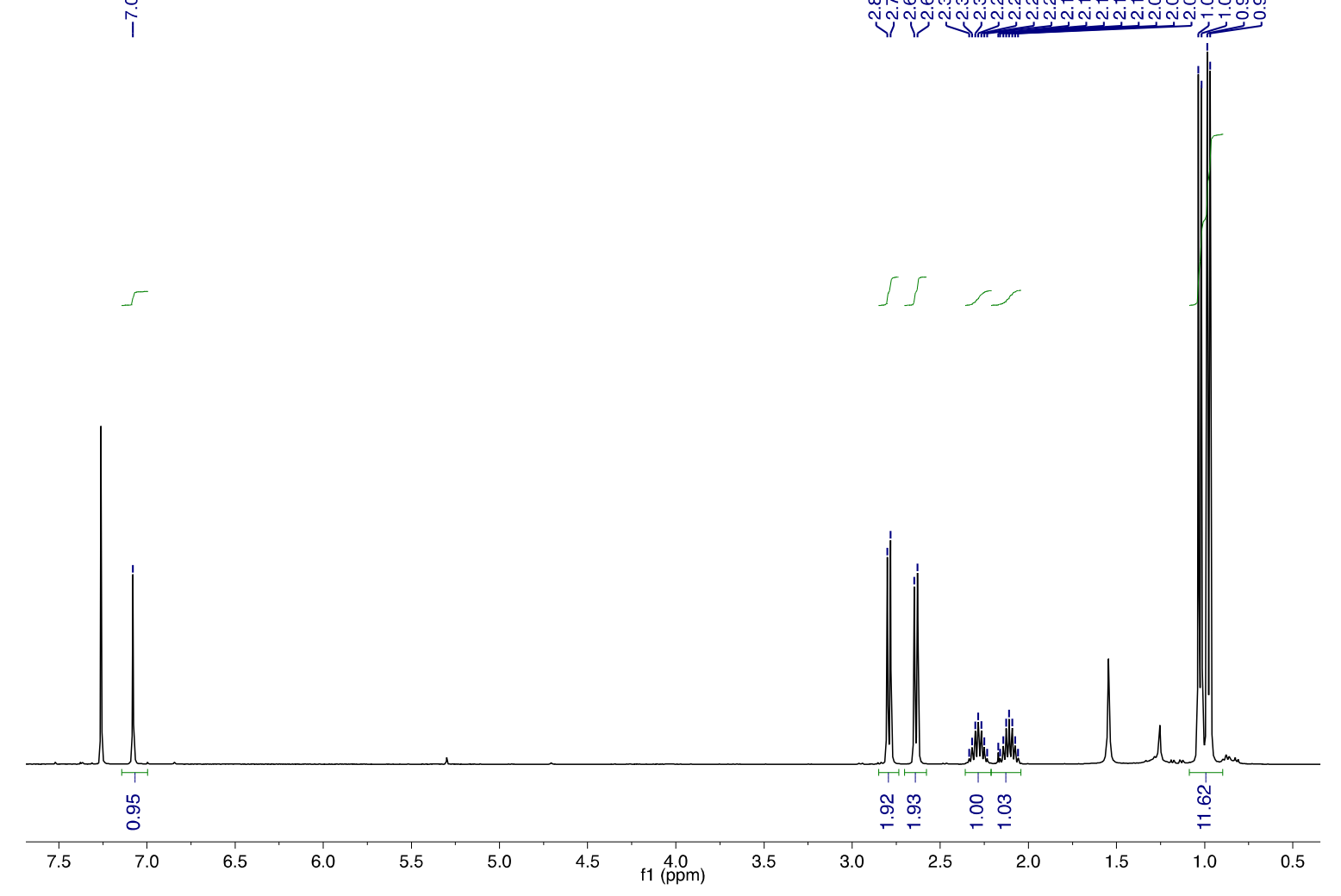

Figure S33. ${ }^{1} \mathrm{H}$ NMR spectrum of 6 in $\mathrm{CDCl}_{3}$.

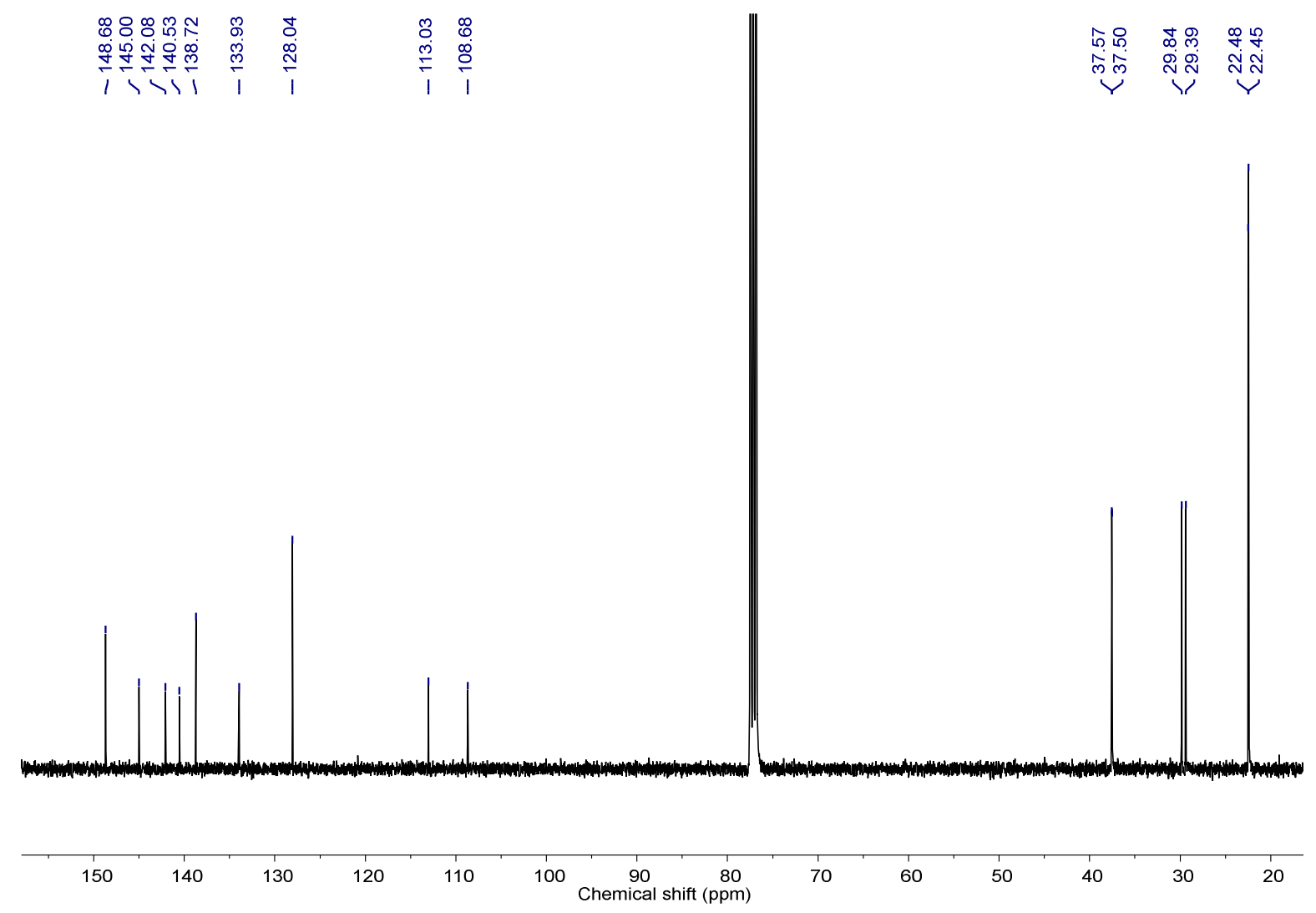

Figure S34. ${ }^{13} \mathrm{C}$ NMR spectrum of 6 in $\mathrm{CDCl}_{3}$. 


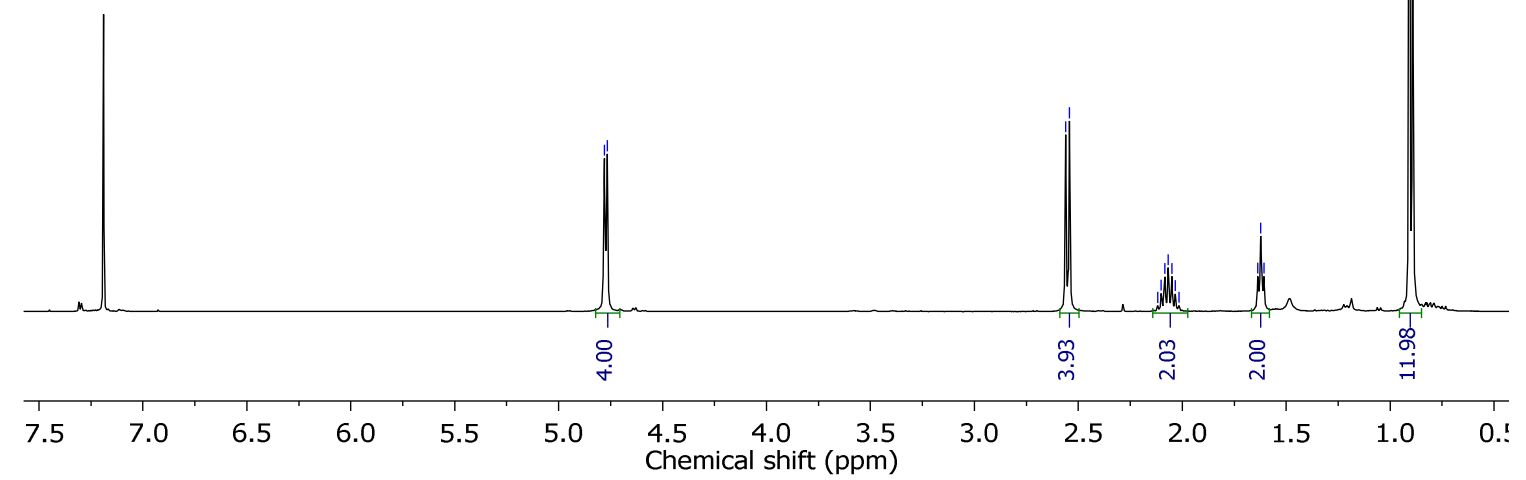

Figure S35. ${ }^{1} \mathrm{H}$ NMR spectrum of 18 in $\mathrm{CDCl}_{3}$.

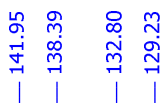
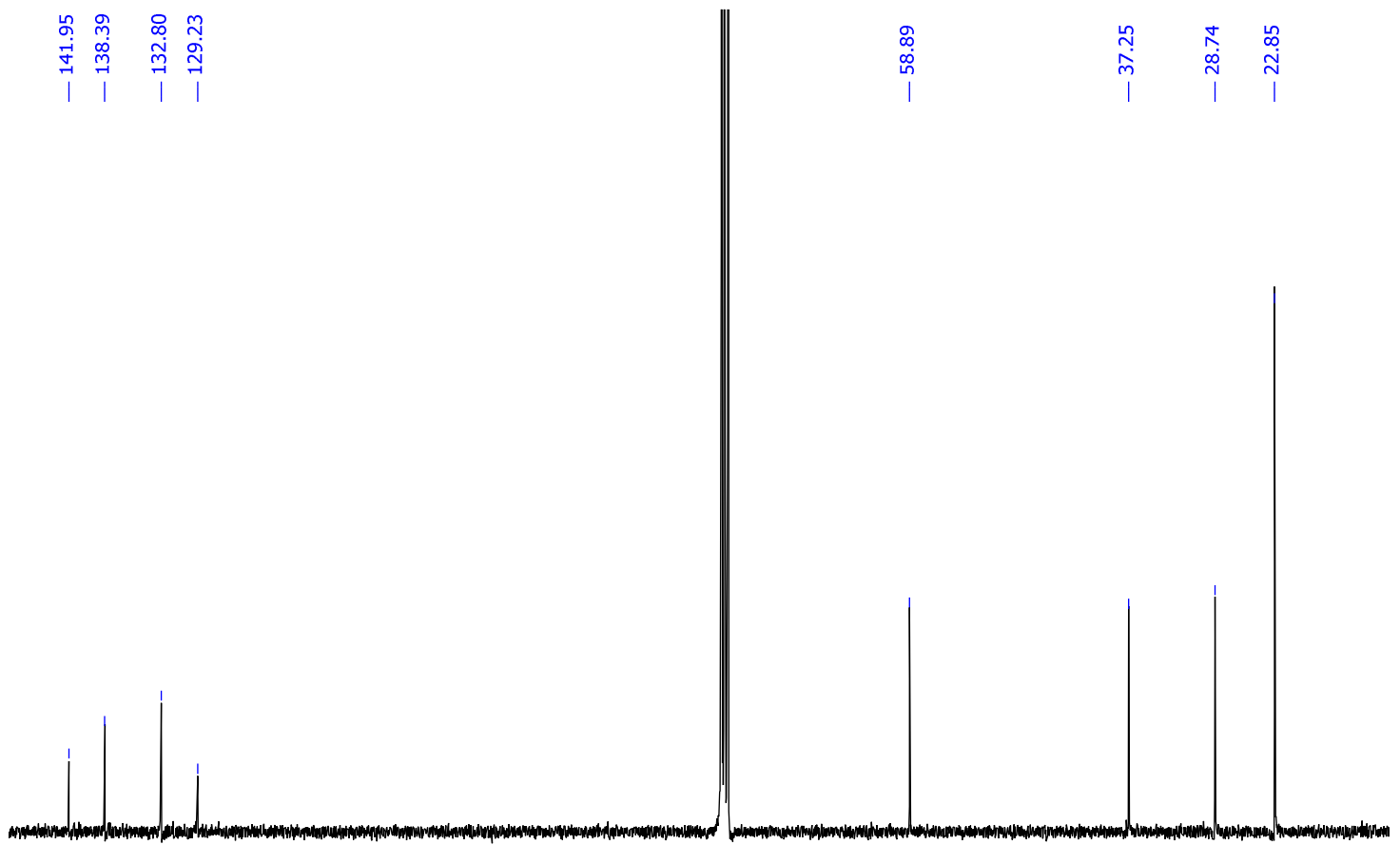

140130

$120-110$

$\begin{array}{lr}90 \quad 80 & 70 \\ \text { Chemical shift } & (\mathrm{ppm})\end{array}$

60

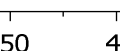

4030

Figure S36. ${ }^{13} \mathrm{C}$ NMR spectrum of 18 in $\mathrm{CDCl}_{3}$. 


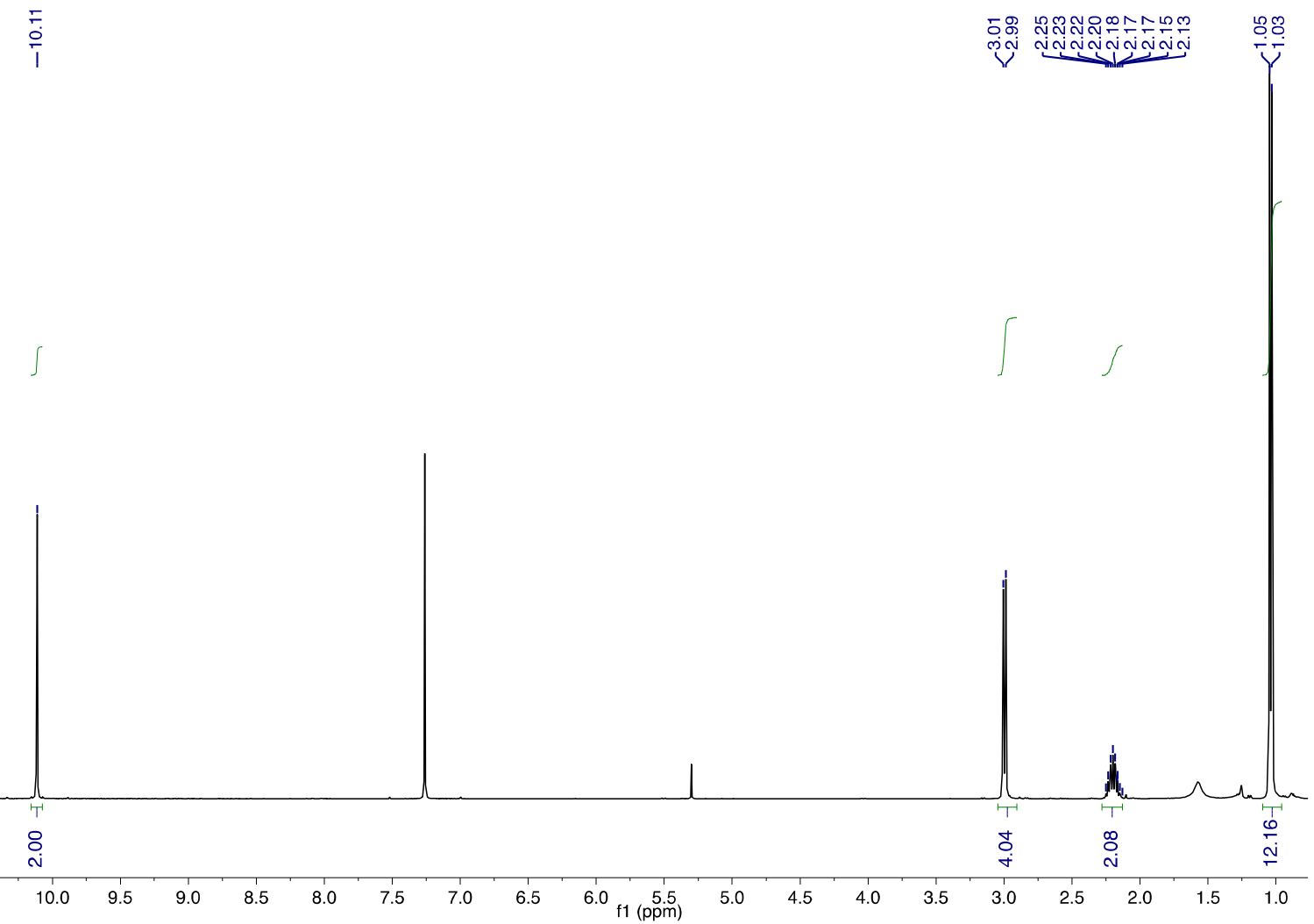

Figure S37. ${ }^{1} \mathrm{H}$ NMR spectrum of 2 in $\mathrm{CDCl}_{3}$.

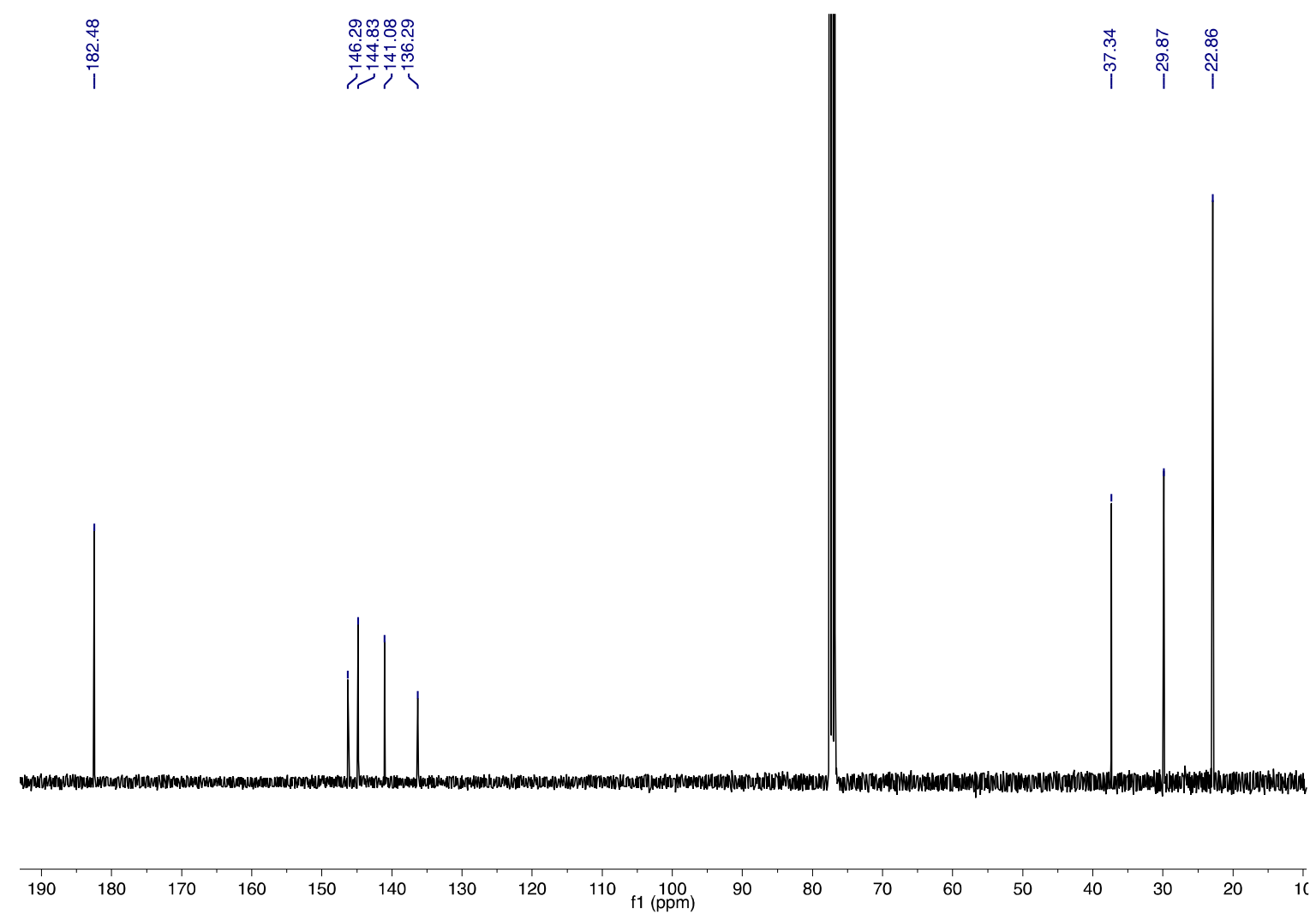

Figure S38. ${ }^{13} \mathrm{C}$ NMR spectrum of 2 in $\mathrm{CDCl}_{3}$. 


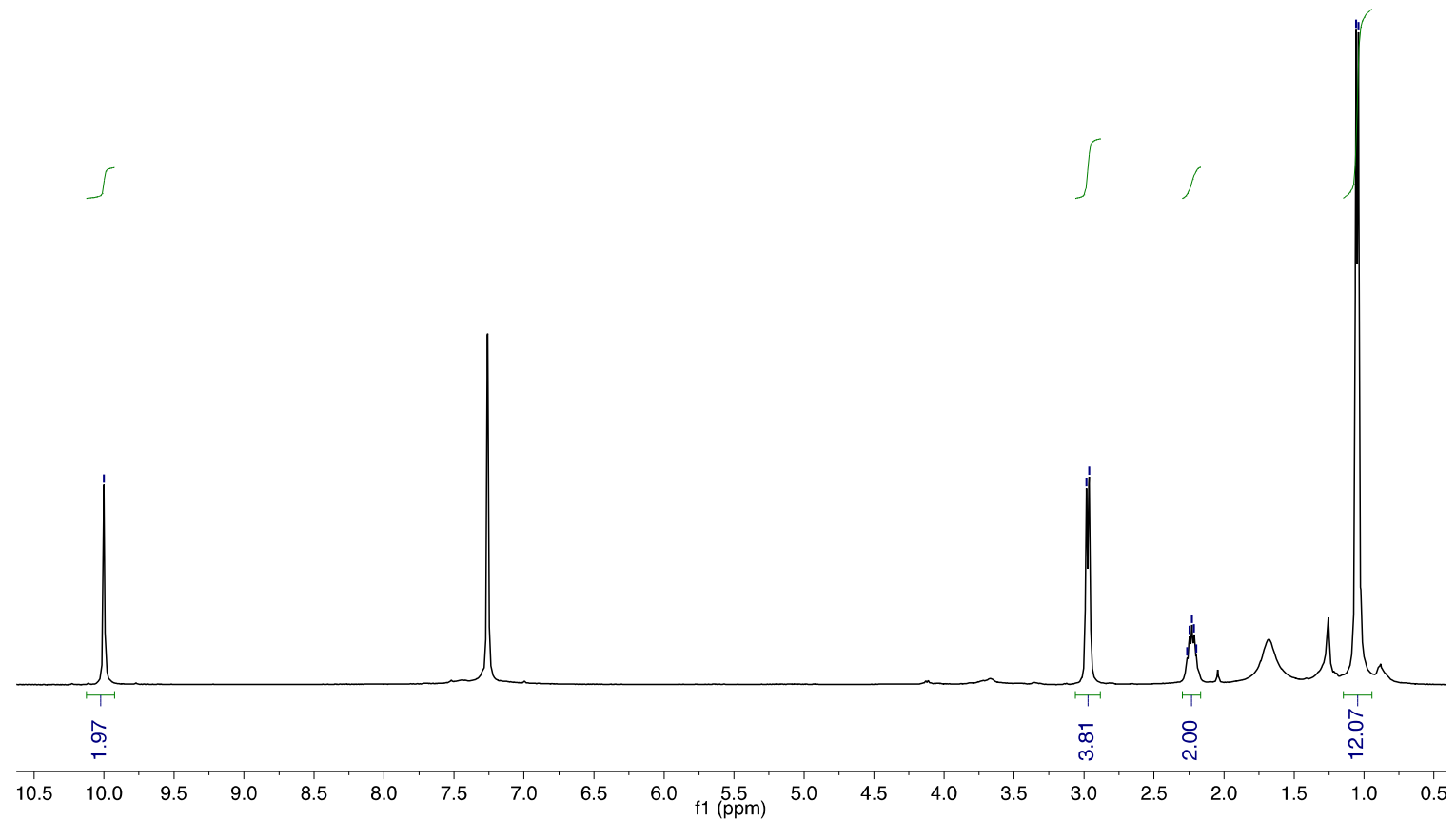

Figure S39. ${ }^{1} \mathrm{H}$ NMR spectrum of 8 in $\mathrm{CDCl}_{3}$.

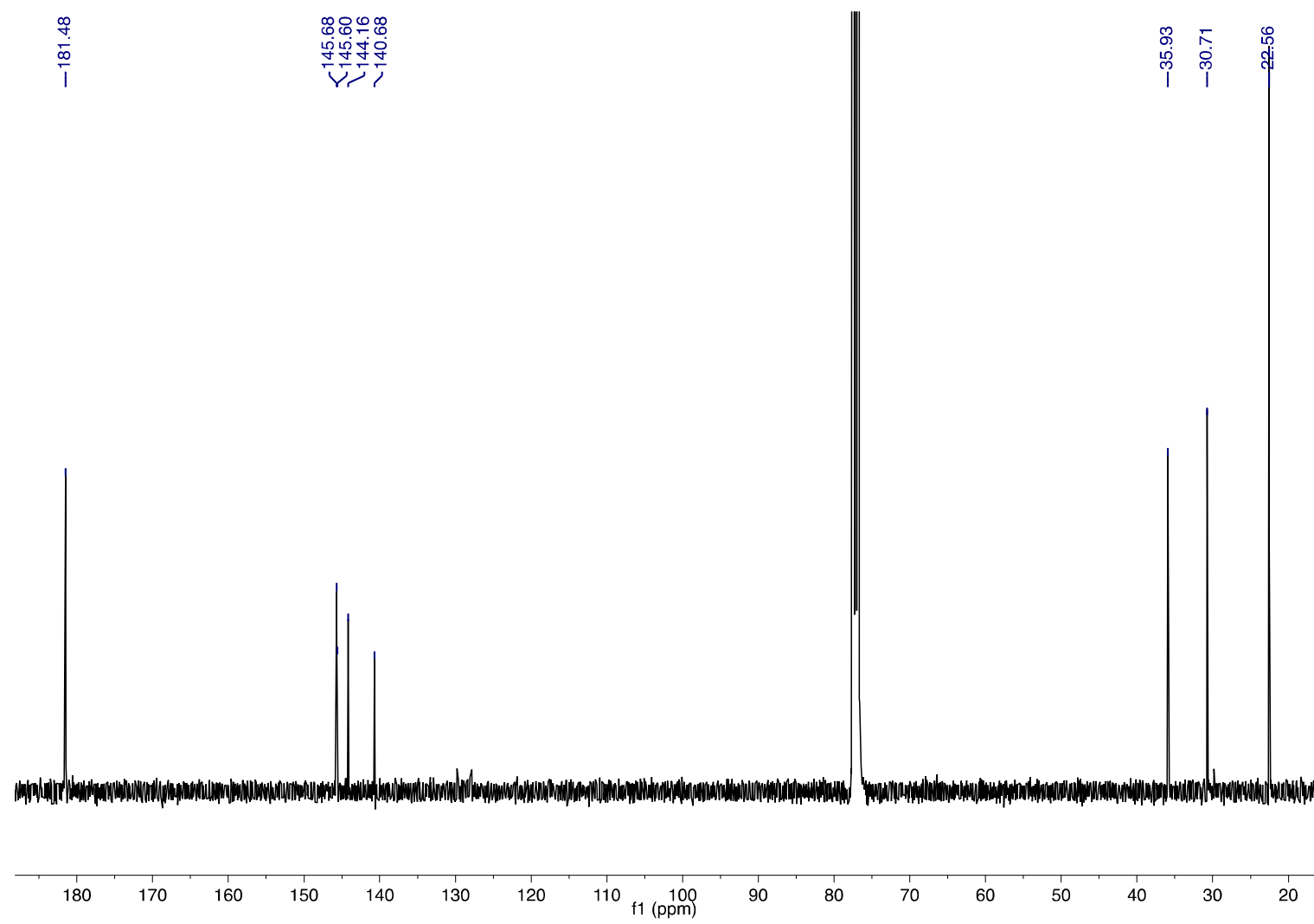

Figure S40. ${ }^{13} \mathrm{C}$ NMR spectrum of 8 in $\mathrm{CDCl}_{3}$. 


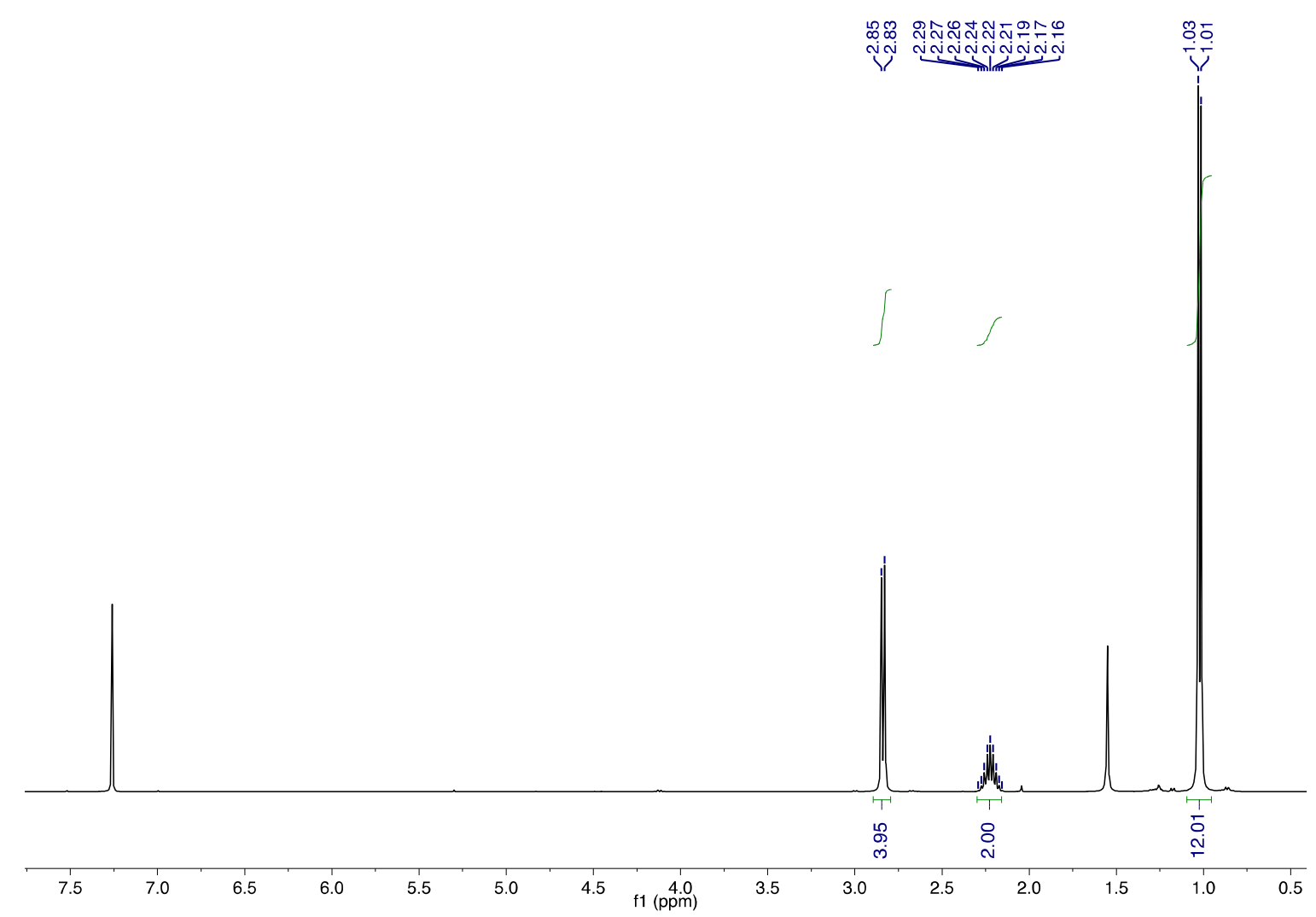

Figure S41. ${ }^{1} \mathrm{H}$ NMR spectrum of 19 in $\mathrm{CDCl}_{3}$.

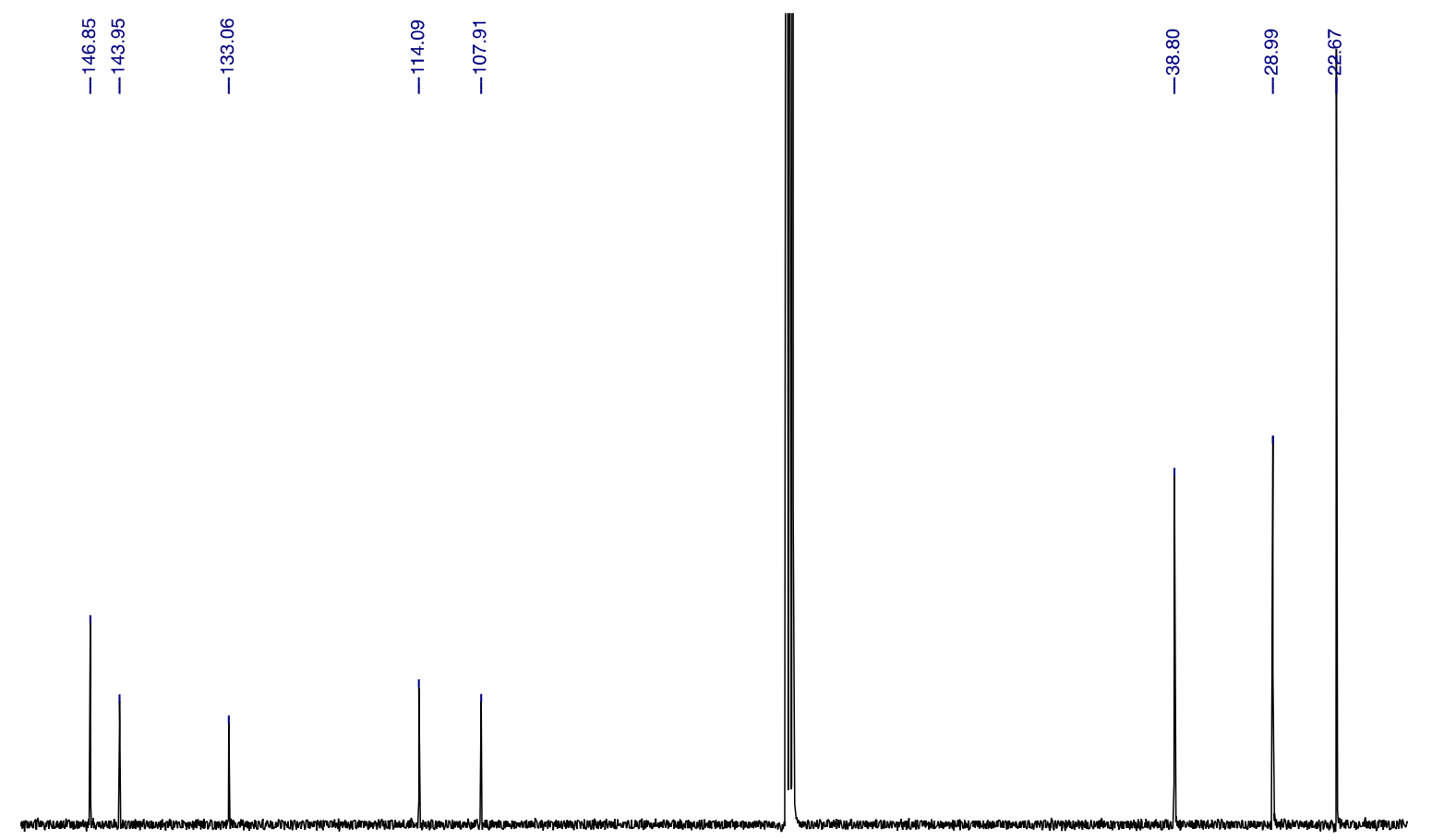

$\begin{array}{lllllllllllllllllllllllllllllllllllllll}150 & 145 & 140 & 135 & 130 & 125 & 120 & 115 & 110 & 105 & 100 & 95 & 90 & 85 & 80 & 75 & 70 & 65 & 60 & 55 & 50 & 45 & 40 & 35 & 30 & 25 & 20\end{array}$

Figure S42. ${ }^{13} \mathrm{C}$ NMR spectrum of 19 in $\mathrm{CDCl}_{3}$. 


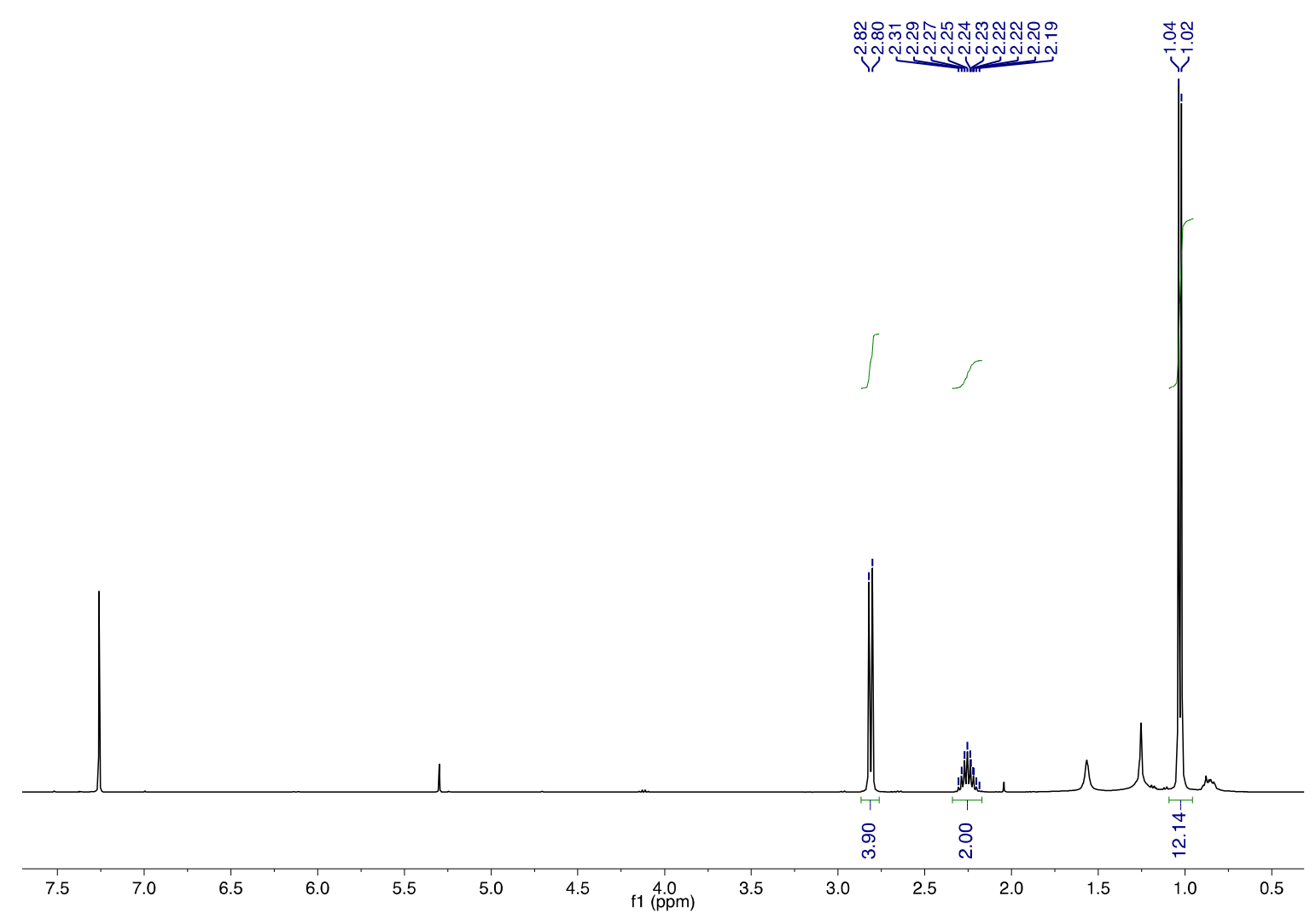

Figure S43. ${ }^{1} \mathrm{H}$ NMR spectrum of 7 in $\mathrm{CDCl}_{3}$.

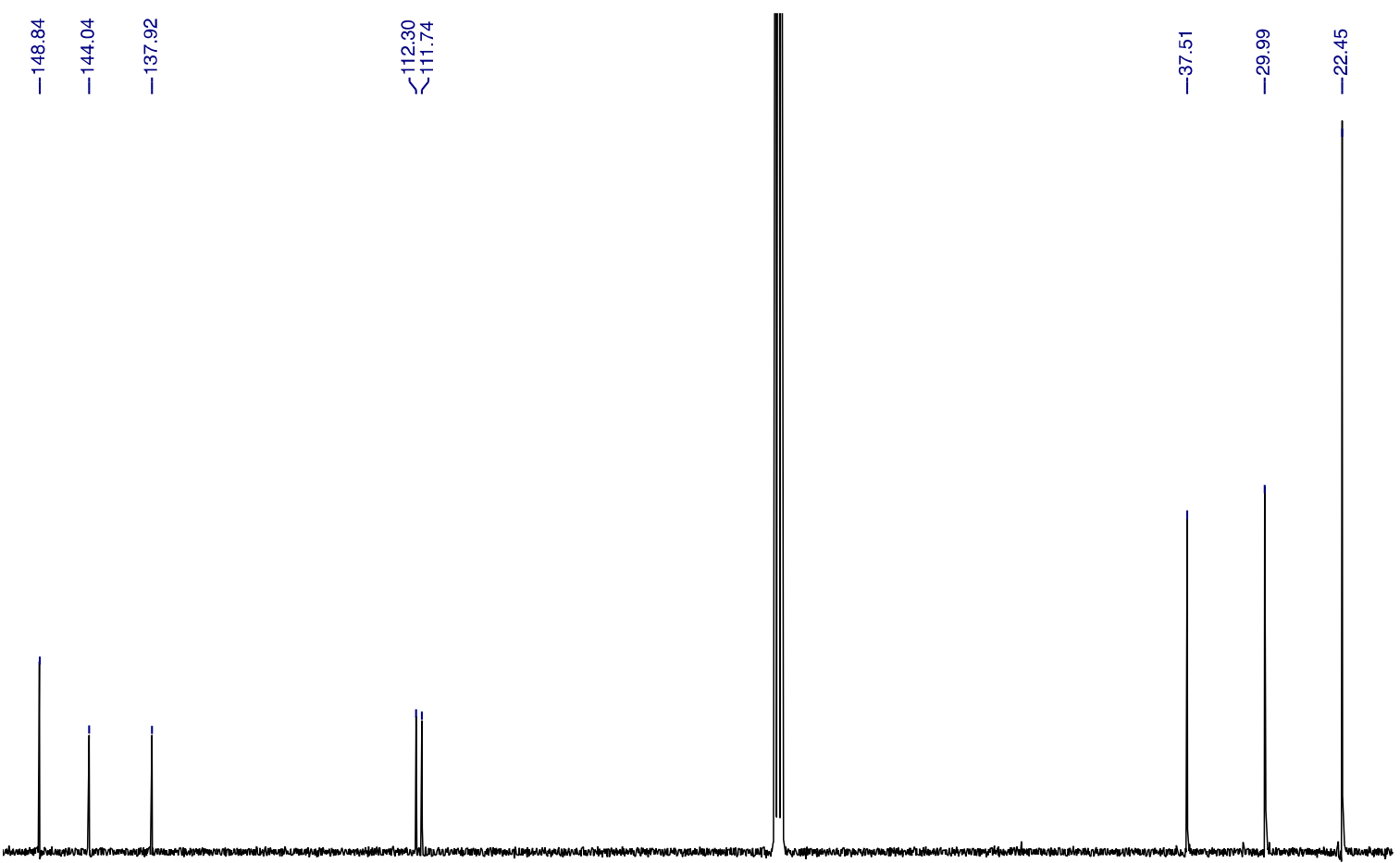

$\begin{array}{llllllllllllllllllllllllllllllll}150 & 145 & 140 & 135 & 130 & 125 & 120 & 115 & 110 & 105 & 100 & 95 & 90 & \begin{array}{c}85 \\ \mathrm{fpm})\end{array} & 80 & 75 & 70 & 65 & 60 & 55 & 50 & 45 & 40 & 35 & 30 & 25 & 20\end{array}$

Figure S44. ${ }^{13} \mathrm{C}$ NMR spectrum of 7 in $\mathrm{CDCl}_{3}$. 


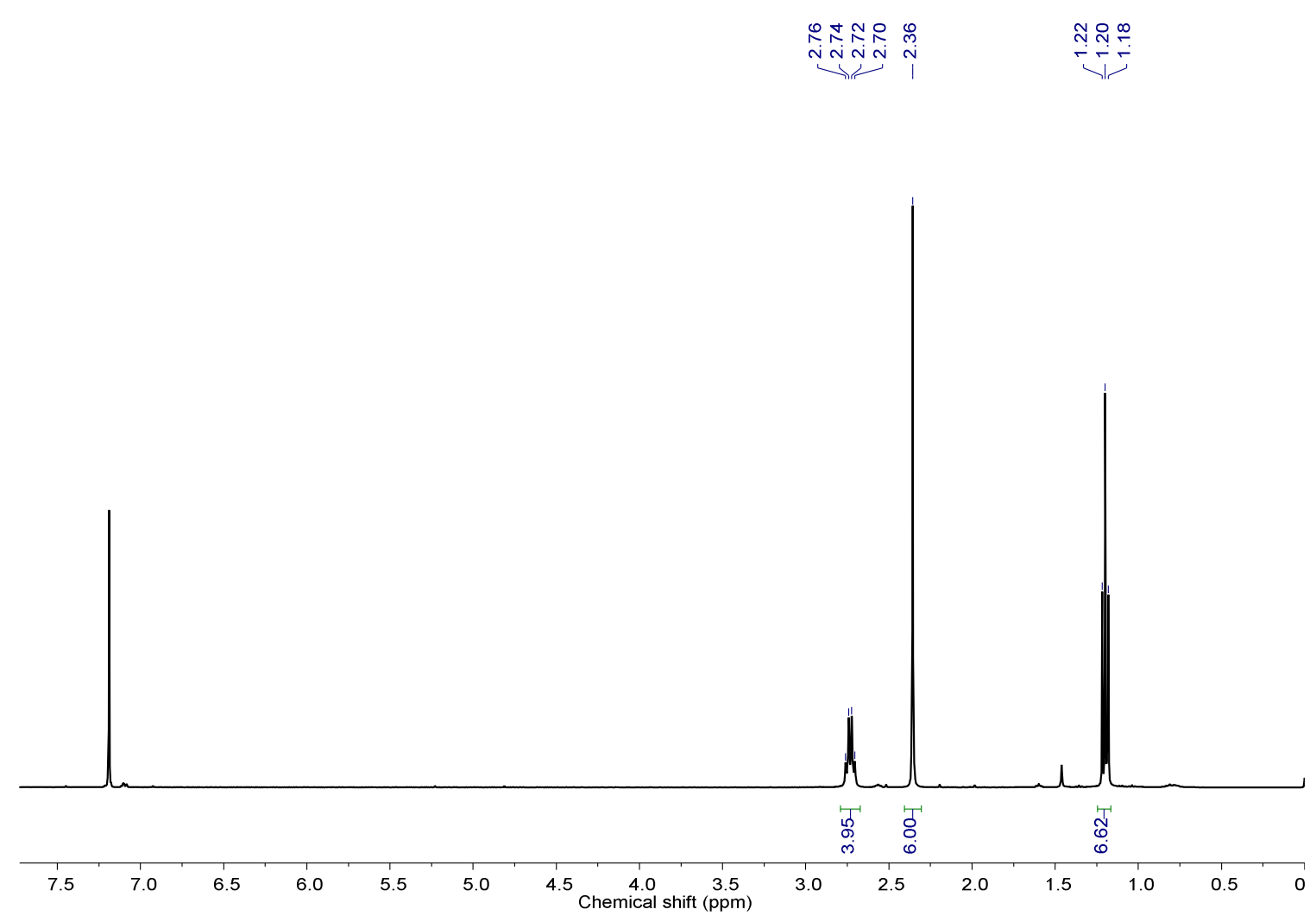

Figure $\mathbf{5 4 5} .{ }^{1} \mathrm{H} \mathrm{NMR}$ spectrum of 23 in $\mathrm{CDCl}_{3}$.

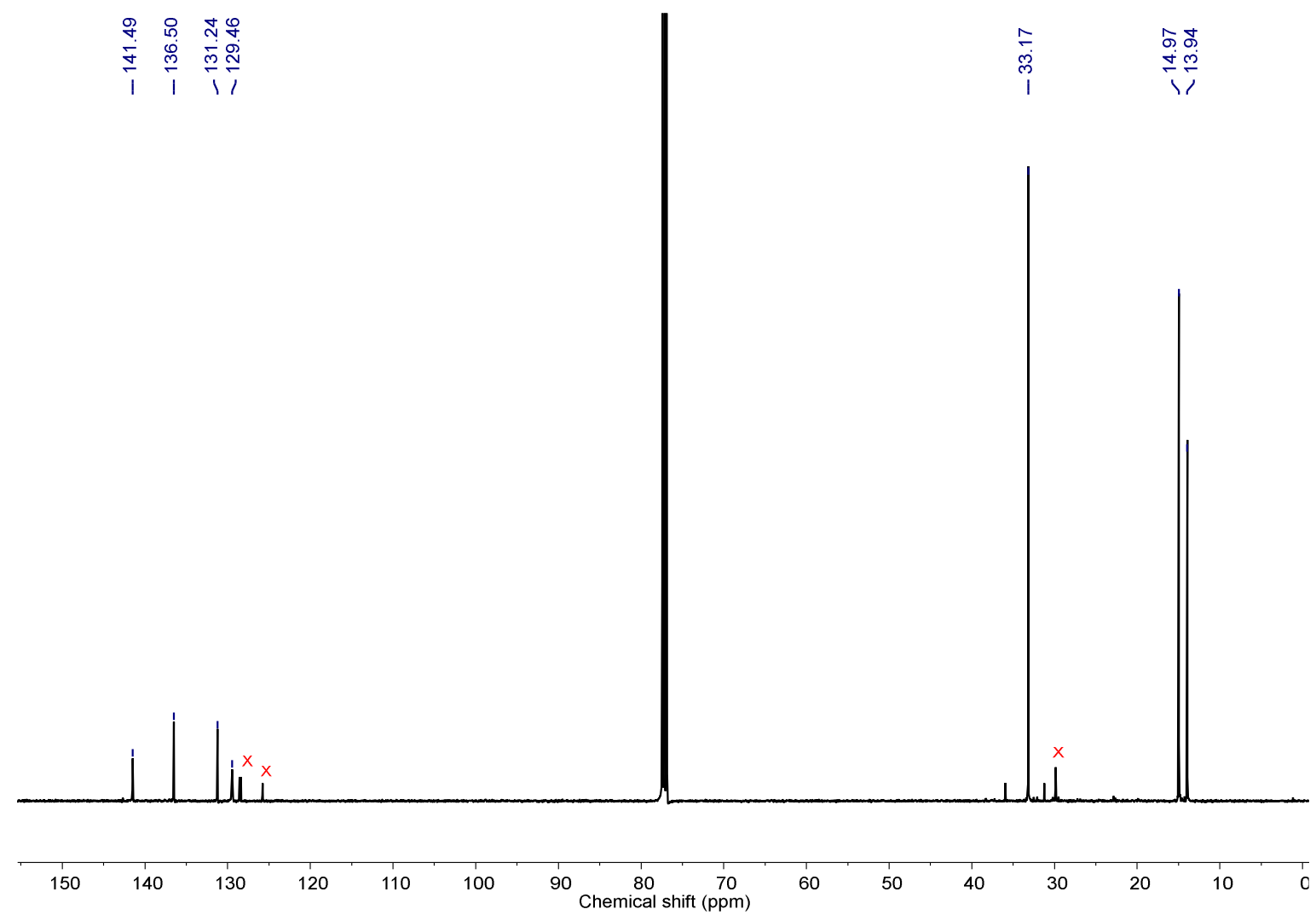

Figure S46. ${ }^{13} \mathrm{C}$ NMR spectrum of 23 in $\mathrm{CDCl}_{3}$. 


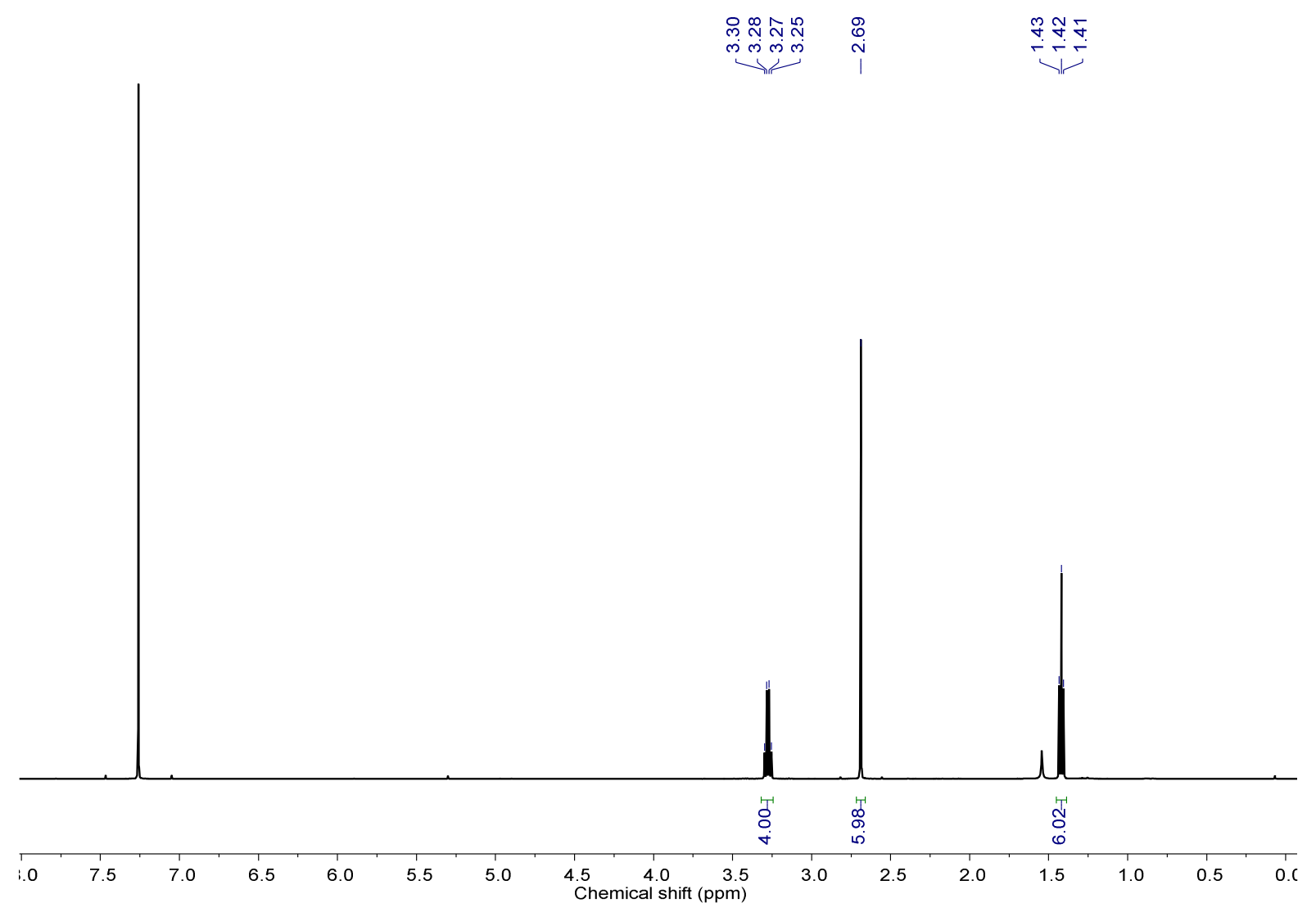

Figure S47. ${ }^{1} \mathrm{H}$ NMR spectrum of 10 in $\mathrm{CDCl}_{3}$.

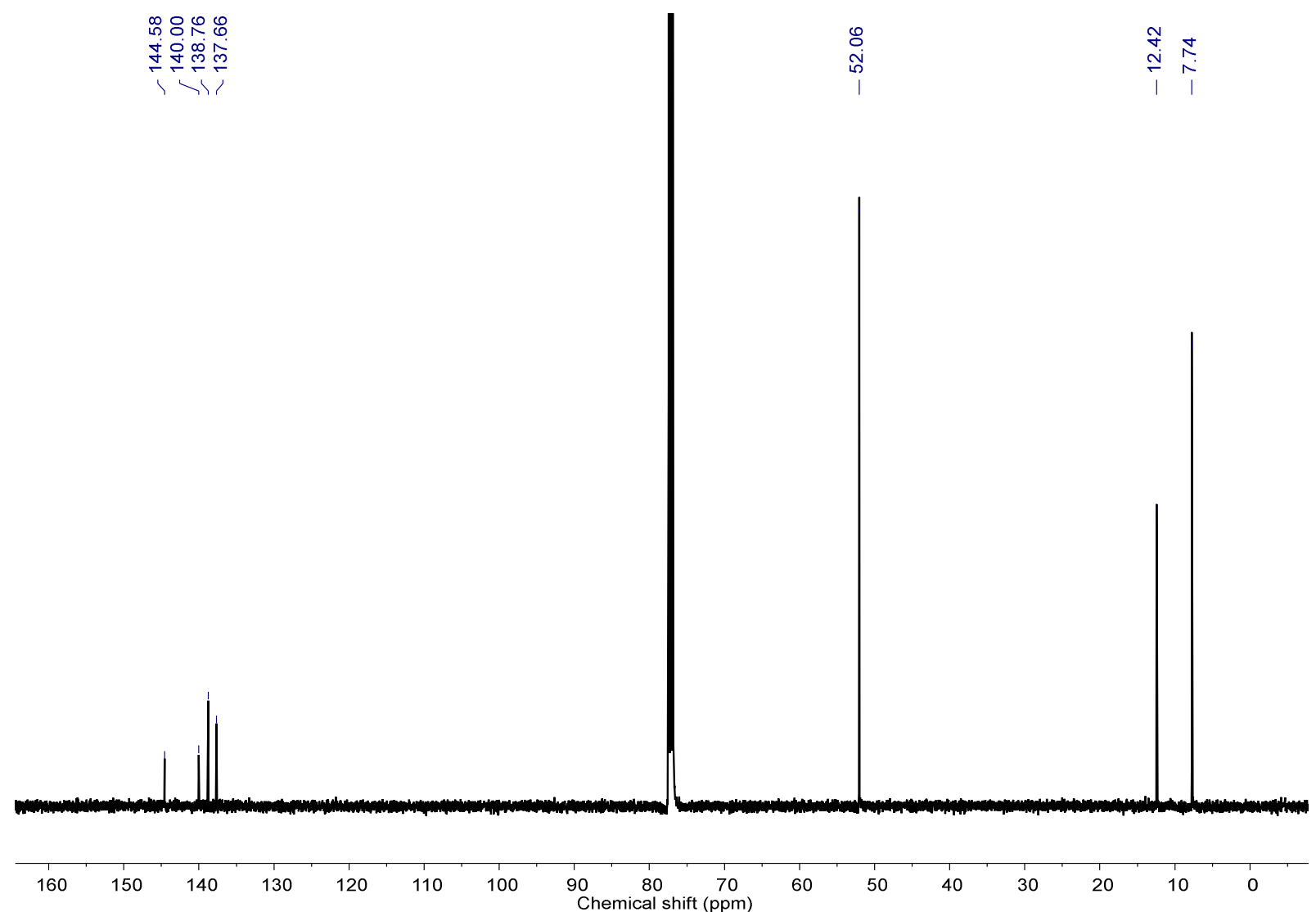

Figure S48. ${ }^{13} \mathrm{C}$ NMR spectrum of 10 in $\mathrm{CDCl}_{3}$. 